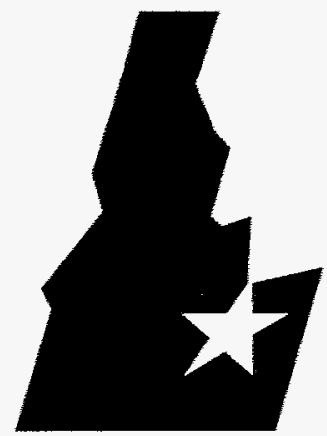

Idaho

National

Engineering Laboratory

\section{AOEIVEO}

AUS 22 得96

OSTI

\title{
Adapting Classical Systems Engineering to Department of Energy (DOE) Needs
}

July 1996

Applied Engineering Development Laboratory Systems Engineering Directorate

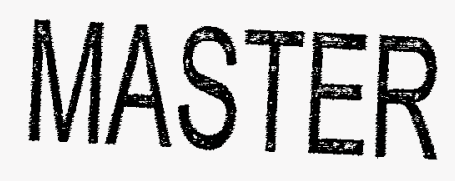

LOCKHEED MATTIN

DSTTRBUTION OF THS DOCUMENT IS UAMITED 


\section{DISCLAIMER}

Portions of this document may be illegible in electronic image products. Images are produced from the best available original document. 


\section{DISCLAIMER}

This report was prepared as an account of work sponsored by an agency of the United States Government. Neither the United States Government nor any agency thereof, nor any of their employees, makes any warranty, express or implied, or assumes any legal liability or responsibility for the accuracy, completeness, or usefulness of any information, apparatus, product, or process disclosed, or represents that its use would not infringe privately owned rights. Reference herein to any specific commercial product, process, or service by trade name, trademark, manufacturer, or otherwise does not necessarily constitute or imply its endorsement, recommendation, or favoring by the United States Government or any agency thereof. The views and opinions of authors expressed herein do not necessarily state or reflect those of the United States Government or any agency thereof. 


\title{
Adapting Classical Systems Engineering to Department of Energy (DOE) Needs
}

\section{Applied Engineering Development Laboratory Systems Engineering Directorate}

\author{
Published July 1996
}

\section{Idaho National Engineering Laboratory Lockheed Idaho Technologies Company Idaho Falls, ID 83415}

\author{
Prepared For The \\ U.S. Department of Energy \\ Assistant Secretary for Environmental Management \\ Under DOE Idaho Operations Office \\ Contract DE-AC07-94ID13223
}




\section{PREFACE}

This document was developed by Systems Engineering (SE) professionals for use within the Department of Energy (DOE) complex in implementing SE within new and existing programs. It is meant to describe an alternative approach to applying techniques discussed in classic SE texts and handbooks. While the techniques remain the same; experiences at the Idaho National Engineering Laboratory (INEL) have demonstrated that they can best be utilized in a different order and in an iterative manner depending on the program to which they are applied.

Consequently, the approach illustrated in this document differs from the traditional view of SE. This difference is the result of over 18 months of effort to integrate the INEL's Environmental Management (EM) programs in order to reduce cost and risk simultaneously. Since the entire DOE complex faces the same budgetary and regulatory challenges, this document becomes an important new resource for insight and practical solutions to meeting the challenge.

Specifically, this document defines how systems engineers at the INEL adapted classical SE for application to existing DOE programs through the EM Integration effort. It also provides the lessons learned that form the basis of these modifications. The traditional SE model is provided for comparison.

Hundreds of people from the DOE-ID Field Office and the Lockheed Martin Idaho Technologies Company (LMITCO), the INEL's Management and Operations Contractor, contributed to the success of the INEL EM Integration effort. While it would be preferable to acknowledge all of their contributions to this document, it is literally impossible. Therefore, Catherine Plowman, a Systems Engineer at LMITCO, has accepted the responsibility to act as a point of contact for any questions, suggestion, or other queries. She can be reached at the following address:

Catherine M. Plowman

Lockheed Martin Idaho Technologies Company

Systems Engineering Directorate

2525 Freemont Avenue, MS 3750

Idaho Falls, ID 83415-3750

Phone: 208-526-4828 / Fax: 208-526-4313 


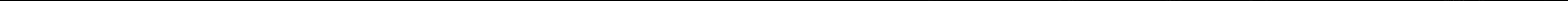




\section{CONTENTS}

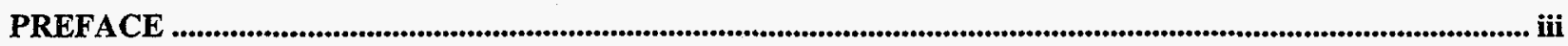

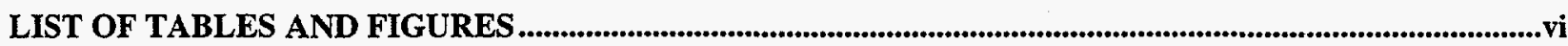

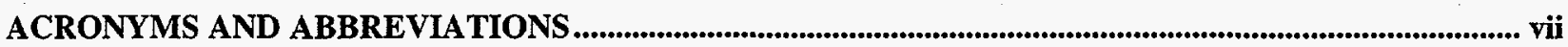

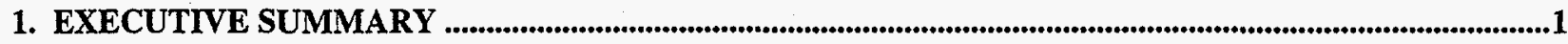

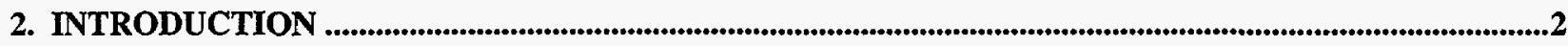

3. INSERTING SE INTO EXISTING DOE PROGRAMS

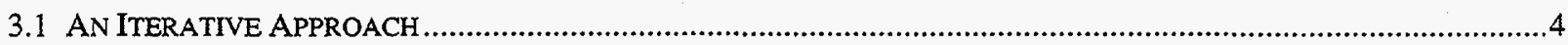

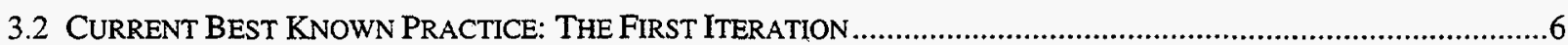

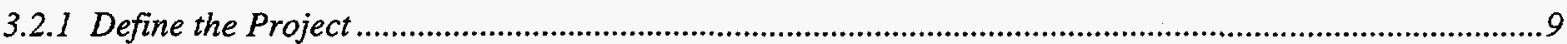

3.2.2 Develop Project Management and Organizational Structure ......................................................................

3.2.3 Define Current Operations Baseline ........................................................................................................

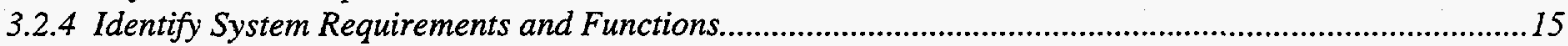

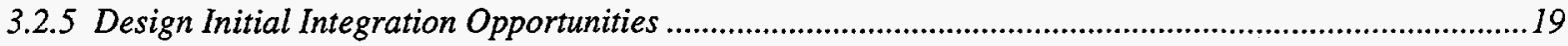

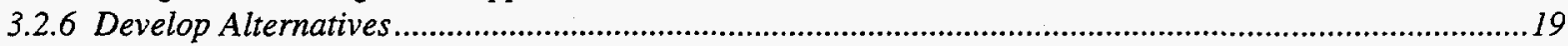

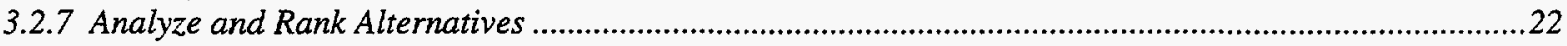

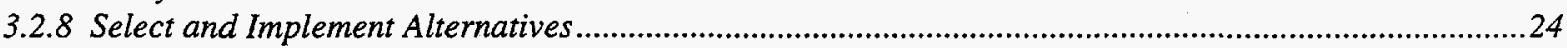

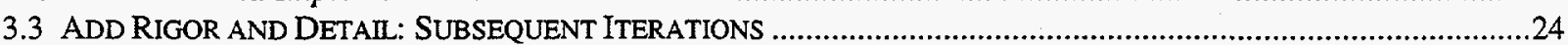

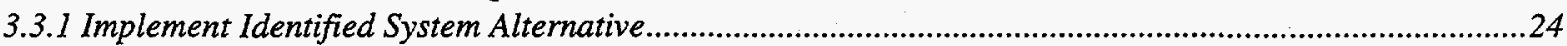

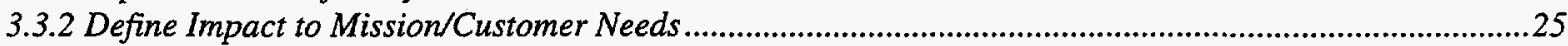

3.3.3 Identify Impact to Stakeholder Requirements ...................................................................................25

3.3.4 Develop Functional Definition of New System .........................................................................................26

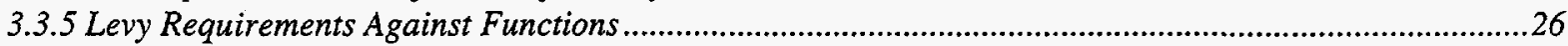

3.3.6 Develop Performance Measures Based on Requirements..........................................................................29

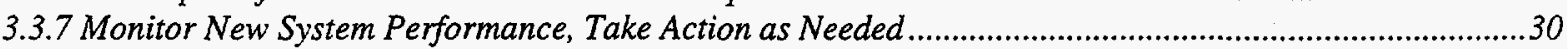

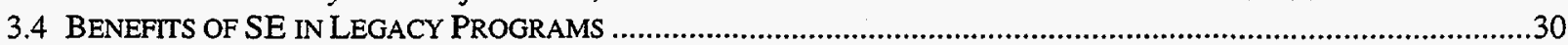

4. ADAPTING SE FOR INSERTION: LESSONS LEARNED FROM THE INEL EM INTEGRATION

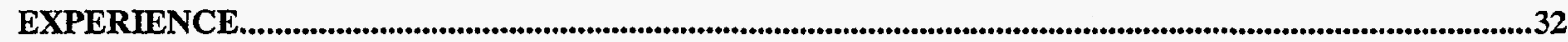

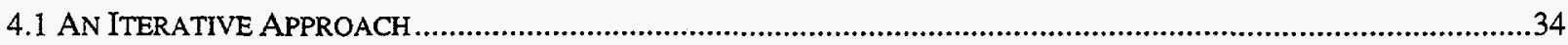

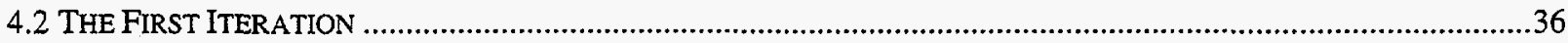

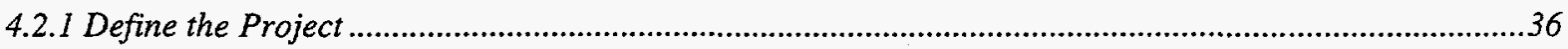

4.2.2 Develop Project Management \& Organizational Structure .......................................................................

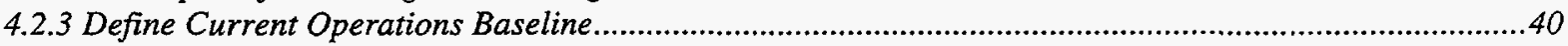

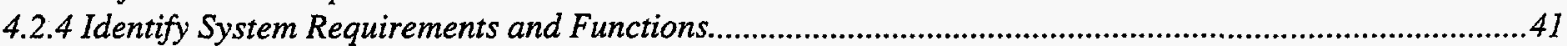

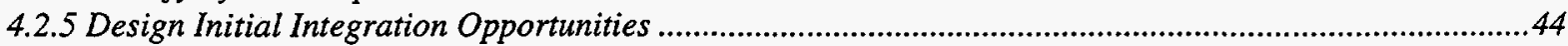

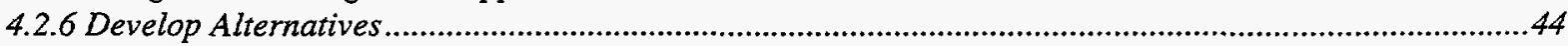

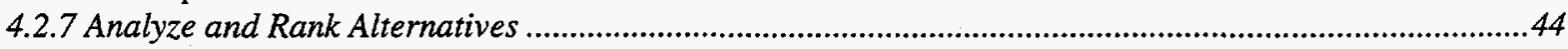

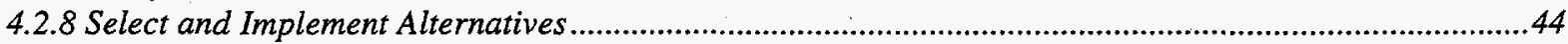

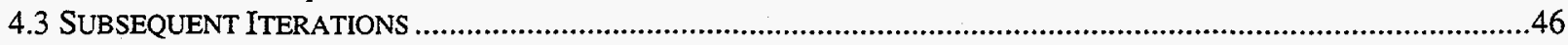

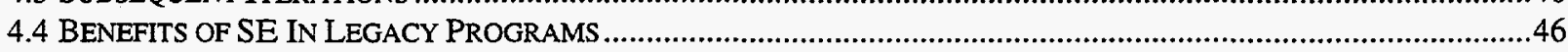

APPENDIX A: A STANDARD SYSTEMS ENGINEERING PROCESS......................................................47

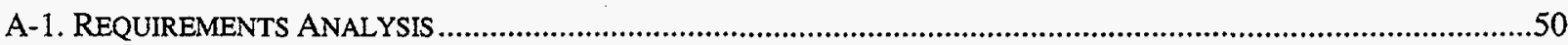

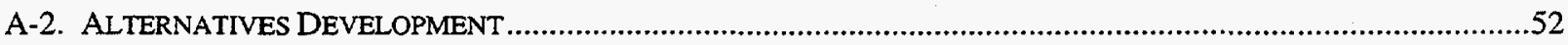

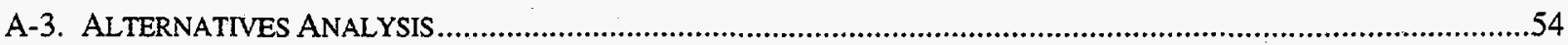

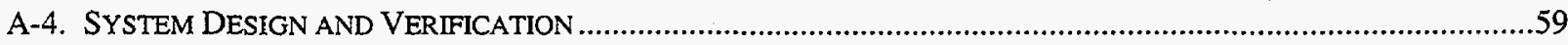


A-5. SYSTEMS INTEGRATION AND CONTROLS

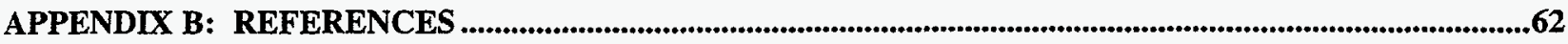

APPENDIX C: ILLUSTRATIONS FOR DEVELOPING ERFORMANCE MEASURES ..............................63

APPENDIX D: GLOSSARY

\section{LIST OF TABLES AND FIGURES}

TABLE A-1. SYSTEMS ENGINEERING SOURCE REFERENCES .

FIGURE 2-1.

FIGURE 3-1.

FIGURE 3-2.

FIGURE 3-3.

FIGURE 3-4.

FIGURE 3-5.

FIGURE 3-6.

FIGURE 3-7.

SYSTEMS ENGINEERING PROCESS..

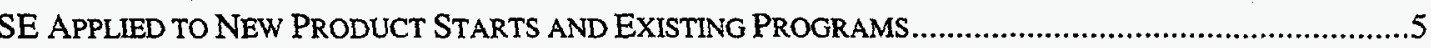

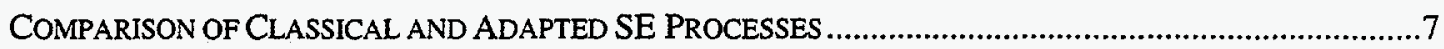

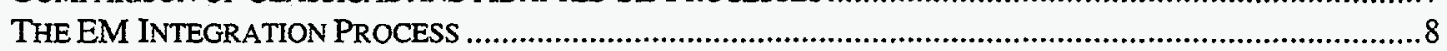

DEVELOPING PROGRAM MANAGEMENT AND ORGANIZATIONAL STRUCTURE .....................................11

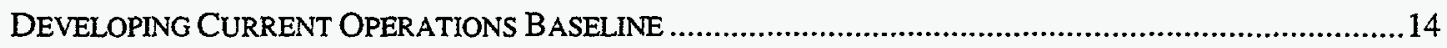

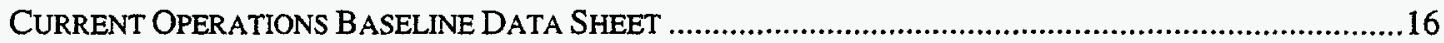

FIGURE 3-8.

IDENTIFYING SYSTEM REQUIREMENTS AND FUNCTIONS.....

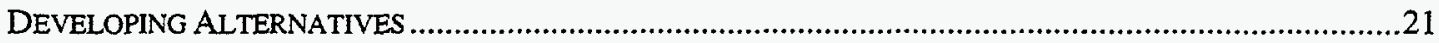

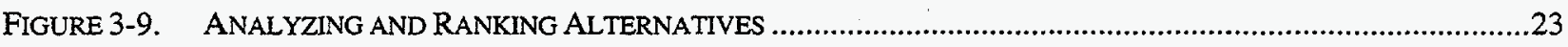

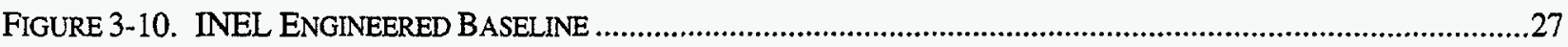

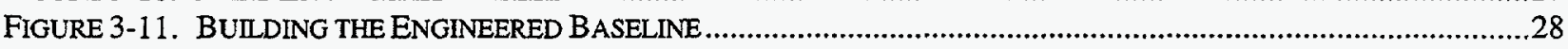

FIGURE 4-1. COMPLEXITIES OF THE ENVIRONMENTAL MANGEMENT SYSTEM …................................................35

FIGURE 4-2. EM INTEGRATION ORGANIZATIONAL STRUCTURE.........................................................................37

FIGURE 4-3. REQUIREMENTS RELATIONSHIPS IN PRIME AND SUPPORT SERVICE CONTRACTOR ENVIRONMENTS.......42

FIGURE 4-4.

FIGURE 4-5.

REQUIREMENTS HIERARCHY

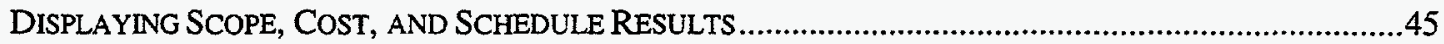

FIGURE A-1.

FIGURE A-2.

SYSTEMS ENGINEERING PROCESS

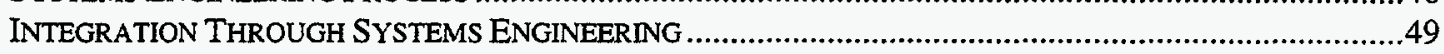

FIGURE A-3.

FIGURE A-4.

FUNCTIONAL MATRIX OF INEL WASTE STREAMS AND TECHNOLOGIES.

INEL EM INTEGRATION ALTERNATIVES AND SCENARIOS...........................................................53

FIGURE A-5.

FIGURE A-6.

FIGURE A-7.

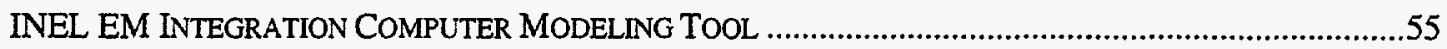

FIGURE A-8.

Figure C-1.

INEL EM INTEGRATION COST PROJECTIONS..

WASTE VOLUMES UNDER THE INEL EM INTEGRATION FULL TREATMENT ALTERNATIVE.....................57

FiguRE C-2. QUALTTATIVE ANALYSIS OF INEL EM INTEGRATION ALTERNATIVES

PROJECT INTIAL CHECKLIST.

FIGURE C-3.

FAMILY OF MEASURES DEVELOPMENT PROCESS

OBJECTIVES MATRIX.

FIGURE C-4. TREND CHARTING.

FIGURE C-5. CUSTOMER SATISFACTION SURVEY FORM 


\section{ACRONYMS AND ABBREVIATIONS}

$\begin{array}{ll}\text { ADS } & \text { Activity Data Sheet } \\ \text { BEMR } & \text { Baseline Environmental Management Report } \\ \text { CERCLA } & \text { Comprehensive Environmental Response, Compensation, and Liability Act } \\ \text { DNFSB } & \text { Defense Nuclear Facilities Safety Board } \\ \text { DOE } & \text { Department of Energy } \\ \quad \text {-EM } & \text { Office of Environmental Management } \\ \quad \text {-HQ } & \text { Headquarters } \\ \text {-ID } & \text { Idaho Operations Office } \\ \text { DU } & \text { Decision Unit } \\ \text { EM } & \text { Environmental Management } \\ \text { ES\&H } & \text { Environmental, Safety and Health } \\ \text { HR } & \text { Human Resources } \\ \text { INEL } & \text { Idaho National Engineering Laboratory } \\ \text { IPT } & \text { Integrated Product Team } \\ \text { LCAM } & \text { Life-cycle Asset Management } \\ \text { M\&O } & \text { Management and Operations } \\ \text { NASA } & \text { National Aeronautics and Space Administration } \\ \text { PM } & \text { Program Manager } \\ \text { PMP } & \text { Program Management Plan } \\ \text { POD } & \text { Plan-of-the-Day } \\ \text { RCRA } & \text { Resource Conservation and Recovery Act } \\ \text { RMDB } & \text { Requirements Management Database } \\ \text { SE } & \text { Systems Engineering } \\ \text { SME } & \text { Subject Matter Expert } \\ \text { SOW } & \text { Scope of Work } \\ \text { SRD } & \text { System Requirements Document } \\ \text { SRR } & \text { System Requirements Review } \\ \text { WBS } & \text { Work Breakdown Structure } \\ \text { WIPP } & \text { Waste Isolation Pilot Plant }\end{array}$

The following abbreviations are specific to the flow diagrams that appear in Section 3 of this document:

$\begin{array}{ll}\text { CUST } & \text { customer } \\ \text { OPS } & \text { operations } \\ \text { PDR } & \text { Preliminary Design Review } \\ \text { RQM'TS } & \text { requirements } \\ \text { SR MGMT } & \text { senior management } \\ \text { TM } & \text { team }\end{array}$




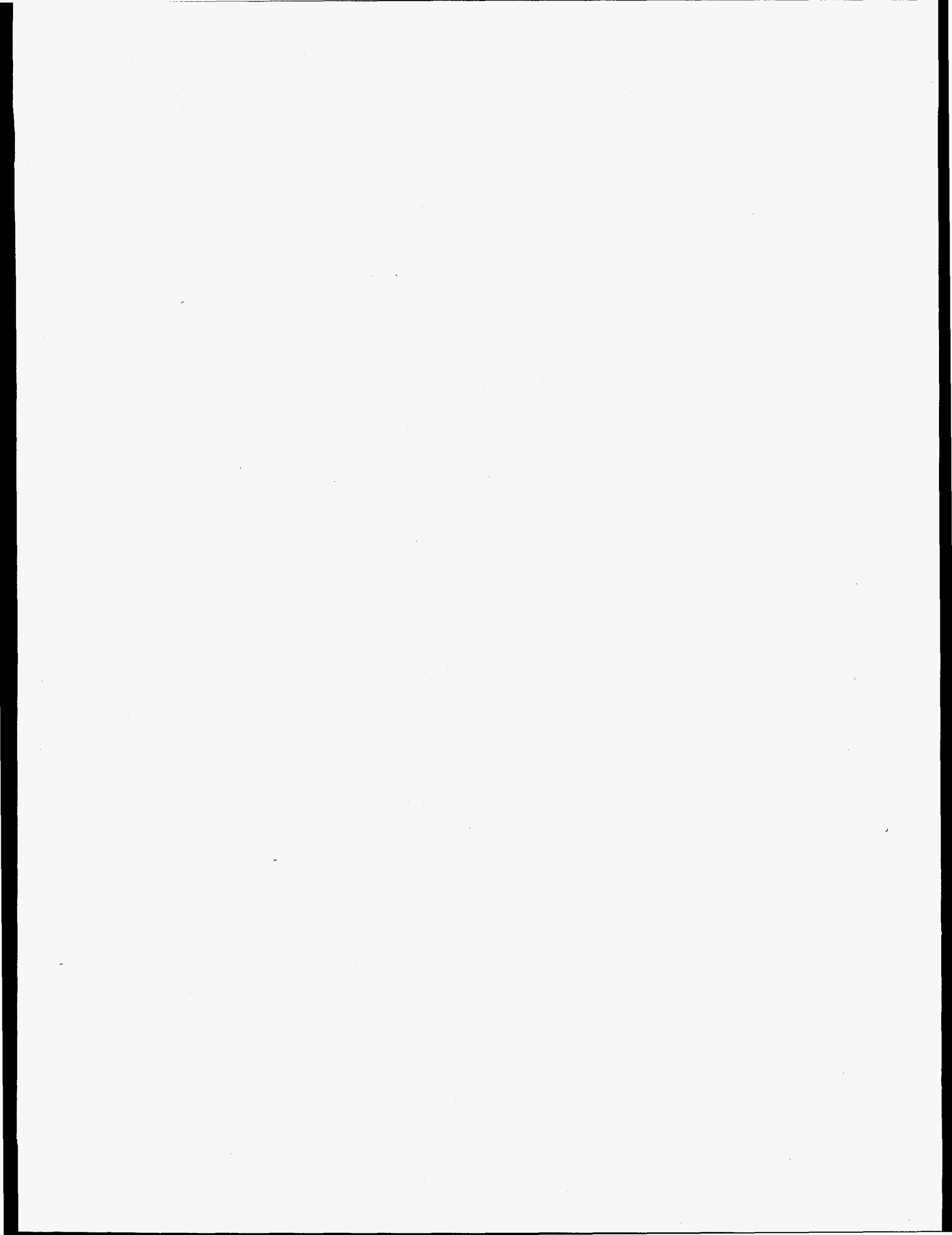




\section{EXECUTIVE SUMMARY}

Rather than discuss Systems Engineering (SE) as applied by aerospace contractors to military programs, this document provides an adapted model well suited for use by the Department of Energy (DOE) and represents 18 months of applying SE principles to the challenges faced by the Idaho National Engineering Laboratory (INEL). The real-life examples used throughout this document are drawn from the INEL's ongoing effort to integrate activities across the entire spectrum of within its Environmental Management program.

Lessons learned at the INEL indicate that the traditional SE process, with its initial focus on requirements identification and analysis, must be modified to provide tangible results in the short term. Consequently, the adapted SE model starts with the external driver of "reducing costs without increasing risks" and performs an initial integration effort to identify high-potential, cost-saving opportunities. From there, elements from traditional alternatives development and analysis stages are utilized. Then, with an illustrated case for change in place, the adapted model cycles back to include more traditional requirements analysis activities. These cycles continue in an iterative manner, adding rigor and detail at each successive iteration, throughout the life-cycle of a program or project. By applying SE principles in this manner, the DOE can realize the benefits of a structured, disciplined approach while meeting many of the short-term stakeholder needs through the early identification of major system changes and elements.

Detailed lessons learned are included in this document to help those pursuing systems engineering or integration efforts. The lessons learned are organized according to the stages of the adapted SE model. Every attempt has been made to provide SE practitioners and program personnel across the DOE complex with an accurate, practical, and easy to use reference to an approach for systematically reducing costs and developing defensible plans. 


\section{INTRODUCTION}

The Idaho National Engineering Laboratory (INEL), like all other Department of Energy (DOE) sites, faces shrinking federal budgets at the same time local stakeholders are calling for greater regulatory accountability on the part of the individual sites. In order to meet the increasing requirements levied by these stakeholders yet remain responsive to budgetary pressures, INEL management requested that the integration of all Environmental Management (EM) projects be pursued using established systems engineering (SE) principles. The outcome of the effort was a modified EM system that could perform all required work at the lower funding levels without increased risk to public, environment, or worker safety.

Active and extensive efforts are now underway to reduce the costs and risks associated with activities throughout the INEL. During the summer of 1996, for example, the processes described in this document are being adapted to indirectly-funded activities to reduce costs and ensure that the proper efforts are being funded. These efforts have come about due to the ongoing tailoring of standard SE practices in order to work effectively within existing programs.

Systems engineering is a structured approach that considers all aspects of a particular program or project in developing products, systems, and services that meet customer requirements and program objectives. Beginning with the identification of requirements and functions, SE integrates program elements into a structured development process that proceeds from product conception, development, and analysis to the implementation, operation, and decommissioning of a complete system. The INEL's standard SE model (see Figure 2-1) is described in detail in Appendix A of this document and comprises the following attributes:

1) Requirements Analysis

2) Alternatives Development

3) Alternatives Analyses

4) System Design and Verification

5) System Integration and Controls.

Experience at the INEL in adapting SE for use within legacy programs has demonstrated that these five basic steps and many of their supporting tools and techniques remain the same. However, the order and rigor of their use differs when applying SE to new product starts versus existing efforts.

This document describes a top-level approach for applying SE in situations where the program has been in existence for many years. In general, it presents modified project management and SE principles and the organizational strategy necessary to affect change amid program constraints. Chapter 3.0 is devoted to describing this modified SE approach. Chapter 4.0, contains lessons learned at the INEL and offers evidence as to why the classical SE method was changed. The appendices contain detailed references and discussions on SE, as well as a glossary of terms used in this document.

This document is not intended as a stand-alone manual; rather, it supplements existing project management and SE documents. As such, it is directed towards people who are familiar with project management and SE practices and who have access to the various documents referenced herein. These references should be consulted, as needed, to provide detailed direction on how to conduct specific aspects of project management and SE. 


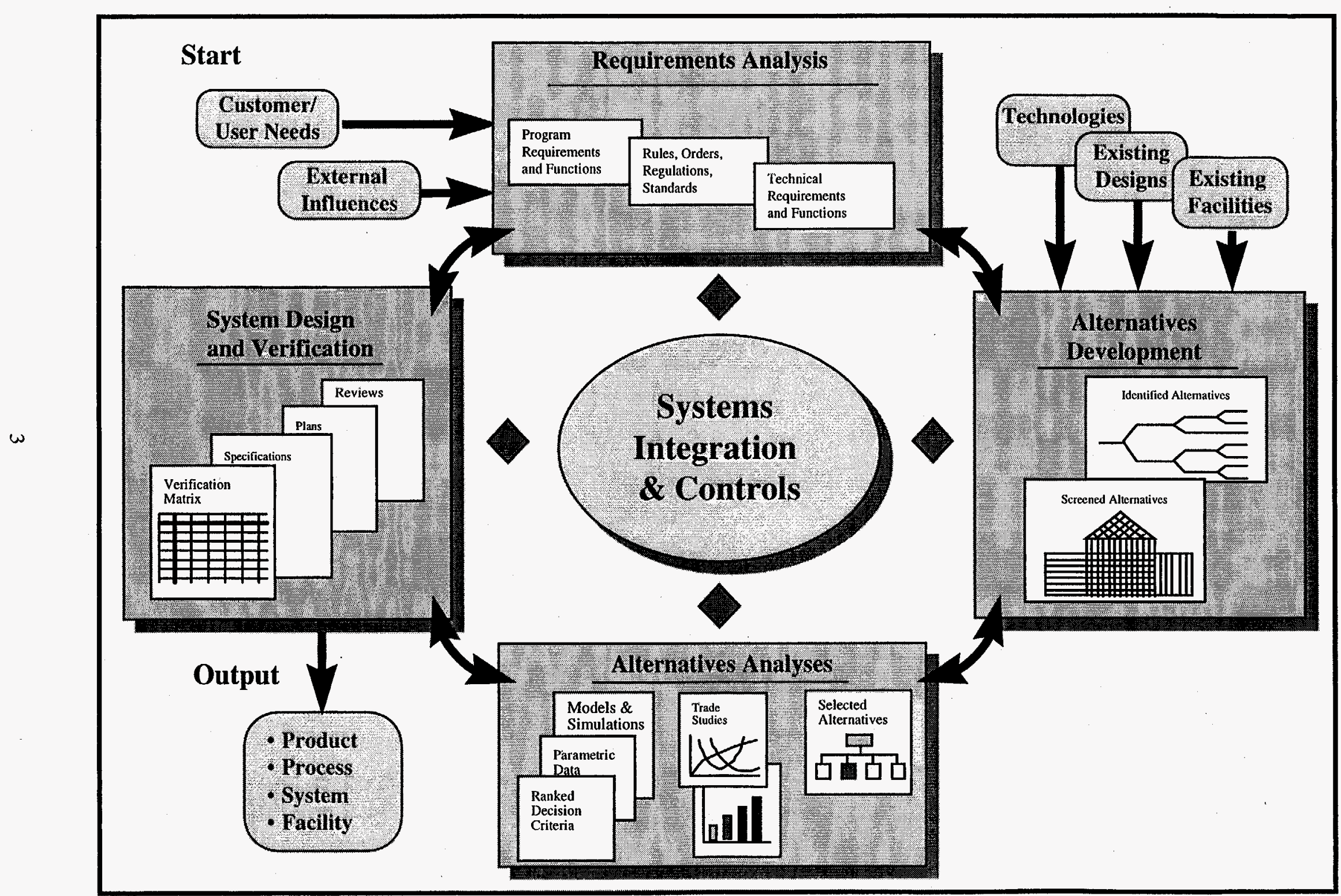

FIGURE 2-1. Systems Engineering Process 


\section{INSERTING SE INTO EXISTING DOE PROGRAMS}

This chapter presents the recommended approach for inserting the concepts and practices of SE into existing DOE programs. The word 'insertion' is used intentionally to emphasize that SE must be an integral part of the program management system and not viewed as "outside the scope of current programs." Consequently, much effort must be applied to the initial organization activities to clearly define the SE role within a given program. Otherwise, SE efforts will proceed, but no significant programmatic changes will occur.

The four main sections within this chapter each have their own focus but, when taken together, represent the best known method for ensuring that legacy programs receive the benefits of SE. Section 3.1, An Iterative Approach, deals with the differences between applying SE in its traditional role within new product starts and using SE to refine and optimize ongoing efforts. It also describes how the SE process must be modified to address the external drivers that exist in the DOE environment. Section 3.2 then describes the eight steps of the first iteration in detail. Subsequent iterations through the SE process are described in Section 3.3 in greater detail and reflect recent experience at the INEL. A brief discussion of the benefits of the described approach are presented in Section 3.4.

\subsection{An Iterative Approach}

One of the most basic tailoring activities discovered through the INEL EM Integration effort was the need to apply SE processes iteratively, continually, and at successively greater levels of detail. This is in contrast to the classical application of SE to new product starts. To illustrate, consider a rubber band and a slinky. Both can be stretched or compressed to fit a certain need or space. However, the slinky is considerably thicker than the rubber band and is composed of connected loops of material while the rubber band is made from one continuous piece of rubber. The rubber band represents the classical definition of SE, where certain activities occur at pre-defined points along the project timeline that help to move a product (or service) from conception to definition through construction and into operation. The slinky, on the other hand, represents the insertion of SE into an existing program by repeating the same classical SE activities over and over again but at successively greater levels of detail and by enrolling more and more program personnel (see Figure 3-1).

The experience at the INEL has demonstrated that external drivers are necessary to affect the significant changes in existing programs being called for today. The shrinking DOE budget and increasing public scrutiny provide these drivers, typically as a request to "... reduce costs ...." As such, SE activities that deal directly with the cost of a system are an acceptable place to start since they provide an answer to the most immediate issue. Once cost reduction possibilities are demonstrated, an opportunity is created to engage in traditional requirements and functional analysis activities and to explore broader reaching integration possibilities.

This opportunity is created through a combination of aspects, including:

1) An initial success has occurred through the first integration effort

2) Program technical personnel have come to know and understand how the structured SE discipline can help them solve program problems and issues. 


\section{DOE Needs Two Different Applications of SE}

For New Product/

Service Starts

Like DNFSB

recommendations

(94-x, 95-x, etc.),

Focus Areas

(plutonium, mixed

waste, etc.),

New R\&D projects

Starts with Customer Saying

"We need a waste treatment facility"
Ends with a new/modified facility, report, service, methodology, technology
For Use Within Existing Programs

Like Environmental Mgt.,

Nuclear Operations,

Waste Operations,

or programs at lower

or higher levels
Starts with Field Office/Contractor Saying

"We need to reduce cost/risk/etc."

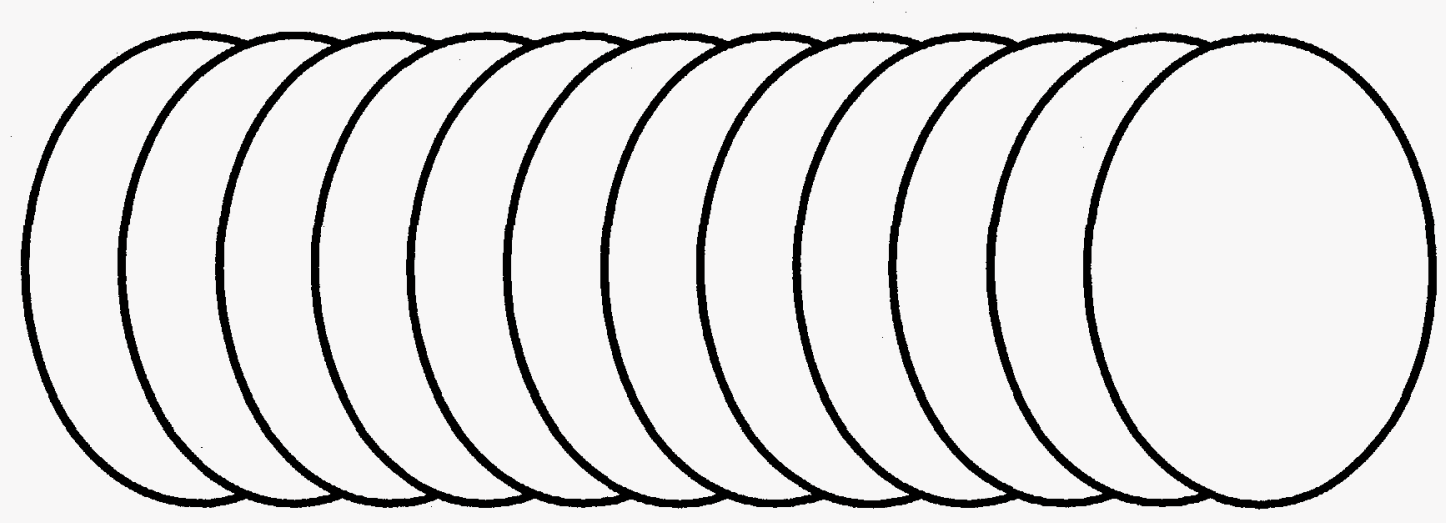

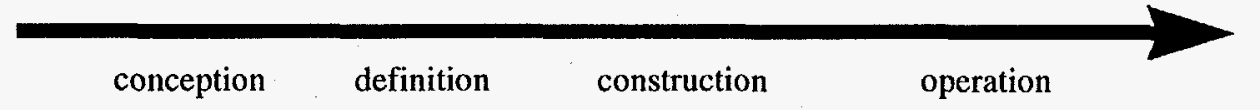

FIGURE 3-1. SE Applied to New Product Starts and Existing Programs 
3) Line organization management are exposed to the activities and outcomes of a structured approach with positive results

4) DOE Headquarters observes the site being responsive to the budget pressure

5) The initial effort results in tools, techniques, data, procedures, etc. that can be built upon in subsequent iterations.

Principle differences between a classical SE approach and the adapted version described in this document are shown in Figure 3-2. Note that each iteration in the "Adapted SE Timeline" starts with the integration step. This is possible because the program team structure is populated with knowledgeable subject matter experts (SMEs) from the affected functional areas, as well as specialty support and project management personnel. It is also possible because the effort is iterative, thus alleviating the need to perform a highly detailed requirements and functional analyses during the first iteration. Section 3.2 describes the first half of the adapted SE process in detail; the second half of the process is described in Section 3.3 .

\subsection{Current Best Known Practice: The First Iteration}

SMEs, systems engineers, project management personnel, and cost and risk experts have been actively involved for over 18 months in adapting classical SE processes to meet EM integration challenges at the INEL. The resulting methodology (see Figure 3-3) has subsequently been refined and used to reduce costs in other areas, such as integrating EM programs throughout the Lockheed Martin Energy and Environment Sector and prioritizing direct- and indirect-funded projects at the INEL. In general, the process consists of defining program requirements, developing tasks that will meet identified requirements, and combining or integrating those tasks into a unified system. The process is generic and scaleable and can be applied to integrate projects within a program, programs within a site, sites within a region, or regions within the DOE complex. The following steps from the adapted SE process (identified by section number) represent the first half of an iteration.

\subsubsection{Define the Project}

3.2.2 Develop Project Management \& Organizational Structure

3.2.3 Define Current Operations Baseline

3.2.4 Identify System Requirements and Functions

3.2.5 Identify Initial Integration Opportunities

3.2.6 Develop Alternatives

3.2.7 Analyze and Rank Alternatives

3.2.8 Select and Implement Integration Alternatives

Sections 3.2.1, 3.2.2, and 3.2.3 outline part of the preparation needed to kick-off the first iteration. As subsequent iterations occur, these sections should be revisited to ensure that the project is properly aligned with its initial objectives. Sections 3.2.4 through 3.2.8 are performed during each iteration but utilize increasing levels of detail as the iterations progress.

Defining the current operations baseline, governing requirements, and functional definition (sections 3.2.3 and 3.2.4) represent the transition for preparation activities to step one of the SE process. Consequently, initial baseline data must be available for the first iteration as a 'kick start' to the whole process. The following sections provide information on how to create this data. 


\section{Start With Integration}

FIGURE 3-2. Comparison of Classical and Adapted SE Processes

Deal SE Timeline (1 cycle):

(1) Define Mission/Customer Needs

(3) Develop Functional Definition of System

(4) Integrate Functions Into Viable Alternatives

(5) Analyze Alternatives

(6) Rank Alternatives via Selection Criteria

(7) Select "Best" Alternative

(8) Develop Implementation and Verification Plans

(9) Implement Identified System Alternative

(10) Verify System Operation Against Requirements

Adapted SE Timeline (many cycles):

(1) Integrate Existing Functions Into Viable Alternatives (2) Analyze Alternatives

(3) Rank Alternatives via Selection Criteria

(4) Select "Best" Alternative

(5) Develop Implementation and Verification Plans

(6) Implement Identified System Alternative

(7) Define Impact to Mission/Customer Needs

(8) Identify Impact to Stakeholder Requirements

(9) Develop Functional Definition of New System

(10) Levy Requirements Against Functions

(11) Develop Performance Measures Based on Requirements

(12) Monitor New System Performance, Take Action as Needed

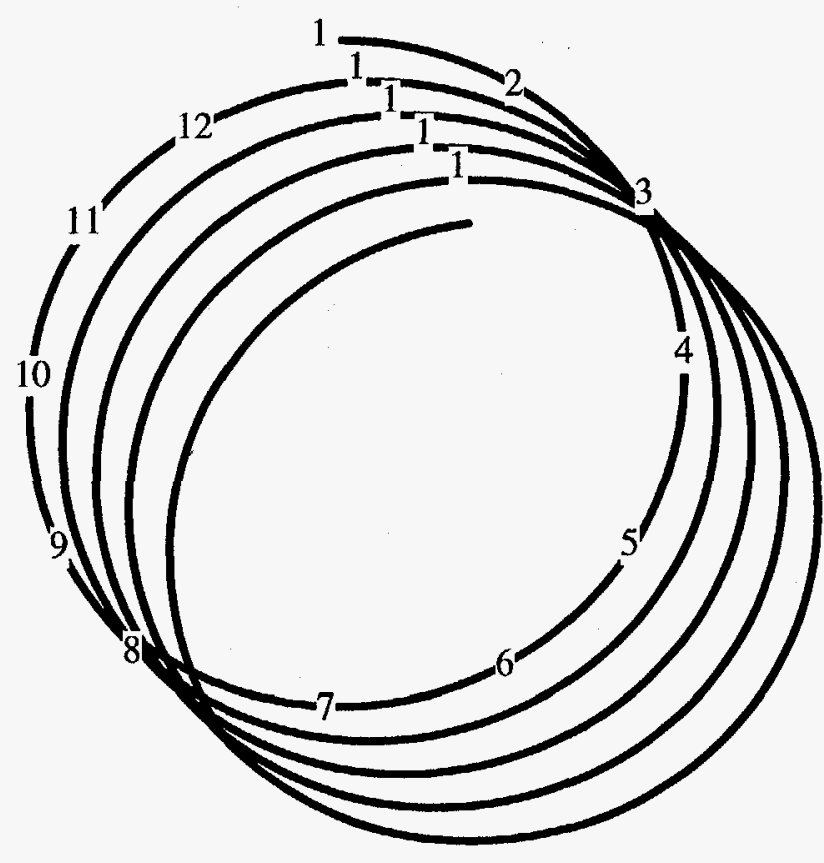




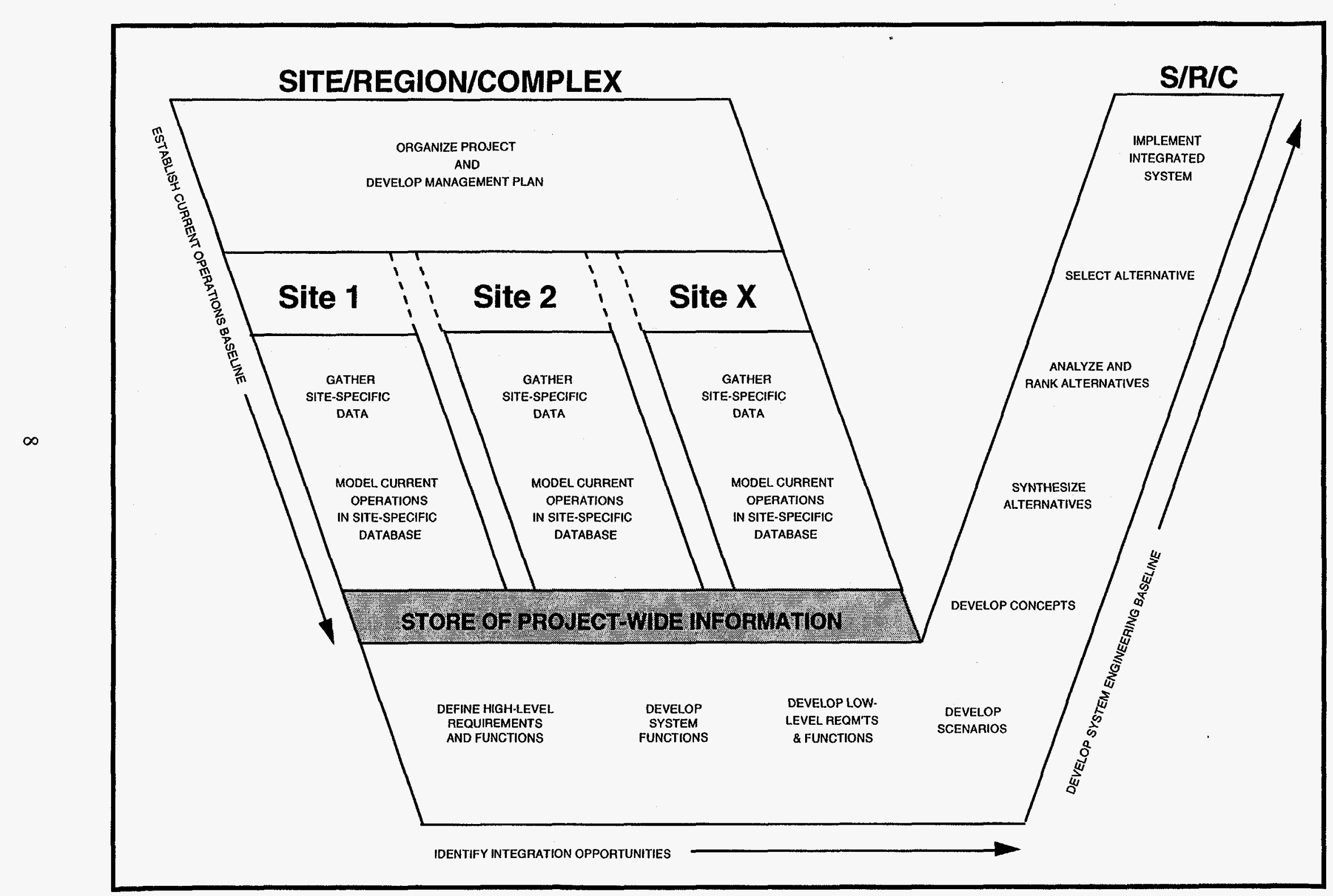

FIGURE 3-3. The EM Integration Process 


\subsubsection{Define the Project}

Projects must be defined as to the customer, scope, overall project schedule, and top-level requirements and specified in terms of priorities. At the outset, senior management from both the DOE and the Management and Operations (M\&O)/support service contractor, when appropriate, should define the expectations for the project and the overall goals. These details form the basis for the basic project organization and must be documented with senior management concurrence.

\subsubsection{Develop Project Management and Organizational Structure}

In order for the project to succeed, thoughtful planning must be applied to the overall process prior to starting any of the project tasks. Success or failure in the exercise will depend largely on how well initial preparations have been made.

As described in Section 4.2.2, the Core Team is responsible for all project management and control functions, including: project planning and oversight, customer interaction, and project data management. Specific guidance on how to conduct project management and control activities can be found in:

1) DOE Order 430.1, Life Cycle Asset Management (LCAM). Washington D.C.: U.S. Department of Energy. September 23, 1995.

2) The "Project Management Guidebook" Series, for use with DOE Order 430.1, Life Cycle Asset Management. Washington D.C.: U.S. DOE Office of Field Management.

3) Applicable site or contractor-specific Project Management guidance documents.

The complexities of integration, however, often present unique concerns that traditional project management and control approaches cannot adequately address. These challenges foster the need to collaborate with a broader range of internal and external contributors, partners, and customers. To address these issues, program management and control practices should be combined on all levels with proven SE practices to form a single-focused effort that promotes open and effective communication and maintains a system-wide perspective in all program decisions. This unified approach further ensures the timely and cost-effective integration of programs and processes by:

- Building a shared understanding of critical issues to aid in the management and control of program problems, complexities, and uncertainties

- Clarifying program objectives, customer needs, program requirements and assumption, and program inconsistencies

- Identifying cross-cutting issues that need high-level attention

- Integrating various engineering and support disciplines into a focused, productive system

- Verifying and validating that program efforts satisfy customer requirements and are consistent with program objectives. 
The initial organization of program elements follows the eight-step process shown in Figure 3-4

ESTABLISH CORE TEAM-Upon receiving direction from the Executive Council (see Section 4), the designated program manager establishes a core team. This core team provides guidance throughout the program. The program manager should carefully select core team members to include representatives from all stakeholding organizations. Representatives should collectively possess experience in all management phases, all affected program areas, and SE practices.

DEVELOP SCOPE OF WORK (SOW)-The core team determines the initial SOW, based on direction from the Executive Council. At a minimum, the SOW should address: (1) the overall problem statement, (2) mission objectives, (3) high-level program and process requirements, (4) support personnel needed to perform program tasks, (5) anticipated deliverables, and (6) time frame of the effort.

The SOW is then sent to the Executive Council for approval. The core team and the Council work together to modify the SOW until it is acceptable. When acceptable, the Council will sign the SOW. This helps ensure agreement on the general activities and direction of the effort.

Once approved by the Council, the SOW is presented to the management personnel that will be involved in the process. This submittal provides the initial notice to the managers of the upcoming effort. The affected managers review and comment on the SOW. The program manager and the core team resolve any issues that arise. If substantial changes are made, senior management is given the opportunity to comment again. This iterative review-comment process continues until the SOW is acceptable to senior management, the core team, and the affected managers. When acceptable, senior management, the program manager (PM), and the affected managers sign the document.

1 The Structured Analysis process used to create the process flow diagrams was developed by Yourdon, Inc. and uses four basic symbols to represent the various activities, resources, and interfaces required for each process being depicted. Numbers are used only to identify one activity from another; they are not intended to represent any particular sequence or chain of events.

Circles indicate process activities, with the responsible agency or group shown in parentheses. Arrows indicate matter or information in motion from one activity or store to another. Parallel lines indicate stores of information from which needed resources are extracted and into which sub-products (i.e., analysis data, etc.) are placed for future reference. Finally, rectangles represent the starting and ending points of each individual process. When used as end points, rectangles indicate the next systems engineering process to be addressed during integration efforts.

Taken together, the activities, flows, and data stores describe activities the system must perform, resources those activities require, and how activities must interact in order to transform inputs into desired outputs. 


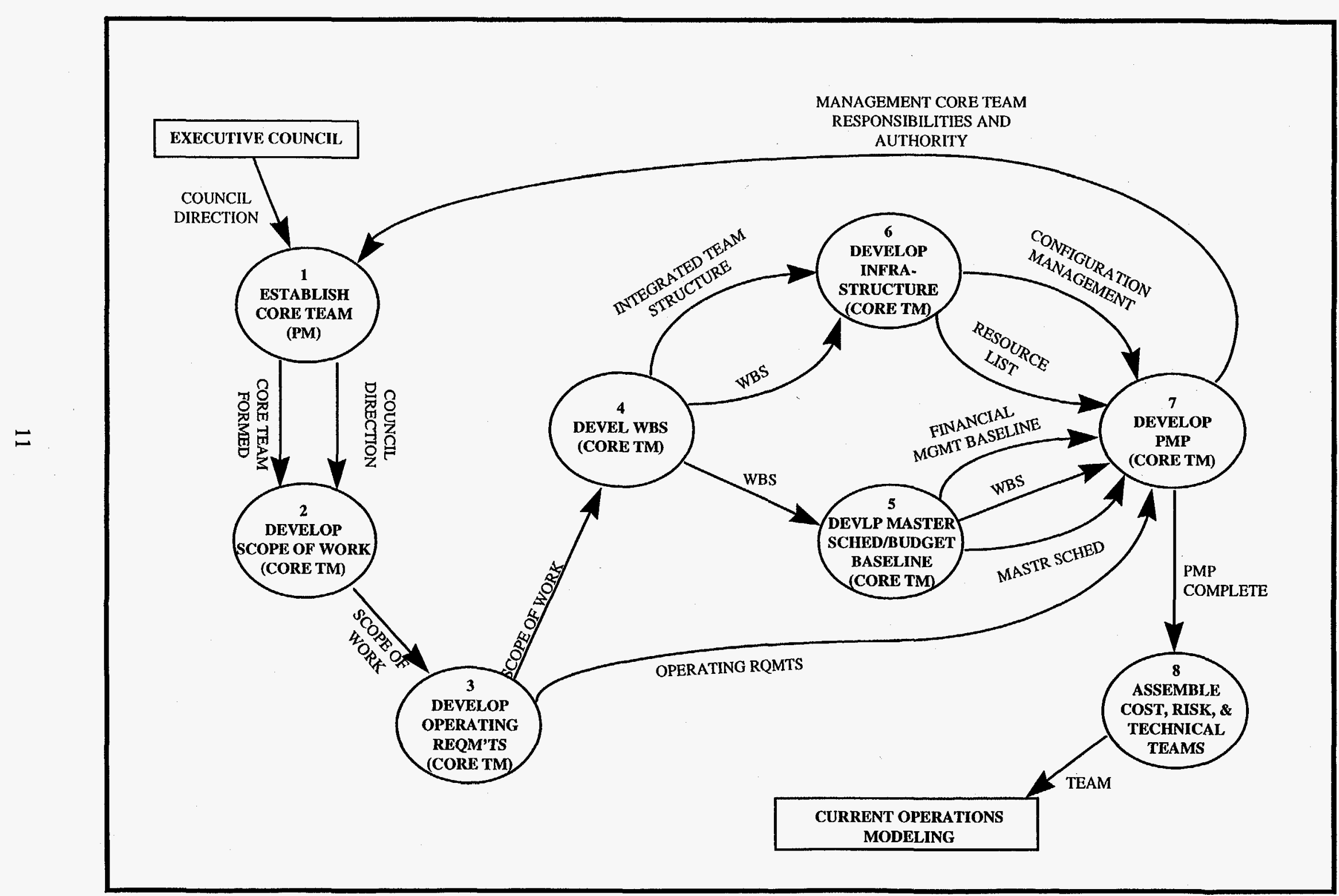

FIGURE 3-4. Developing Program Management and Organizational Structure 
DEVELOP OPERATING REQUIREMENTS - This step of the program organization phase determines the requirements that will govern activities performed during the program. The core team clearly states program expectations as measurable requirements for activities such as data and document review and control, the approval processes to be followed, who makes program commitments, financial control, etc.

The intent is to have the core team set the requirements for activities and outcomes but allow the assigned program team members to tailor their particular systems to meet these requirements. This promotes individual creativity, ownership, and flexibility in meeting changing circumstances. The program operating requirements become part of the Program Management Plan (PMP).

DEVELOP WORK BREAKDOWN STRUCTURE-A Work Breakdown Structure (WBS) must be developed to show schedule and cost and describe in detail the tasks to be performed by the program team in accomplishing the SOW.

DEVELOP MASTER SCHEDULE/BUDGET BASELINE-A master schedule and budget baseline with deliverable milestones needs to be developed to ensure that all project work is time-phased to meet critical need dates and to show interfaces among project participants and activities. Costs and schedules at this point should not exceed rough order of magnitude. They should merely indicate a general idea of the expected costs and timeframe to the program team without being prescriptive. Costs and schedules will be revisited and refined, as necessary, throughout the process.

DEVELOP PROGRAM INFRASTRUCTURE-Using the WBS, the core team investigates the types and number of activities in the technical, risk, cost, and SE areas needed to complete the program. The core team then uses the WBS and the designated team make-up to determine the infrastructure necessary to implement the program. At a minimum, the following issues should be addressed.

- Is sufficient authority granted to the PM and team members in order to carry out their assigned responsibilities?

- Should participants be sequestered or called to periodic meetings?

- What level(s) of configuration management procedures are necessary to provide traceability while not hindering progress?

- What support supplies and tools (white boards, wall space, computers, etc.) will be needed?

- Where will the team(s) meet, and where will they work?

- Will the computers be networked? What computing platform(s) will be used?

DEVELOP THE PROGRAM MANAGEMENT PLAN (PMP) In order to ensure a single source of program rules, procedures, and guidelines, the core team develops a PMP. The PMP incorporates the following items.

- Team members list

- Team members roles and responsibilities 
- Authority to match responsibilities

- Operating requirements

- Decision criteria for major milestones

- Scope of Work

- Specific deliverables

- WBS

- Financial management baseline

- Master schedule

- Infrastructure description

- Configuration management procedures

- Program structure and controls

ASSEMBLE COST, RISK, AND TECHNICAL TEAMS-When program activities start, the PM assembles team members to outline program objectives and to provide training on the processes and practices to be used throughout the effort.

\subsubsection{Define Current Operations Baseline}

Current operations baseline development is the process of investigating and recording the technologies, facilities, functional flows, and personnel resources associated with current activities. The gathered information serves as the current operations baseline for the remainder of the SE process. This step should result in the following products:

- A documented baseline

- An initial list of associated requirements

- Scope, schedule, and costs of current operations

- Inventories and functional flows of materials and processes

- A list of existing technologies

- A list of program and material interfaces

- A list of facilities used for current activities

- An initial picture of the magnitude of the current situation

- Increased enrollment of the team members process.

Current operations baseline development follows the seven-step process shown in Figure 3-5.

DETERMINE ACTIVITIES-SMEs for each product line, discipline, or area meet to list the sequence of activities associated with their respective area. Identification of such activities is addressed at a high-level to avoid the risk of becoming enmeshed in unnecessary details. At the INEL, high-level activities included: storage, handling, characterization, packaging, preparation, transportation, disposal, etc. An effective approach to modeling current operations is to segregate adjacent wall or whiteboard spaces for each area so that team members can then post their findings where others can view them. This encourages interaction and team development. Identified activities are then validated by peer review and area program managers.

DETERMINE REQUIREMENTS- The team records, to the best of their knowledge and available resources, all customer, supplier, and internal requirements associated with the management of their respective areas. These requirements are then validated, with appropriate references to source documentation, and serve as the baseline for requirements development. 


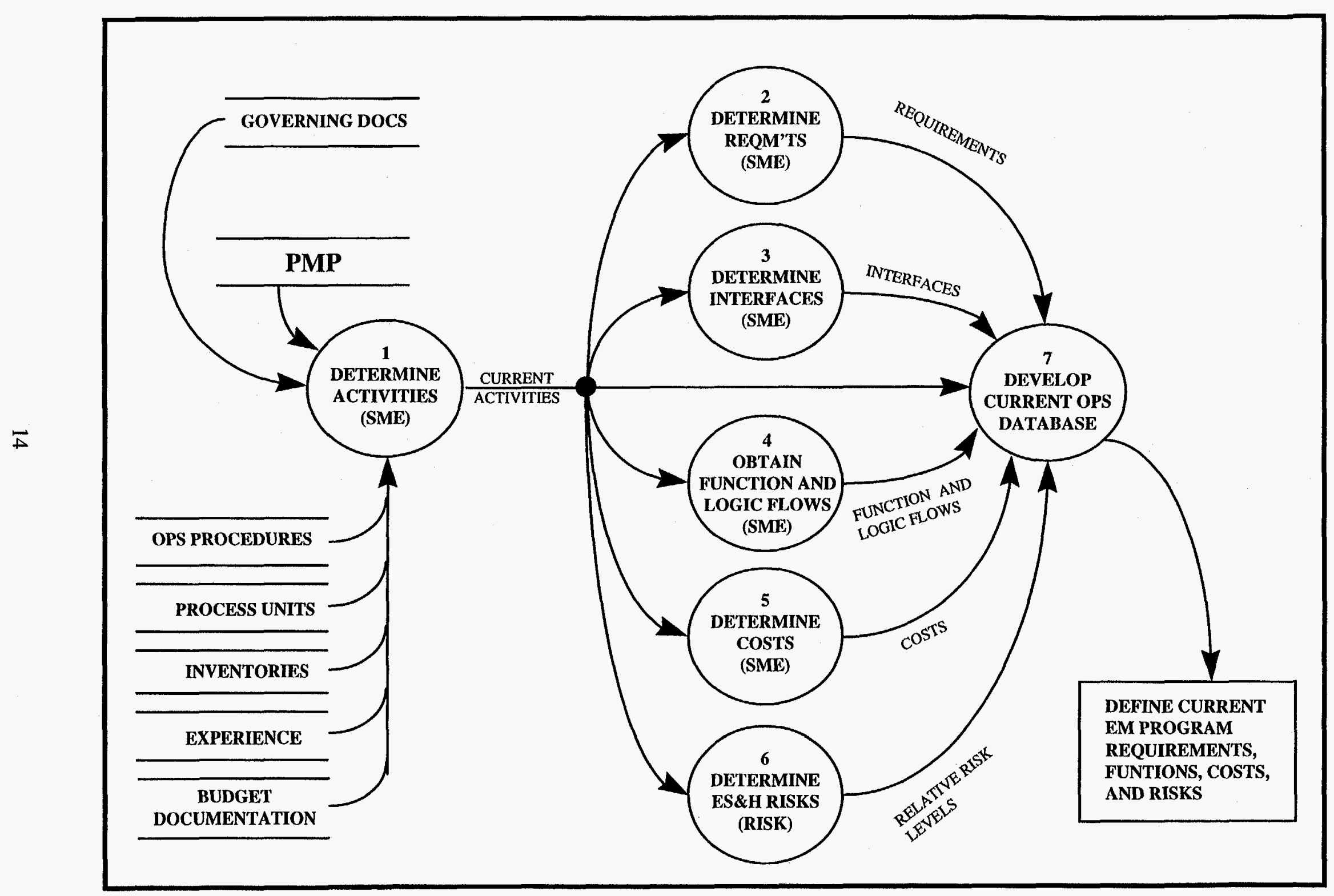

FIGURE 3-5. Developing Current Operations Baseline 
DETERMINE INTERFACES- During development of the current operations baseline, team members list all identified interfaces, including interfaces with suppliers; storage, handling, treatment, and disposal facilities; and transportation organizations. The interfaces provide key focal points for potential integration opportunities.

OBTAIN FUNCTION AND LOGIC FLOWS-Once the activities associated with a particular area are identified and recorded, the team records how the current system functions and what decisions are made along the way. At the INEL, for example, this was accomplished by determining such items as material types, amounts, and locations; fractional distribution of material as it is processed; and material generation rates.

DETERMINE COSTS-In order to have a valid baseline against which to compare alternatives, the actual cost of current activities must be established. Since the sum of individual activity costs may not equal budgeted amounts, a combination of expert knowledge, prioritization studies, cost accounts, activity data sheets, and cost estimates should be used to assess actual costs. These costs are validated by the respective managers and their cost advisors.

DETERMINE ENVIRONMENTAL, SAFETY, AND HEALTH (ES\&H) RISKS-Following costs, ES\&H risks should be calculated for each activity. There are two objectives for this task: (1) to determine whether or not current activities satisfy established health and safety requirements and (2) to establish a foundation for comparing alternatives on the basis of estimated risk. "A Simplified Method for Quantitative Assessment of the Relative Health and Safety Risk of Environmental Activities," INEL-95/0645, describes a simplified health and safety risk assessment methodology for estimating the relative risk of a given activity or alternative.

DEVELOP CURRENT OPERATIONS DATABASE-All validated information (e.g., activities, requirements, costs) should be recorded in a current operations database for management and control. This database will be integrated with databases from the other sites and programs and provides the basis for identifying and developing integration opportunities. A sample current operations baseline datasheet appears in Figure 3-6.

\subsubsection{Identify System Requirements and Functions}

Identifying system requirements and functions is the process of translating customer needs; applicable regulations, laws, policies, orders, and agreements; program schedules; and existing operating parameters into a set of quantified, verifiable requirements and functions. Up to this point, this document has referred to requirements and activities, where activities was used to indicate those things actually being done. Functions are now defined to indicate those things that need to be done. While there are many similarities, the differences between these terms is critical. Specifically, requirements and functions define (1) what the system must be capable of accomplishing, (2) how well system products must perform, (3) how and in what environment the system must operate, and (4) the assumptions and constraints that will affect design solutions. Additionally, they provide the basis for system design and integration, cost estimation, alternatives development and analysis, verification, and implementation. The resulting systems can be expected to fulfill mission objectives and ensure that systems perform according to customer requirements.

Identifying system requirements and functions follows a five-step, iterative process, shown in Figure 3-7. This process is applied incrementally and at successively greater levels of detail until a system design is established. 


\section{Current Operations}

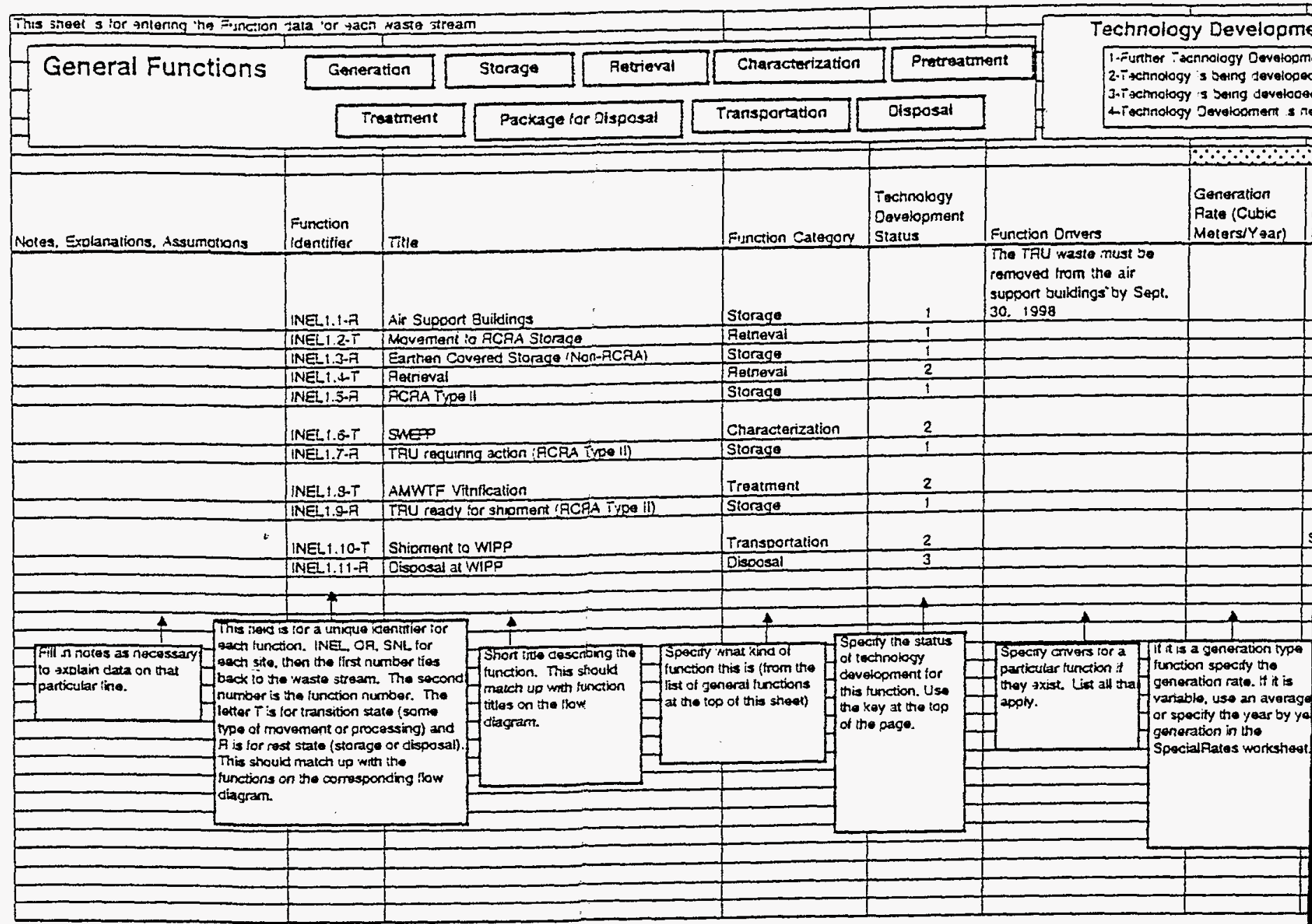

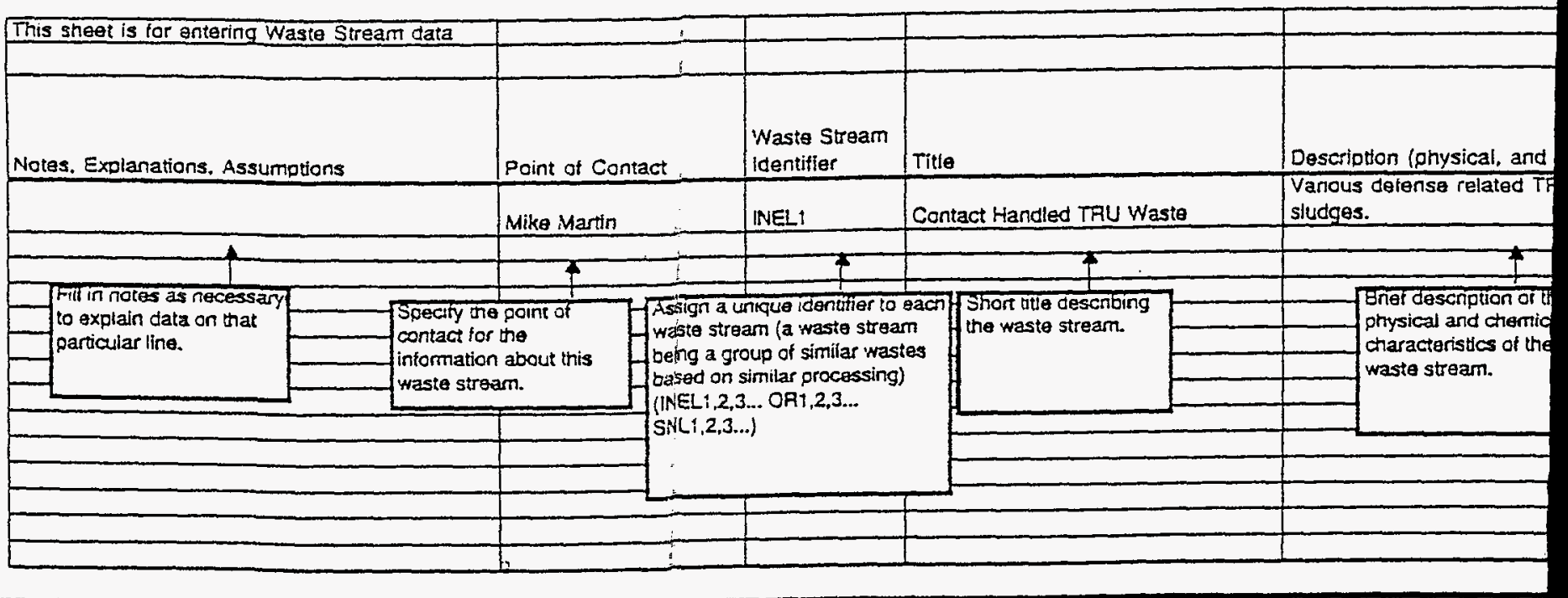

FIGURE 3-6. Current Operations Baseline Data Sheets 


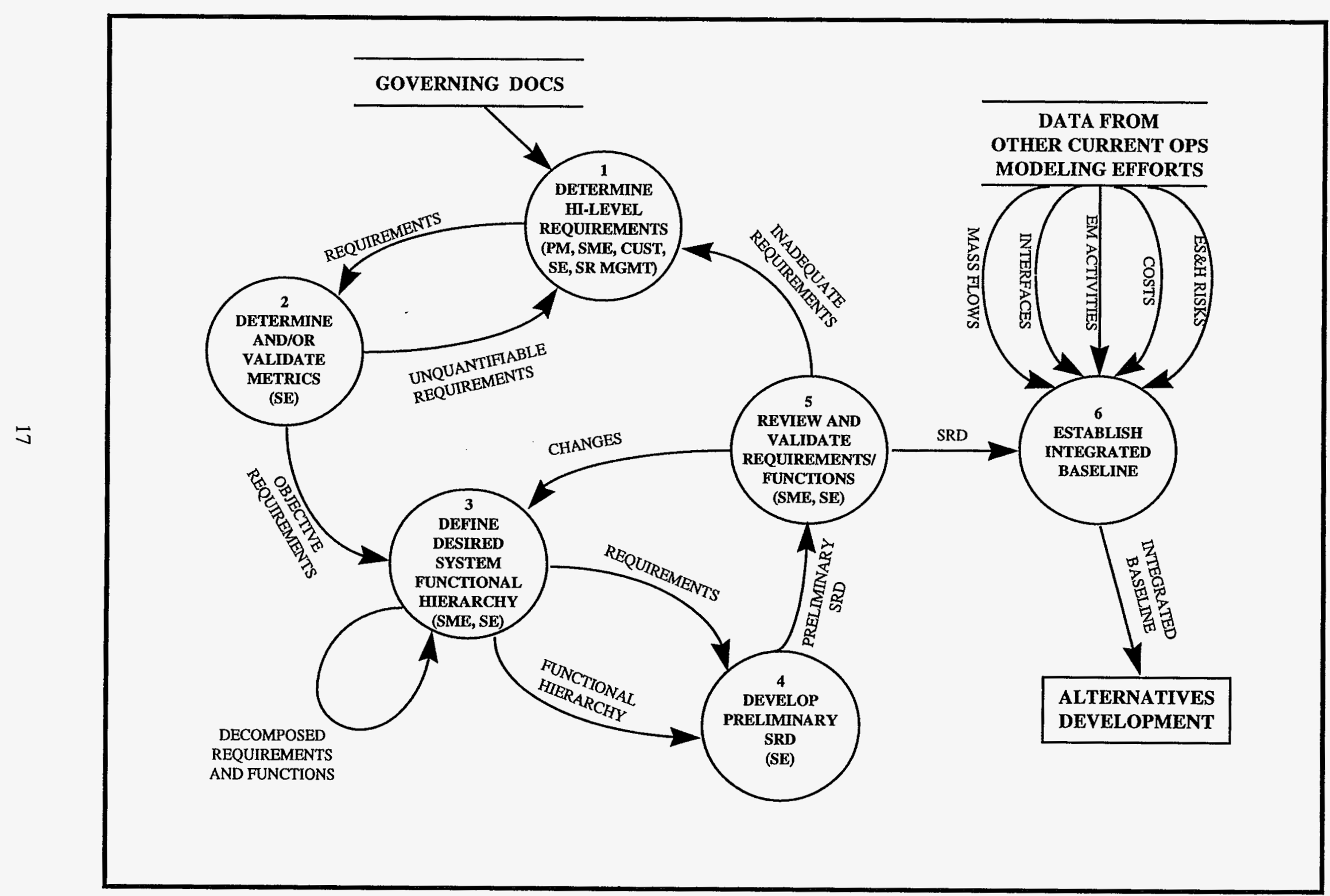

FIGURE 3-7. Identifying System Requirements and Functions 
DETERMINE HIGH-LEVEL REQUIREMENTS-Program management and systems engineers meet with the customer and senior management to identify the requirements, constraints, assumptions, and expectations under which the proposed system must be developed and operated. This is accomplished by:

- Reviewing governing documents (including applicable state and federal regulations, court orders and agreements, mission needs statements, strategic and program management plans)

- Reviewing current operations baseline data developed during the preparation phase of the SE process

- Interviewing customers and stakeholders for additional expectations and requirements not identified in document review activities

- Formally documenting identified requirements and sources in a requirements management database $(\mathrm{RMDB})$ to ensure traceability

- Listing known metrics (i.e., quantified, measurable parameters) for incorporation into integrated baseline.

In later stages of the process, this step is revisited to consider requirements for which no measurable parameters can be identified. This will be discussed in greater detail below. The overall mission requirements and the site-specific requirements identified during the Develop Project Management and Organizational Structure and Define Current Operations Baseline steps of the SE process provide the basis for these activities.

DETERMINE AND/OR VALIDATEMETRICS - It is not uncommon for many of the identified requirements to lack quantified, verifiable parameters. It is essential that specific metrics be identified and assigned. This will most likely involve additional research into governing documents (as defined above), reviewing current operations, and consulting with customers and stakeholders. It is also common to perform some basic trade studies during this step to quantify previously qualitative requirements (e.g., benchmarking with industry to translate 'monitor periodically' into 'test once a week.')

Requirements for which measurable parameters exist are iteratively decomposed to lower levels of detail and entered into the integrated baseline. These entries will be extracted in later phases of the SE process and used as the basis for technology development and system integration.

DEFINE DESIRED SYSTEM FUNCTIONAL HIERARCHY - For each higher-level requirement there will be found an optimum set of functions and sub-requirements describing those actions necessary and sufficient to meet or perform the original requirement. These provide the basis for developing and analyzing individual system components and must be explored, refined, and reiterated with higher-level requirements and functions to ensure consistency and traceability. As part of this process, a tabular or graphical representation of the functional hierarchy should be created to aid in continued development and decomposition of functions, identification of interfaces, group understanding, allocation of system functions to development teams, and overall system design. 
DEVELOP PRELIMINARY SYSTEM REQUIREMENTS DOCUMENT (SRD)-Using the RMDB, the systems engineer prepares an SRD for program management, senior management, and customer review. When agreed upon by all parties, this document will represent the technical baseline for all subsequent development, analysis, design, verification, and implementation activities.

REVIEW AND VALIDATE் REQUIREMENTS/FUNCTIONS-Program management, senior management, the systems engineers, and the customer conduct a System Requirements Review (SRR) prior to proceeding with the SE process. The purpose of this review is to verify that identified requirements and functions (1) define how the system must perform in quantified, verifiable terms; (2) establish what the system must accomplish and the environment in which it must operate; and (3) address customer expectations. During this review, inadequate requirements and functions are extracted and fed back to the Determine High-level Requirements step for further refinement. Additionally, inaccurate parameters are corrected and fed back to integrated baseline.

ESTABLISH INTEGRATED BASELINE-All validated requirements and functions for the integrated system should be recorded in the integrated program database for management and control. This database represents the central store of system information from which integrated alternatives will be developed, assessed, ranked, and selected. All subsequent data resulting from the SE process will be stored here.

\subsubsection{Design Initial Integration Opportunities}

Designing initial integration opportunities is an intermediate step in the SE process that can be performed when the current operation baseline is complete or nearly compete, requirements and functions have been determined, but detailed alternative assessments have not yet begun. Basically, this step involves an effort by the program team to take a broad-based look at the overall process and determine what integration opportunities are readily apparent. This is particularly useful if the integration involves more than one site. In this case, the baseline information and system requirements may quickly lead to the conclusion that one or more site-specific projects or programs can be combined to reduce overall program costs, enhance schedules, or deliver a superior product. This will need to be closely coordinated with the PM, the Executive Council, and the Program Core Team.

If integration opportunities are apparent, the PM will determine how to proceed. In the simplest case, the project will continue on the normal path shown in Figures 2-1 and 3-3. However, if there is any urgency in developing the integration opportunity, a separate project team may be formed to develop the process if resources are available. The Executive Council will support the PM in making this determination.

\subsubsection{Develop Alternatives}

This part of the SE process identifies various alternative integration opportunities and develops approaches that can perform the functions determined during establishment of an integrated baseline. This creative activity challenges existing facility use, rules, and ways of doing business to see how they can be improved, integrated, or eliminated. Many solutions exist that could satisfy the identified requirements and desired system functionality; for that reason, alternatives development strives to produce a broad range of potential system alternatives so that desirable solutions are not overlooked. 
Alternatives development follows the seven-step process shown in Figure 3-8.

DEVELOP SCENARIOS - This is a highly creative stage of developing alternatives. Scenario development involves brainstorming ways to deal with requirements and coming up with innovative paradigm shifts. The intent is for the entire program team to explore previously unexamined possibilities and record the associated assumptions. The assumptions represent a degree of programmatic risk which accompanies the scenario and must be balanced by potential gains in an eventual alternative design.

After the scenarios are developed, the program team assesses each scenario's credibility. If the scenario is truly not credible, then it is dropped from further consideration. Credible scenarios and assumptions are entered into the integrated database.

DEVELOP CONCEPTS-Concepts are developed by first placing credible scenarios into logically consistent groups. The SMEs then decompose scenarios into lower-level supporting functions and refine the lower-level design to integrate the separate functions of the scenario components. These concept design elements will be assembled later into alternatives and the relative assumptions recorded. Individual scenarios may be used in more than one system concept.

DEVELOP OPPORTUNITY MATRIX - Using current operations baseline information as a starting point, team members develop an opportunity matrix comparing desired system capabilities with existing facilities, technologies, etc. The goal is to identify common technologies and facilities that can meet the needs of more than one desired system component. The matrix is checked and, when acceptable, entered into the integrated database.

IDENTIFY COMMON FUNCTIONS AND INTERFACES-Using the opportunity matrix and the concepts developed earlier, project teams search for common functions, common facility use, synergistic activities, and technological and organizational interfaces. The team seeks opportunities to integrate activities as much and on as many levels as possible.

GENERATE ALTERNATIVES-Using the concepts, opportunity matrix, and the commonalties developed earlier, the team will generate alternative methods for dealing with identified requirements. Alternatives are created by reassembling the concepts (basic process building blocks) while capitalizing on the integration opportunities discovered in the opportunity matrix and during identification of commonalties. The integrated alternatives deal with all program activities and are bounded by the requirements identified earlier. All assumptions associated with the alternatives are recorded.

ASSIGN COSTS, RISKS, AND LOGIC-For each alternative generated, the program team along with cost estimators develop the appropriate cost, risk, and logic models. These are validated by peer review and entered with associated assumptions into the integrated database.

REVIEW AND VALIDATE ALTERNATIVES- Alternatives are reviewed against established requirements and, when determined satisfactory, are entered along with assumptions into the integrated database. 


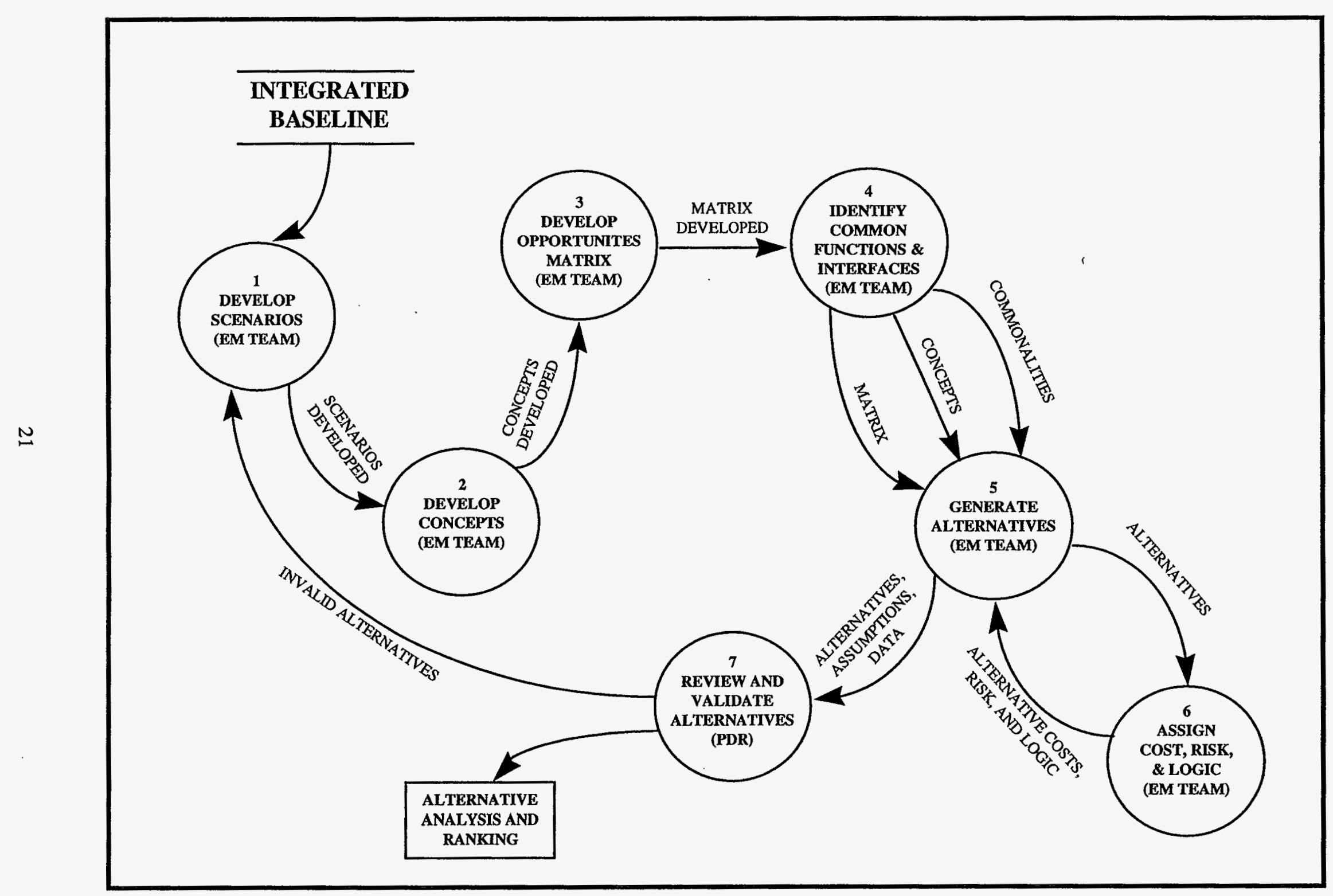

FIGURE 3-8. Developing Alternatives 


\subsubsection{Analyze and Rank Alternatives}

Alternatives analysis and ranking closes the loop that started with requirements and functional determination and provides decision-makers with a ranked set of alternatives that meet the mission requirements. Each alternative represents an internally consistent design choice that integrates many design elements. These elements, in turn, satisfy the functions and lower-level requirements derived from top-level mission requirements and objectives. These integrated designs represent a spectrum of risk and reward and are presented in the order of their desirability, based on criteria linked to the mission requirements and outlined in the recommendation. Alternatives analysis and ranking follows the fivestep process shown in Figure 3-9.

DEVELOP DISCRIMINATING CRITERIA- This activity involves gathering, selecting, and weighting various discriminating criteria as follows:

- Gather Potential Discriminating Criteria-Beginning with the basic criteria identified in the PMP, team members assess all aspects of the problem definition, mission analysis, and governing requirements efforts. The objective is two-fold: (1) build a list of those aspects that reflect the mission, objectives, and goals of the program; and (2) identify those parameters that, while not necessarily reflected by absolute metrics, allow for comparative analyses.

- Select Discriminating Criteria-The program team jointly selects a set of criteria that will, through appropriate weighting, form a composite picture of the fit of each alternative to the overall goals of the program. The intent is to limit the set to an affordable and measurable group of parameters whose weights may be negotiated with the decision-makers, establishing a supportable ranking of the alternatives.

- Weight the Discriminating Criteria - Finally, team members negotiate a set of weighting values that can be applied to the results of the analyses. This requires participation and buy-in by the decision-makers.

DEVISE THE ANALYSIS PLAN-A plan for calculating and compiling the chosen parameters is then devised, documenting any algorithms and approximations not in the standard suite of statistics and business analysis. Any parameters that are determined not feasible or affordable will be subsequently rejected. Team members should periodically return to the previous steps of the process, as necessary, in carrying out this step.

CONDUCT ALTERNATIVES ANALYSES-The calculations, analyses, and data compilations outlined in the analysis plan are then performed to rank the overall feasibility of each alternative. This will include, among other things, analyses of costs, risks, technical maturity, and processes.

RANK ALTERNATIVES - Using the weighting factors agreed upon, the program team produces a ranked list of alternatives, consisting of a criteria list, weighting agreement, alternatives descriptions, analysis results, and the rankings themselves.

PROVIDE A RECOMMENDATION-The program manager should then present the analysis results and rankings to the Executive Council as a formal recommendation, allowing decision-makers to make a selection. Formal implementation will be a reflection of the proposed plan included in the selected alternative. This presentation concludes the first half of the design effort. 


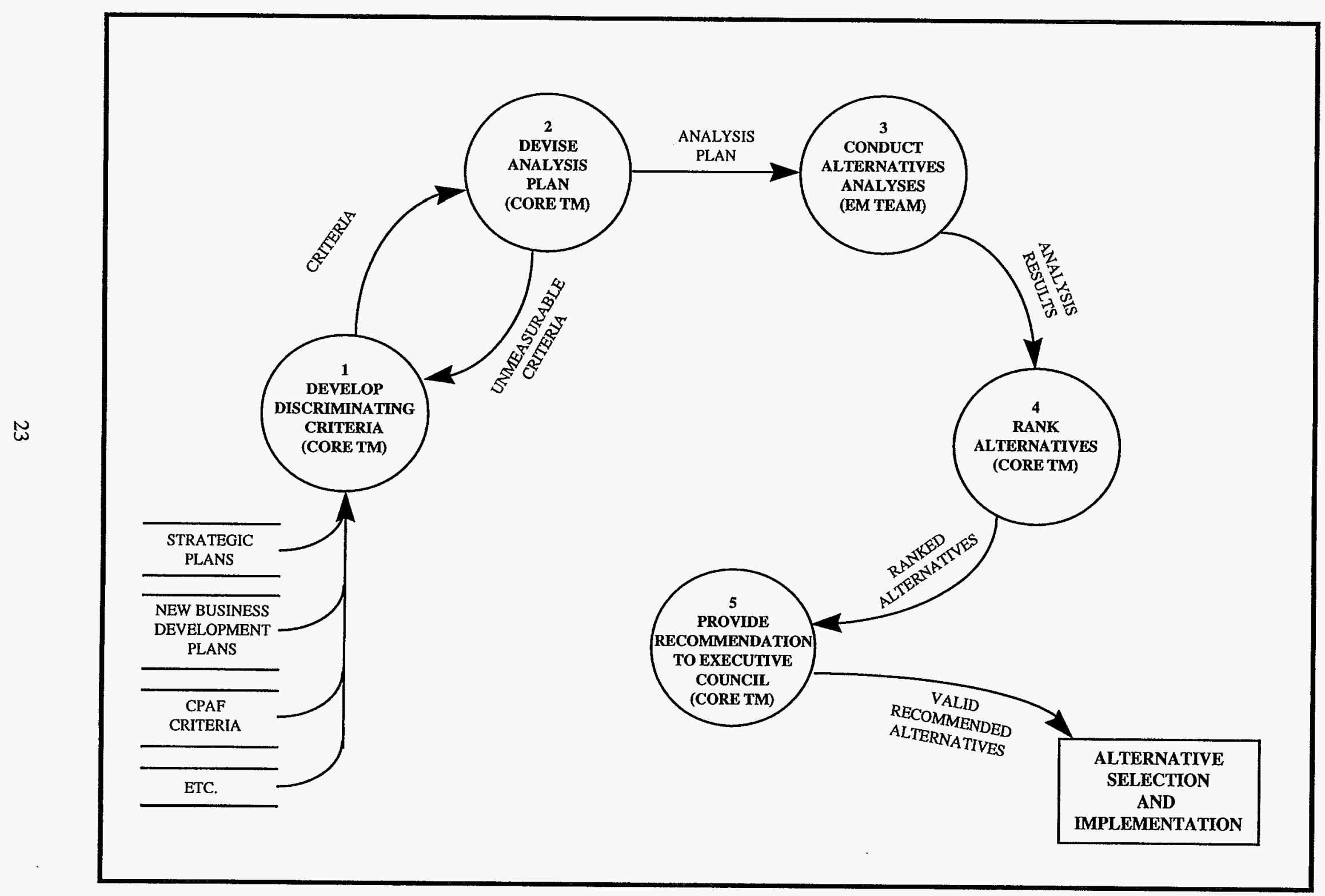

FIGURE 3-9. Analyzing and Ranking Alternatives 


\subsubsection{Select and Implement Alternatives}

Alternative selection is made according to the process defined and outlined in the PMP. The ranked alternatives will be reviewed and a decision made. This process may include the option of returning all the alternatives to a synthesis process that will provide an improved alternative for final consideration.

\subsection{Add Rigor and Detail: Subsequent Iterations}

Once a new or modified system has been designed for the program, the SE effort focuses on documenting, implementing, and monitoring the results of each iteration. This section discusses the last half of an iteration, emphasizing how it becomes the catalyst for the next. The key point to remember is that although team members continue to perform the same general process activities during subsequent iterations the level of detail and the accuracy of data will increase. As a result, more rigor is applied as the innovative ideas from earlier iterations are implemented in and propagated through existing program(s). The following steps from the adapted SE approach (identified by section number) represent the last half of an iteration:

\subsubsection{Implement Identified System Alternative}

3.3.2 Define Impact to Mission/Customer Needs

3.3.3 Identify Impact to Stakeholder Requirements

3.3.4 Develop Functional Definition of New System

3.3.5 Levy Requirements Against Functions

3.3.6 Develop Performance Measures Based on Requirements

3.3.7 Monitor New System Performance, Take Action as Needed

Each step is discussed below but with much less detail than those steps discussed in Section 3.2. This document is being written concurrently with the INEL's involvement in many of the activities described below. Consequently, lessons are still being learned as the INEL continues to adapt classical SE processes to meet its needs.

\subsubsection{Implement Identified System Alternative}

Having a new system definition is only the start to changing an existing program or site; implementing the new system is the real challenge. It seems easier for people to get excited about a new idea, than it is to embrace that idea and affect change. After attempting different methods of implementing change at the INEL, it became clear that the best approach was to engage those mechanisms already in place and familiar to the personnel being affected. As a result, implementation becomes an integral part of the yearly budget preparation, Activity Data Sheet (ADS) preparation, and Baseline Environmental Management Report (BEMR) input cycles. By linking the implementation step with those activities that define and impact the actual work, changes in the system occur with less active and vociferous complaints and obstructions.

However, the right data must be fed into these existing mechanisms in order for the desired change to occur. Consequently, a rigorous review of each program's plans is necessary prior to the budget and work scope development cycle. The INEL utilized extensive peer reviews to scrub each organization's plans before submitting the ADS. These reviews, known as "murder boards," were staffed by senior management from both the contractor and the DOE-Idaho Operations Office (DOE-ID). A predetermined murder board package was prepared to ensure all organizations developed and presented data at a consistent level and in a consistent format. That allowed the boards to make "apple-to-apple" 
comparisons and determine the relative value (need and cost) for each piece of work. Once a package received board approval to proceed, it became the basis for ADS preparation.

For more information on the murder board process, see:

"Environmental Management Requirements/ Defensible Costs Project: Final Report" (INEL-96/0101), Idaho Falls, ID: Lockheed Idaho Technologies Company, EM Integration Office, February 1996.

\subsubsection{Define Impact to Mission/Customer Needs}

Since not everyone affected by system- or program-wide changes is part of initial problem definition, alternative development, and/or planning and implementation activities, a great deal of communication must occur to enroll all affected stakeholders. Without this enrollment, many barriers to implementation can be raised, consciously and unconsciously, by the uninformed.

For local projects, this communication must include at the least all affected contractor, sub-contractor, and field office personnel. For large programs across a site, the list grows to include program personnel at DOE Headquarters and from local stakeholder groups (i.e., Site Specific Advisory Boards, congressional offices, political action committees, and public information groups). For programs that cut across site boundaries, the number of communication needs is multiplied by the number of sites involved.

The types of communication vary with the persons doing or receiving the information. Formal presentations, demonstrations, informal discussion groups, one-on-one meetings, public relations announcements, and employee newspaper articles are all types of communication used by the INEL in its recent efforts. The best option for communicating information depends on the relative volatility of the situation being faced.

This step has two important objectives: (1) the accurate and timely dissemination of what is changing, and why/how that change is occurring; and (2) to opportunities for gathering input and reaction to proposed programmatic modifications. The results of this step become important input into the rest of the implementation cycle.

\subsubsection{Identify Impact to Stakeholder Requirements}

Responses from the dissemination of program information feed this step and are used to determine to the level at which subsequent requirements derivations need to occur. This review provides the focus for the current cycle. Since requirements tend to flow down from an external demand to an internal procedure, following all requirements down all paths can become quite laborious. Instead, use the feedback from stakeholders and the new program definition to identify those areas in which resources must be invested to further derive requirements. Leave lower priority areas for later iterations or until they become a higher priority.

This step is also used to more fully document modifications to requirements or those requirements that need to be challenged. For programs already in operation, the ability to challenge requirements is critical. New external drivers often force new and sometimes conflicting requirements onto the system; hence, the need for large scale change creates a real need for innovative solutions that may be hindered by outdated restrictions. 
At this point, a formal data management system capable of growing as the iterations progress should be implemented, if not already in existence. At a minimum, be prepared to manage requirements (external and internal), functions and the work scope tied to them, task/functional costs, and cognizant organizations and individuals. A commercial requirements management tool, such as CORE or SLATE, can be of great assistance in managing and reporting the data. The resulting database will become the Engineered Baseline of the system, program, or site being integrated.

\subsubsection{Develop Functional Definition of New System}

The Identify System Requirements and Functions and Develop Alternatives steps discussed in Sections 3.2.4 and 3.2.6, respectively, define for each EM major task, the driving requirements, the tasks to meet those requirements, the cost to perform those task, and the relationship between these three components. This establishes the major components necessary to initiate an Engineered Baseline for the affected program or site that will ultimately lead to a requirements driven organization. Figure 3-10 shows the components that make up the INEL Engineered Baseline.

To produce this Engineered Baseline, system engineers work with program personnel to gather, negotiate, and secure individual components into the controlled baseline, as described in Figure 3-11. The Engineered Baseline also includes an accountability loop in which the requirements agreed upon by the various program elements are validated by comparing the work performed against the performance metric and the agreed upon cost to meet the requirements. At the INEL, this process is still in design and will undergo design changes as it is negotiated with the program management personnel.

During the cost basis exercises at the INEL, the entire EM scope of work was subdivided into discrete, interrelated chunks of work to enable the murder boards to perform a quality validation of the cost basis. This division of the scope also served to identify the slices of the program that could be incrementally developed and placed into the Engineered Baseline. A computerized Engineered Baseline prototype was developed and configured with the data produced during the murder board process to ensure data management of the Engineered Baseline. It was during this prototyping that the needed data sets shown in Figure 3-11 were identified and defined.

\subsubsection{Levy Requirements Against Functions}

In this step driving requirements are broken down into lower-level derived requirements and allocated to program functions through negotiation with the appropriate program elements. Derived requirements go through a review and approval cycle by the appropriate program management personnel before being accepted. Once accepted, the 'manager' of the function to which the requirement is allocated becomes accountable for meeting or performing against that requirement. When a requirement demands more than one function, then deriving the next level of requirements can help identify specifically who is responsible for what. At this point in the modified SE process, all the information necessary to fully implement desired changes exists. The changes don't occur, however, until accountability is assigned to individuals who make sure the changes are implemented by measuring progress and performance. 


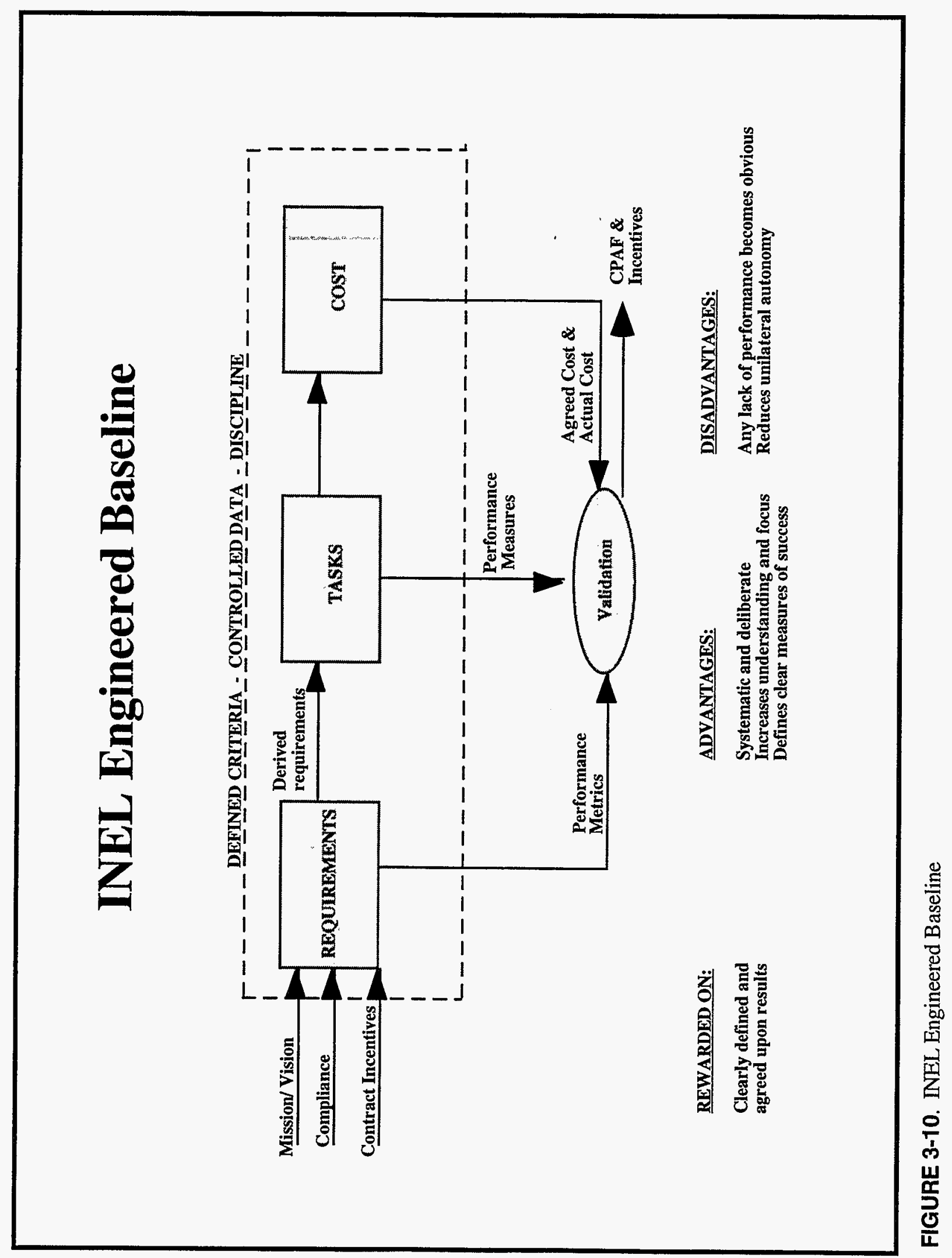




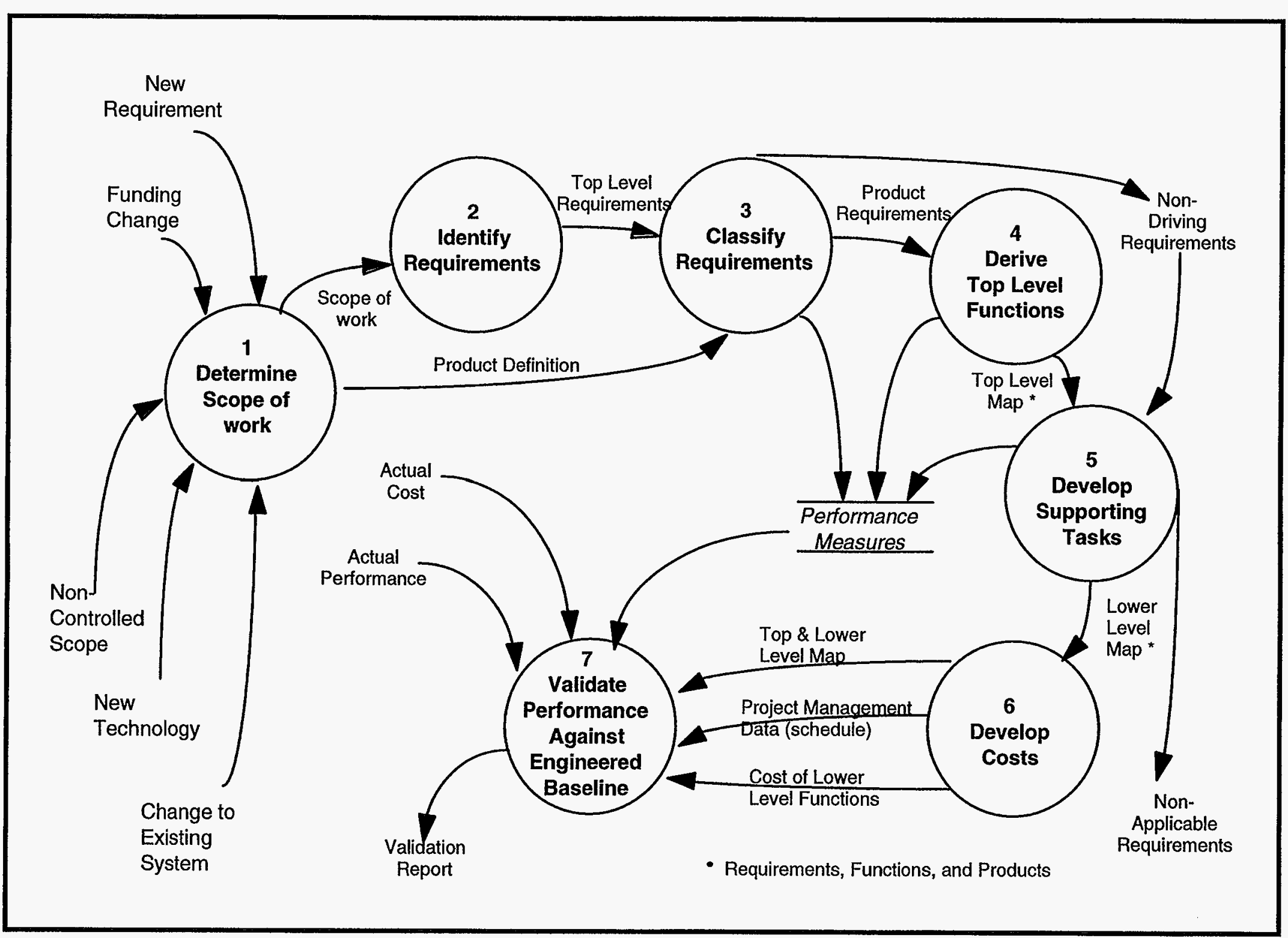

FIGURE 3-11. Building the Engineered Baseline 


\subsubsection{Develop Performance Measures Based on Requirements}

To ensure accountability and compliance, a set of performance measures must be developed that accurately reflect program requirements. Ideally, these measures would be balanced between infrastructure and project performance. This balance is important for corrective action to be effectively taken and for performance-based awards to be determined.

Infrastructure efforts, such as procurement, human resources (HR), payroll, etc., are necessary to support people doing the work for paying customers. Infrastructure elements are generally process-oriented, removed or insulated from the paying customer, and driven by company policy and procedures. In these cases, the program requirements are usually defined by contract or policy statements and are generally slow to change.

The project side of an organization, on the other hand, provides products and services to external paying customers through projects and programs, such as engineering, product lines, operations, etc..' The efforts are generally product-oriented, require face-to-face interaction with the paying customer, and are driven by many aspects (e.g., customer satisfaction, technology, funding levels, personnel skills). Project requirements are, therefore, defined by the customer and can change quickly.

The distinctions between the process- and product-oriented sides of an organization provide insight into the development of requirements-based performance measures. The infrastructure of a company is fairly permanent. Once requirements are derived and levied, process performance measures can be collected and process improvement or re-engineering tools used consistently. Projects within a company come and go. The requirements may be difficult to identify and can change rapidly, so project performance measures tend to be more difficult to identify, collect, track, and report. The traditional use of product measures provides only after-the-fact performance data. Tying measures to requirements provides inprocess performance data even if the requirements change. As a result, what is measured is different, but how it is measured and reported remains the same.

The same basic tools can be used for both types of performance measurement to properly manage requirements, tie performance measures to those requirements, solicit customer satisfaction levels more frequently, and calculate incentives based on the performance. These tools are briefly illustrated in Appendix $\mathrm{C}$ and described below.

A PROJECT INITIATION CHECKLIST is used to identify initial requirements at the outset of a project and track how mature and stable those requirements are. This tool is applicable to process design, integration, and improvement efforts (see Figure C-1).

THE FAMILY OF MEASURES DEVELOPMENT PROCESS is used to determine the 5-10 measures that most accurately reflect performance, defines importance weights for each measure, and includes all stakeholder input (see Figure C-2).

OBJECTIVES MATRICES are used to identify minimal and target performance levels, track current performance, and provide a normalized score for comparison and roll-up across the company (see Figure C-3).

TREND CHARTS are used to display the normalized measures over time, provide feedback at all levels of the organization, and illustrate improving performance or corrective action needs quickly and intuitively (see Figure C-4). 
CUSTOMER SATISFACTION SURVEY FORMS are used to capture customer satisfaction of performance quickly and often, provide timely insight and objective measurement, and allow both internal and external customers to provide oversight, guidance, and input while minimizing directions (Figure C-5).

Detailed instructional materials on how to use these tools can be found in the following references:

Plowman, Catherine, "Requirements-Based Performance Measures in Incentives Contracting," Lockheed Martin Idaho Technologies Company SE Working Paper, May 1996.

-...-., "Determining Customer Requirements for Engineering \& Science Projects," Lockheed Martin Idaho Technologies Company SE Working Paper, April 1996.

-----, "Performance Measurement Development," Lockheed Martin Idaho Technologies Company SE Training Package, April 1996.

\subsubsection{Monitor New System Performance, Take Action as Needed}

The requirements and their associated functions, performance metrics, and agreed upon costs are entered in a configuration controlled Engineered Baseline, as described in Section 3.3.4. Functional areas can then access their assigned requirements and performance metrics directly from the baseline and compare their performance to the agreed upon metrics and costs. If problems are highlighted, corrective action is applied. If not, the function continues along its original plan.

Without the use of measures, the effects of the designed change on the affected program cannot be objectively assessed. The results of the assessment set the stage for the next iteration of the adapted SE model. It will probably take a few iterations before the requirements and performance management system are mature and fully operational. Once they are, though, business planning and performance reporting become much easier for the entire organization. Subsequent iterations will utilize, build on, and refine the data stored in the system.

\subsection{Benefits of SE in Legacy Programs}

Systems engineering methods, which have been tried and proven for a variety of complex projects, can be applied to any project for determining the most efficient and cost-effective solution. For DOE programs, applying a systems-based process to programs and projects will increase operating efficiency and reduce costs by combining, eliminating, and/or simplifying similar activities. This results in an integrated plan which specifies the best alternatives for meeting goals and objectives within established programmatic guidelines. The plan is based on an integrated and defensible life-cycle baseline that is tied to requirements and drivers. A systems-based process for integration also provides the tools and methodology to rapidly alter existing plans in a controlled and responsive manner in response to changes in funding allocations, regulatory issues, or stakeholder influences.

When applied to individual programs or projects, such as the Integration of EM Activities at the INEL, the SE process provides the following benefits:

1) Decomposing top-level requirements into workable lower-level specifications and guidelines provides a framework for integrated product development 
2) Reporting programmatic changes and assessing and integrating the impact of those changes back into established baselines ensures that there are no surprises in the development of products and services

3) Integrating various engineering resources ensures products and services will perform as intended and meet customer requirements

4) Eliminating duplicate efforts reduces program costs and expedites schedules

5) Establishing a basis for informed decision making results in defensible decisions and increased customer acceptance of products and services.

In addition, applying and integrating the SE process into the management of DOE programs provides a characterized, integrated, and defensible baseline that will facilitate:

- Preparation of ADS for out-year activities

- Budget defensibility for near-term programs and projects

- Realistic and defensible approach for program life-cycle planning

- Rational and defensible prioritization of programs

- Development of logic ties to Technology Development needs

- Rapid turnaround for preparing technical reports and papers

- Common sense solutions to long-term problems

- Mission performance measurement. 


\section{ADAPTING SE FOR INSERTION: LESSONS LEARNED FROM THE INEL EM INTEGRATION EXPERIENCE}

During the rapid growth of the chemistry division at the INEL in the mid-1980s, a culture developed acknowledging that a mistake not recognized will be repeated. An award was instigated by Clyde Frank, now at DOE-Headquarters (DOE-HQ), to encourage open, fearless discussion of mistakes to allow the entire division to learn and move forward. "The Knight of the Day" award, featuring a self-indulged dragon picking his teeth with the lance of a recently devoured knight, was given to the individual who made the biggest mistake. The decision on award was made by the current holder, who would go privately to the individual and discuss the problem with them. The new award holder would then present the mistake in staff meeting, explain what had happened, and discuss what was being done to correct the problem. He would then sign the back of the award and retain possession of it until he felt compelled to pass it on to another team member.

In that spirit, "The Knight of the Day" award has been symbolically given to the INEL EM Integration staff in light of the problems encountered in implementing SE processes and integrating EM programs at the INEL. Those problems and the subsequent lessons learned are discussed below.

EM INTEGRATION BACKGROUND-Since the early 1950s, DOE-owned wastes and materials have been placed at various DOE sites within the United States. Most of these wastes and materials were a result of weapons development and production for defense purposes. The cold war effort left a legacy of radioactive and chemical waste, as well as environmental contamination, which has affected soils, groundwater, and air. In 1989, the DOE created the Office of Environmental Management (DOE-EM) to address the environmental problems associated with wastes and materials. EM activities encompass environmental restoration, waste management, nuclear material and facility stabilization, and technology development. These activities, often referred to simply as "cleanup activities," are heavily interrelated and must be conducted even as some defense work continues.

Life cycle costs associated with EM activities across the DOE complex are large, with early midrange program costs ranging up to $\$ 230$ billion in constant 1995 dollars. Competing national priorities make such expenditures impractical. As national priorities shift and congressional budgets for the DOE are reduced, DOE sites are faced with significant budget reductions for EM activities. Budget guidance provided by the DOE in the spring of 1995 , generally indicates insufficient dollars for planned cleanup activities at each DOE site ranging from 100 s of millions to billions of dollars over the cleanup life cycle assuming the sites continue to conduct business as usual.

Just as funding is becoming more restrictive, regulatory issues are becoming more complex. DOE-EM programs must comply with a variety of state and federal regulations, agreements and commitments which drive program costs and add to the complexity of these programs. The overall performance of the EM program has been constrained by multiple and sometimes contradicting regulations, making compliance increasingly difficult and expensive.

The DOE-EM funding structure, with four distinct and competitive areas (Waste Management, Environmental Restoration, Technology Development, and Nuclear Material and Facility Stabilization), promotes funding requests that tend to focus along programmatic and subcontractor lines, with subdivisions based on facilities, geographic locations, technology programs, and national charters. These funding practices make integration and synergism 
between intersite and intrasite activities difficult and often impede efforts to identify costefficient, effective solutions to managing EM programs.

The challenge for each DOE site is to find ways to proceed with cleanup activities under a more restrictive budget, heavy regulatory and stakeholder involvement, and significant competition between programs for existing funding. This requires new methods of doing business.

The DOE recognized the existing problems and the need to generate a systems approach in planning site and complex-wide EM activities. The latest BEMR guidance provided a basic architecture for resolving these problems. The guidance further encouraged sites to integrate their EM activities as a preparatory step for the 1996 BEMR planning. This included the construction of an integrated base case for each site that describes a "complete set of activities/projects necessary to complete the EM program at the site." The guidance went on to say, "The 1996 Baseline Report offers an opportunity for the integrated site team to review activities between Programs at each Operations Office to ensure appropriate integration of schedules." It is clear that DOE-EM recognizes the importance of an integrated approach for planning EM programs on a site-specific and complex-wide basis and desires to formulate outyear planning based on an integrated approach.

The INEL, like all other DOE sites, faces shrinking federal budgets at the same time local stakeholders are calling for greater regulatory accountability on the part of the individual sites. In order to meet the increasing requirements levied by these stakeholders yet remain responsive to budgetary pressures, INEL management requested that integration of all EM projects be pursued. The outcome of the effort was a modified EM system that could perform all required work at the lower funding levels without increased risk to public, environment, or worker safety.

EM Integration applied a systems-based process to EM projects to increase operating efficiency and reduce EM costs by combining, eliminating, and/or simplifying similar activities found in the EM arena. In general, the process consisted of defining EM requirements, developing tasks that will meet identified requirements, and combining or integrating those tasks into a unified system.

Initial integration efforts in March, 1995, produced a new EM system design for the INEL that would efficiently remove all hazardous waste from the state of Idaho by the year 2035 while simultaneously reducing operating costs by several billion dollars. As the U.S. Navy and the State of Idaho imposed even greater requirements on the current EM system at the INEL, additional activities were performed during the remainder of 1995 to further refine alternative solutions, define programmatic costs, reduce health and safety issues, and prioritize waste management activities. These activities ensured compliance with all currently defined requirements resulted from the application of traditional $S E$ techniques to the integration of the EM projects active at the INEL. In addition to these traditional techniques, highly tailored activities were utilized to address concerns and issues unique to DOE site management and operations.

Immediately following INEL EM Integration efforts, key members of that particular effort's integration team and project management core team were interviewed to determine the lessons learned that could be applied to future EM Integration activities throughout the DOE complex. In addition, nearly 60 participants in the INEL effort met in a four-hour, facilitated session to further identify and discuss lessons learned and associated project issues. 
Comments from the one-to-one interviews and the group session are consolidated according to the modified process outlined in Section 3 of this document. Initially identified through the EM Integration effort, the adaptations presented herein are not unique to either EM or integration. Instead, they represent general adaptations that should be made to the traditional SE approach when operating in a support services contract environment.

\subsection{An lterative Approach}

Traditional product-oriented SE tends to focus on the technologies and processes necessary to fully support the production, deployment, operation, maintenance, etc. of a product. While this is true of $\mathrm{M} \& \mathrm{O} /$ support service organizations as well, the support service view of a system generally includes at least two more dimensions, as shown in Figure 4-1: culture and organization.

These additional dimensions add complex characteristics to the system being integrated. Organization brings communication lines, authority chains, and positional hierarchy, while culture adds a value system, group norms, and communication nomenclature. These complexities represent the people and paradigms of the system and cannot be ignored during integration efforts. In fact, experience has demonstrated time and time again that the real barriers to and opportunities for integration lie in these last two dimensions.

Integrating culture and organization into EM activities avoids some potential pitfalls such as: (1) relying on an empowered, self-directed work group model when the existing culture doesn't support such alternate work structures; (2) assuming that PMs can accept or deny a requirement when the authority hierarchy dictates that the PM must be part of a team decision; or (3) rewarding team members who voluntarily reduce work scope or costs in an environment where power and control continue to be equated with the number of people and/or dollars in the organization. These pitfalls occur due to the perception of pushing the organization too far, too fast, or in an uncertain direction. Resolving these issues requires visible, decisive leadership; open, ongoing communication; and an iterative approach that addresses programmatic changes at a pace that program personnel can accept.

Recognize that innovative technical solutions are only a small part of the effort; the real benefits of integration will occur by changing the way business is conducted. Prepare to respond to resistance by: ensuring that the $S E$ activities are clearly understood by both the program team and senior management; keeping the home organizations well informed of all activities and plans; clearly defining any terms used in limited or specialized ways (such as, EM Integration, requirements, functions, scenarios, concepts, alternatives, empowerment, and authority); and taking corrective action based on lessons learned throughout the process.

Take into consideration the following aspects that generate a turbulent environment for integration: the magnitude of the effort is difficult to grasp; the rewards and/or consequences of integration are vague; political and/or funding constraints may restrict creative solutions; and integration may not appear to be in the best interests of individual programs.

Because integration cuts across program stovepipes built up over the lifetime of the program, support of and commitment to integration by company and DOE management at all levels is crucial. Senior management must participate on a regular basis in the integration process to ensure that the natural resistance to change is overcome, that requirements and expectations are clearly understood, and that management stays informed of the direction integration efforts are headed. This participation should be as either informed team members or as non-participating observers. 


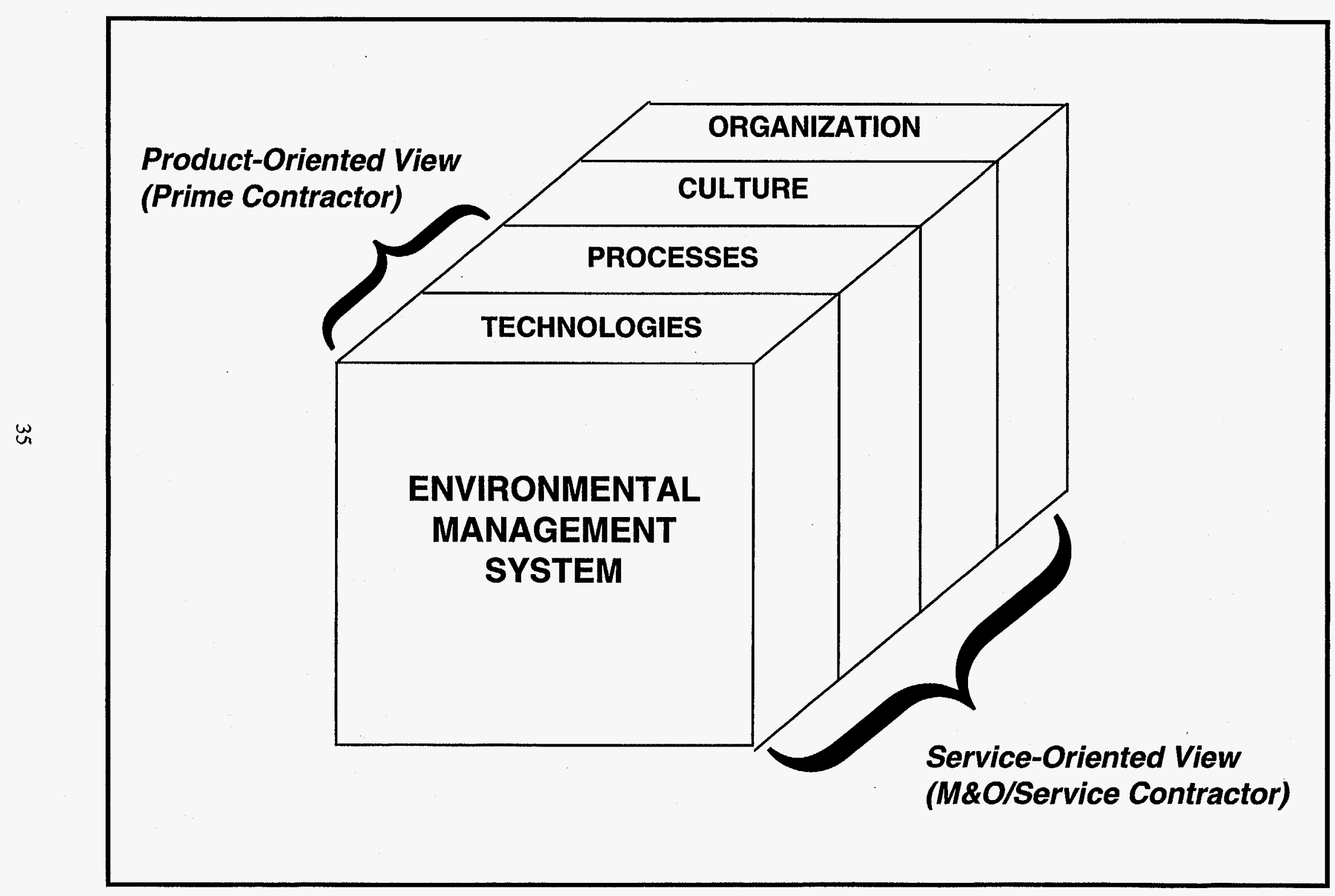




\subsection{The First Iteration}

The first iteration should begin with defining the minimal set of program requirements and objectives prior to developing alternatives so that realistic, yet innovative solutions can be realized. Due to the relatively tight schedule typically imposed develop a comprehensive plan for carrying out integration and communicate that plan to all participants. Include an agreed upon a method for resolving internal conflicts/issues as well as a high-level champion or sponsor who can resolve issues across department lines. Conduct a Plan-of-the-Day (POD) meeting and a team debriefing, respectively, at the start and conclusion of each day's effort.

A formal, controlled standard for submitting, reviewing, approving, and disseminating data and documents should also be established to govern integration activities. Include, as appropriate, any procedures, training, forms, and configuration management practices necessary to ensure consistency throughout the process; procedures should be both functional and clear to everyone involved.

\subsubsection{Define the Project}

Project participants must share a common goal and understand the direction of the effort in order to effectively integrate programs and processes. Management should develop a clear problem statement and program goals definition. Revisit them occasionally to ensure that integration efforts stay on course.

Associated schedules should be realistic, but aggressive. Avoid imposing unrealistic deadlines that require team members to work overly long hours. Doing so has negative impacts on team morale and can significantly reduce the quality of program results.

\subsubsection{Develop Project Management \& Organizational Structure}

To achieve timely and cost-effective integration of activities in light of program complexities, a teambased organization with clear lines of authority and responsibility must be established at the outset of the project. This is especially true of the full-time team members from program management, program controls, and SE since hierarchical structures often cause decisions to wait until the 'manager' is available, information to flow improperly (or not at all), and accountability to be easily avoided. The organizational structure for integrating EM activities consists primarily of three components (see Figure 4-2): an Executive Council, a Program Team, and Integrated Project Teams (IPTs) that draw on the capabilities of participating organizations, federal labs, and the private sector, and that are directed by the Environmental Executive Council to address individual projects in support of the overall program.

THE EXECUTIVE COUNCIL-The Executive Council is chartered to review and approve program proposals, communicate those proposals to DOE, obtain DOE approval, and provide oversight and direction to the Program Team. This Council, composed of senior management personnel from each participating site or program as appropriate, is chaired by a designated Executive vested with the responsibility and authority to direct program efforts. DOE is, however, the decision making authority and is responsible for providing top-level requirements to and approving the recommendations of the Executive Council. 


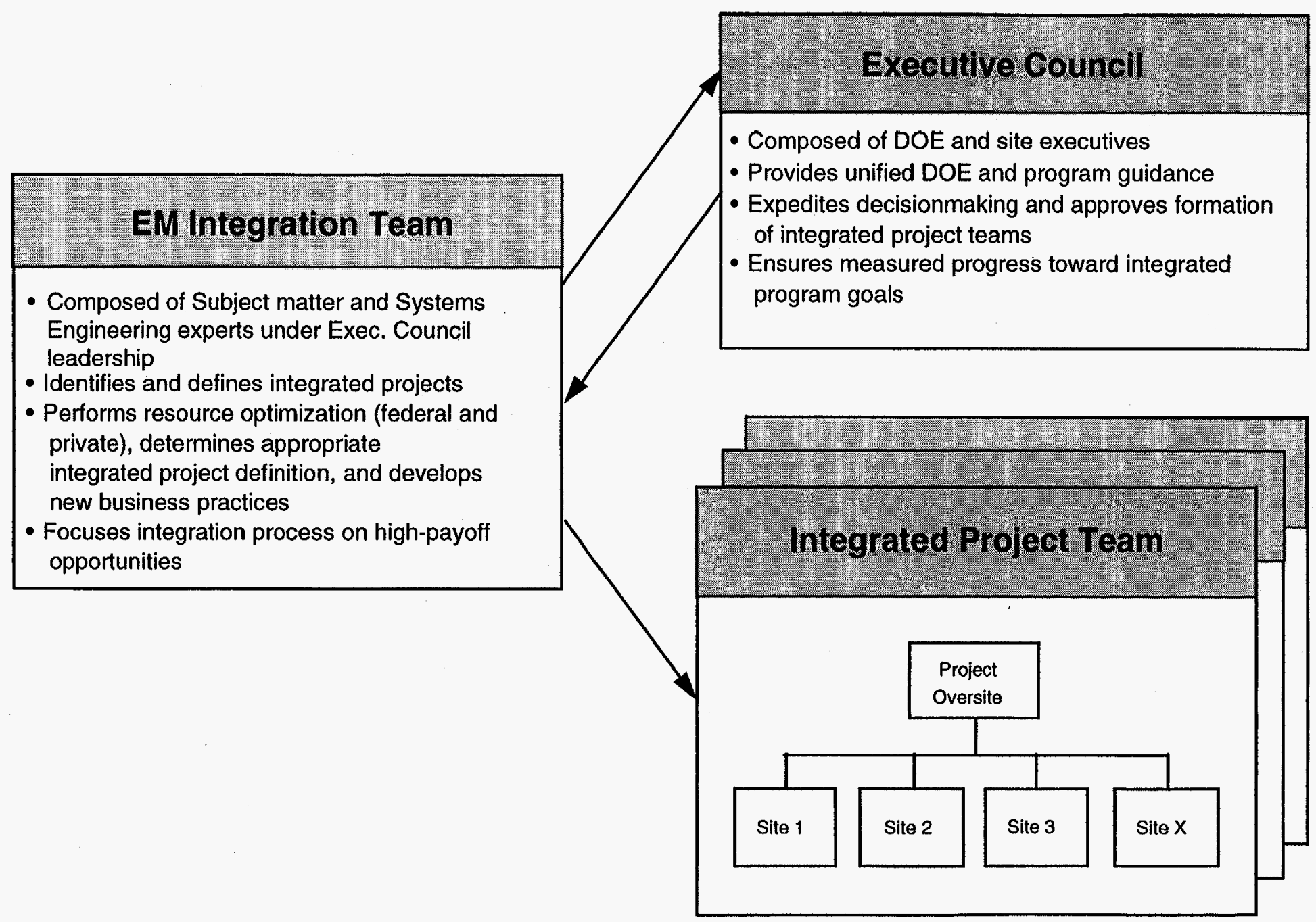

FIGURE 4-2. EM Integration Organizational Structure 
It will be difficult to resist the temptation to use specialty managers (e.g., HR, procurement, ES\&H) and staffers to handle integration projects because of the demands on line management. However, specialty managers and staffers typically do not have a vested interest in the outcome of integrating line organizations. They may also suffer from a lack of credibility with the line organization, insufficient technical knowledge, and/or an inability to see the 'big picture' point of view. Any of these issues can have an adverse affect on the SE process, data, outcome, and implementation.

THE PROGRAM TEAM-The Program Team is composed of a Project Manager, a Deputy Project Manager from a participating program or site, and five jointly-staffed teams: a management core team, a technical team, a cost team, a risk team, and an SE team. This structure has been proven at the INEL and reflects the lessons learned during the past year. This program team is empowered to gather site- or program-specific data; establish the current operations baseline; develop systems requirements and functions; identify integration opportunities; develop, analyze, and rank alternatives; and present recommendations to the Executive Council.

The program team must include technical experts from all functions or organizations that play a key role in the program, including representatives from programs, operations, infrastructure, ES\&H, SE, and DOE. The team members should also have budgetary and scheduling experience in their respective field of expertise. Once the team is formed, resist changing membership. Important team history and project knowledge will be lost and additional time will be needed for trust and effective interaction to be re-developed if team membership is altered prior to completing the SE process. When the situation warrants, consider breaking the large program team into sub-teams. This will allow program activities to proceed in parallel and could save significant time and money.

Individual sub-team responsibilities are as follows:

- Management Core Team-The Management Core Team is composed of the designated project management and controls personnel, as well as senior members from each of four support teams described below, and is responsible for Executive Council interaction and for overall program success. While other members of the management core team may frequently interact with the Executive Council and their representatives, only the designated PM can receive direction from the Council and commit resources or initiate approved modifications to baseline commitments. The management core team maintains control over program planning, opportunity assessment, alternative development, testing, and implementation activities, and is responsible for ensuring that Quality Assurance and ES\&H requirements are met.

The management core team is also responsible for tracking program cost and schedule issues and for ensuring that related data are accurate. The designated program controller is responsible for analyzing and reporting the status of these issues and for forecasting potential impacts to the management core team.

- Technical Team-The technical team is composed of SMEs representing all programs, facilities, technologies and processes under consideration. Typically, this is the largest team and contained approximately 60 members at the height of the INEL effort. This team is responsible for gathering, analyzing, and documenting program-specific data (e.g., costs, tasks, skill levels, programmatic requirements, technical performance 
measures). The members of this team are also utilized to design and evaluate alternative system solutions that minimize cost and risk while ensuring compliance to requirements.

- Cost Team-The cost team contains program control experts that support and assist the Technical team in developing defensible cost estimates for both the current operations baseline as well as for any alternative systems designed. This team is responsible for ensuring that the identified costs contain all pertinent elements (i.e., salary multipliers for benefits, redistributed organizational taxes, and facility-dependent costs). A fairly small and compact team, the cost team typically has between 5 and 12 members.

- Risk Team-The risk team may be the smallest team, but it is very important to the success of the efforts. While the SMEs are providing insight on the programmatic risk of a potential solution, the Risk Team is analyzing public, environment, and worker safety risk inherent in the designed change. This team is responsible for using DOE-accepted risk calculation methods and providing relative risk data back to the Technical Team and Management Core Team.

- Systems Engineering Team-The SE cadre supports the management core team, as well as the other program sub-teams, by providing the expertise necessary to carry out the following activities in a thorough and systematic manner:

1) Collate, document, and disseminate the consolidated requirements baseline

2) Define the desired system functionality, performance, and cost

3) Identify uncertainties and assess tradeoffs between various performance criteria, including near-term and life-cycle costs

4) Test the near- and long-term consequences of various strategies and scenarios

5) Verify system conformance and traceability to established requirements through formal program reviews at appropriate points in the program's life cycle

6) Provide specific documentation and reporting to establish a basis for informed decision making.

Additionally, management must empower their program team representatives to make critical decisions for them. When team members are used solely for the purpose of communicating ongoing activities to their managers and then relaying the manager's instructions back to the team, program activities take more time and the team members become demoralized. Instead, by assigning energetic people who want to make important contributions and vesting them with appropriate levels of decision making authority, management can make a significant contribution to the success of the endeavor.

During critical phases of the SE process, sequester the program team in an isolated area to minimize interruptions and foster team building. Also consider restricting cellular phones and pagers in the work area so that attention can remain focused on program activities. Additional work area considerations should include: the need for a large conference room or open area for 
facilitated meetings and compatible hardware and software for the timely and efficient dissemination of data among team members.

INTEGRATED PRODUCT TEAMS (IPTS)-Following approval of identified integration opportunities by the Executive Council, specific IPTs will be chartered to carry out the individual tasks required to meet program objectives. These may include such things as: assessing the capabilities of a particular facility to see if it can be expanded to accept tasks; evaluating mature technologies for the characterization, treatment, storage, or disposal of hazardous wastes and materials, where appropriate; surveying promising technologies for applicability to programs; and revisiting and updating program procedures to ensure compliance with new ways of doing business. The IPTs will be supported in all endeavors by the program team and the Executive Council.

\subsubsection{Define Current Operations Baseline}

Control all data in order to maintain a consistent technical baseline. The following guidelines apply:

- Use consistent metrics to allow direct comparison of information

- Be sure assumptions associated with given data are recorded

- Maintain a data library, with access for the program team

- Obtain mutual agreement from program team members for all changes to controlled data

- Make sure data, and subsequent changes, are disseminated quickly to ensure team members use the most current information available.

Develop realistic and fully defensible cost estimates for the projects and/or programs being integrated since program costs are one of the most scrutinized aspects of the program. This will involve the following:

- Establish a method to control and document costs and to approve changes to them

- Ensure that cost accounts, estimates, activity data sheets, and prioritization sheets are consistent

- Involve cost estimators early in the SE process so that they are familiar with the effort and how conclusions were reached

- Allow sufficient time for accurate cost estimation to avoid guessing on the part of the team

Have all data consolidated and reviewed prior to conducting any workouts. Make certain all data required for analyses and decision making is available, in the right format, and understandable before expanding the resources to bring a large IPT together. This can all be handled electronically and via phone calls or telecons. 


\subsubsection{Identify System Requirements and Functions}

Key differences between $\mathrm{M} \& \mathrm{O} /$ support service contractor and prime contractor relationships, as discussed in Section 4.1, play an important role in defining the interactions between requirements and other system attributes relevant to programs. In a Prime contractor relationship, the customer typically provided an SRD that fully outlines the desired characteristics of the product being acquired. Service contractors, on the other hand, tend to receive direction as high-level program guidance rather than definitive system specifications and must generate an SRD prior to beginning system design.

Additionally, programs and projects in a service contractor environment are much more subject to political, budgetary, and regulatory change, requiring closer interaction between customer and contractor.

Figure 4-3 shows seven distinct relationships between and involving requirements in a prime contractor relationship, while the $\mathrm{M} \& \mathrm{O} /$ support service contractor has 19 different relationships or interfaces to deal with. Both this diagram and INEL experiences fully support the assertion that requirements-related work is three times as difficult and takes three times the resources for $\mathrm{M \& O}$ /support service contractors than for prime contractors. In general, the complex nature of the contractual relationship is important to the complexity of program requirements.

Because of the greater complexity of requirement relationships in and $\mathrm{M} \& \mathrm{O} /$ support service environment, developing a traditional requirements hierarchy becomes more difficult. Figure 4-4 illustrates the current visualization of how requirements tie together. Note that the requirements hierarchy is shown as an $\mathrm{N}$-sided pyramid, where the number of sides is equal to the number of unique, external requirement sources (i.e., court orders, consent orders, state agreements).

Beginning with top-level agreements and consent orders, the hierarchy flows down to include federal laws (CERCLA, RCRA, etc.), DOE Orders, and other external sources. These requirements are interpreted by the EM programs, and a key assumption set is developed to represent the current interpretation. This assumption set translates the external driving requirements into internal derived requirements that define functional, operational, regulatory, safety, parameters. Technical experts then identify the work scope and associated tasks necessary to meet identified requirements.

By utilizing the requirements hierarchy as described, external requirements are translated into internal ones; internal requirements are used to drive work scope; and the prioritized work scope is used to define the programmatic costs. This structure provides a defensible cost and work scope estimate and ensures that work is aligned with the operative requirements.

Since most of the EM programs exist already, this traditional top-down requirement flow must be balanced against a bottom-up functional flow. At present, only part of the requirements pyramid overlaps the existing system functionality. The efforts of the program team will ensure that over time the requirements and system functionality become aligned into one continuous and coherent system. In that way, requirements will define the work that is necessary, and the entire system will meet the goal of being requirements driven.

With the requirements and functional hierarchy established, perform cross-process and/or cross-program functional analyses to find real savings and integration opportunities. Optimization within a program or funding stovepipe can be accomplished by the cognizant departments with some SE assistance. Largescale programs utilizing a great number of SMEs are more expensive and should be leveraged to find the greater opportunities. 


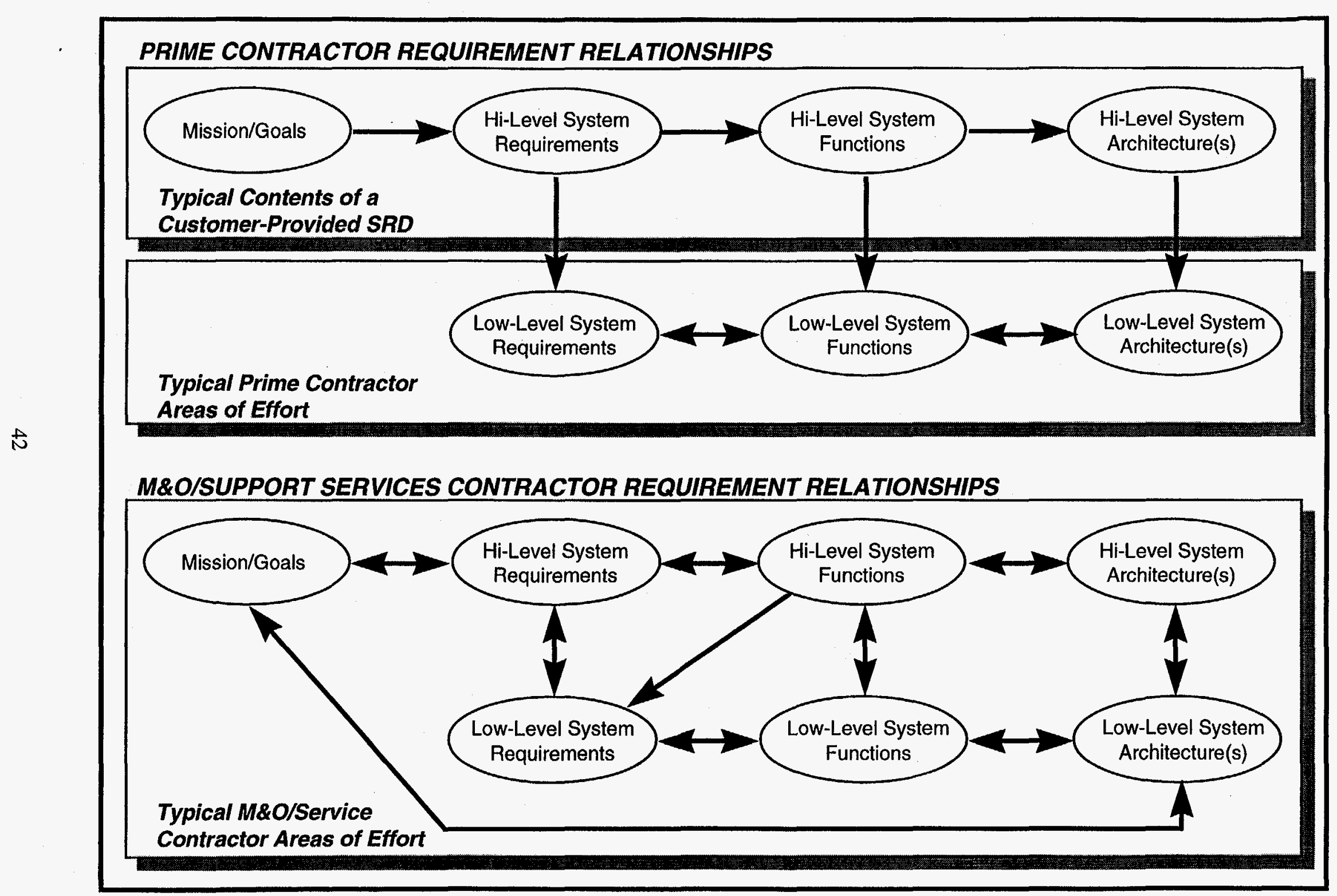

FIGURE 4-3. Requirement Relationships in Prime and Support Service Contractor Environments 


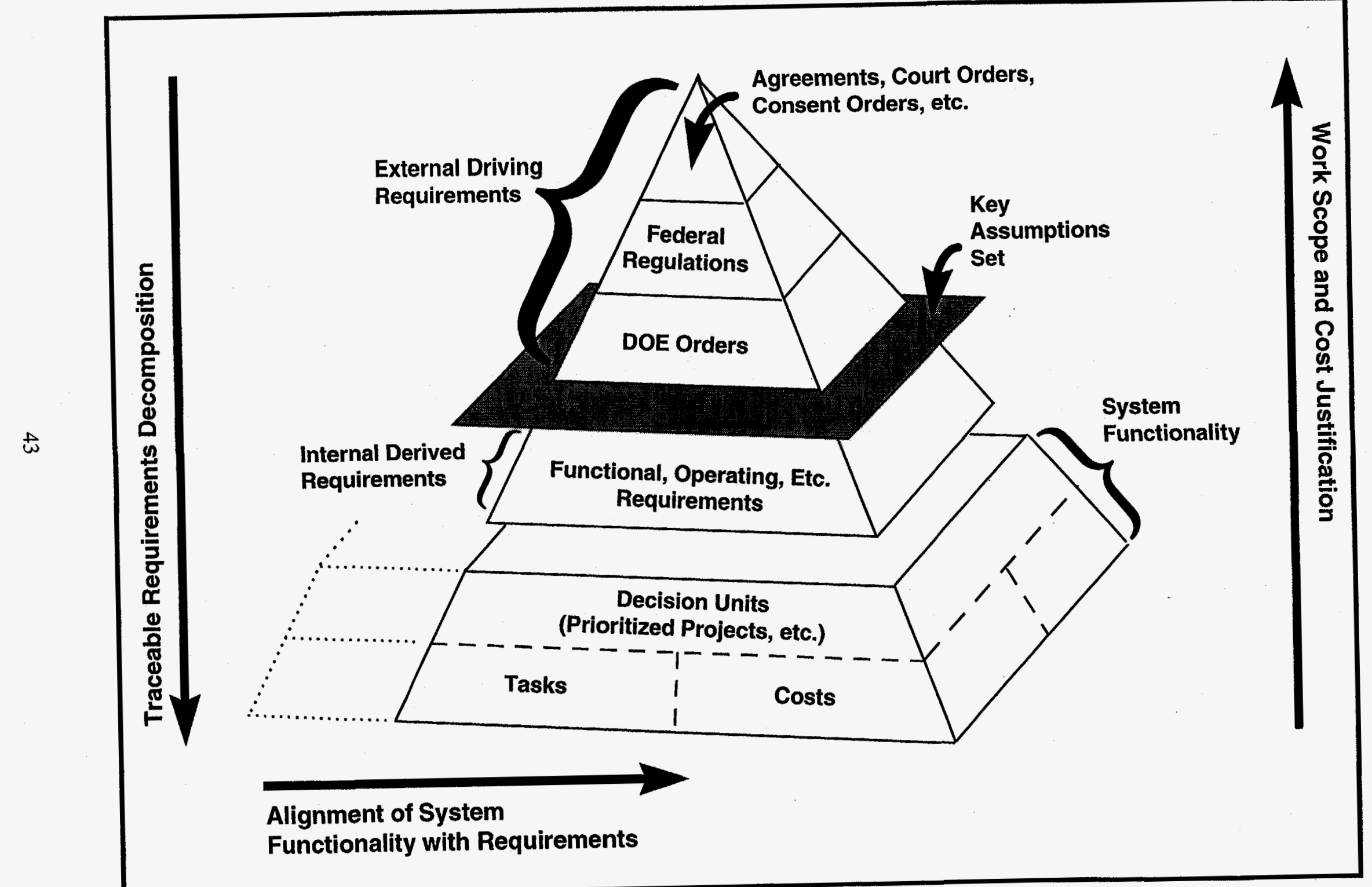




\subsubsection{Design Initial Integration Opportunities}

Methodologies used in this phase of the classical SE model are well suited to this adapted approach.

\subsubsection{Develop Alternatives}

Methodologies used in this phase of the classical SE model are well suited to this adapted approach.

\subsubsection{Analyze and Rank Alternatives}

One of the most important aspects of conducting alternatives analyses is the ability to quickly and intuitively display the results. The complexity of integration makes this aspect especially difficult. Figure 4-5 displays a format for illustrating scope, schedule, and cost data in a unified, informative manner. Additionally, as projects proceed, the effects of those projects can be displayed concurrently with the initial operations baseline to demonstrate progress.

The Current Operations chart (top) in Figure 4-5 uses a simple set of symbols to communicate the complexity of the total EM system. The time frame of interest is used as the common horizontal axis, while each major EM program is listed along the left axis (waste streams, environmental remediation, technology development, etc.). The major scope elements for each program are identified in blocks located on that program line at the appropriate time. The lower case letters are used to represent generic scope elements. These scope elements are tied together using lines to illustrate whether activities are happening in serial or in parallel. The cost scale is along the right axis. The continuous gray line in the background of each chart is the total system cost and reflects the cost of the diagrammed work scope.

As efforts proceed, individual programs remove parallel efforts and begin to rely on each other for shared technologies and/or facilities, as shown in the Initial Integration chart (middle) of Figure 4-5. This change in scope is defined by modified functions (signified by a 'symbol), lines crossing from one program to another, and the removal of some functions. The cost line reflects these scope changes.

In the Optimal Integration chart (bottom), where all integration opportunities have been implemented, the work scope map appears simplified although highly interrelated between EM programs. The cost line has changed again to stay aligned with the new integrated work scope. This method of displaying the complex results of the program as it proceeds allows the decision makers in the organizations to quickly and accurately see the impacts of the changes and determine the next course of action.

Be careful, however, to minimize unrealistic expectations and undue criticism by planning presentations well. Avoid presenting work informally; additionally presenters should have one or two technical experts present to answer detailed questions and to provide a more balanced view of the audience's responses. This will help prevent miscommunicating program results and making unrealistic commitments.

\subsubsection{Select and Implement Alternatives}

Aversion to risks dominate decision-making and action taking. Consequently, many good ideas never come to fruition. Changing reward and recognition policies to reward those who actively participate in generating change will create an environment where change is valued and sought. 


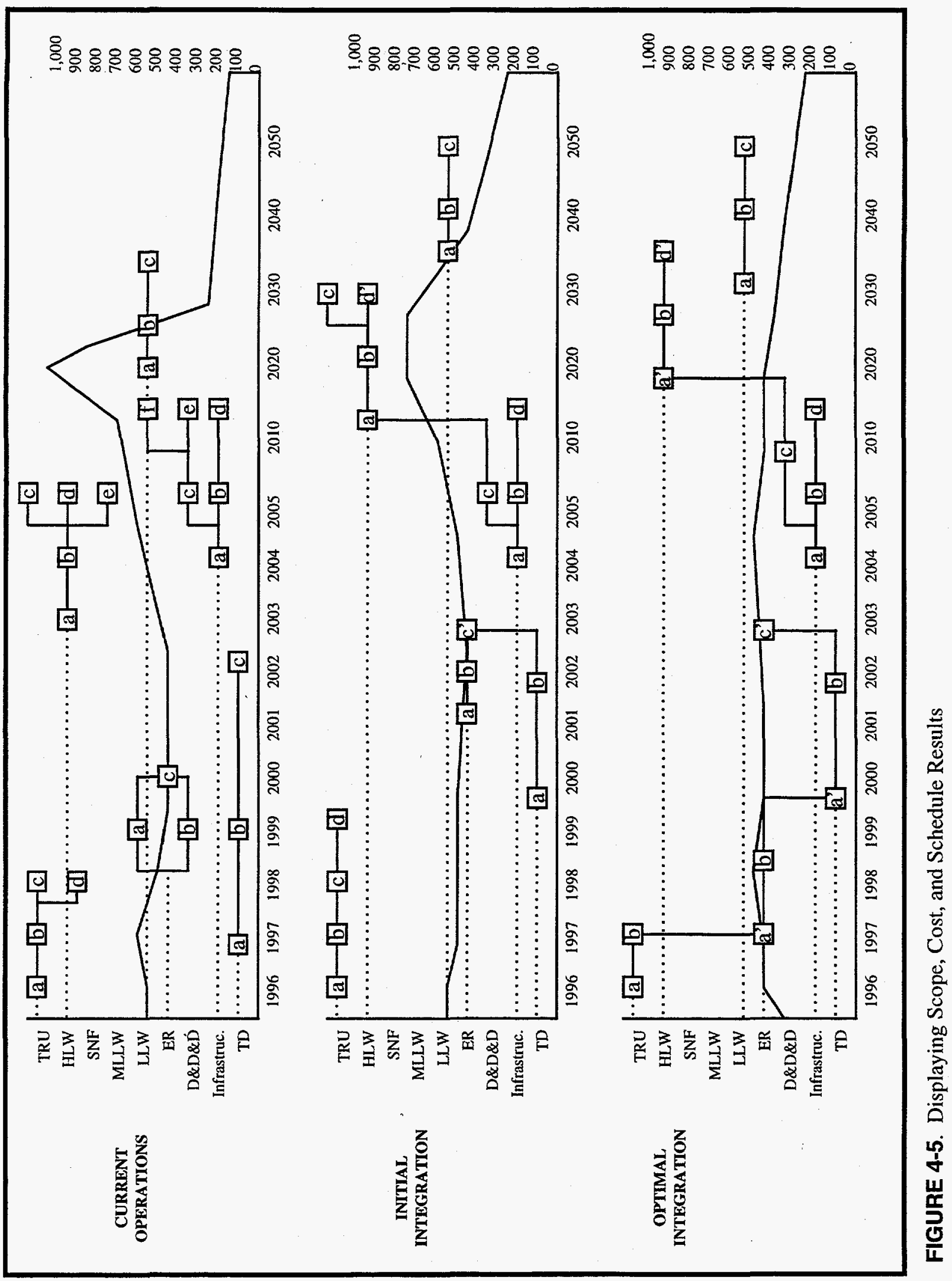


Constantly assess the environment and take advantage of opportunities in accordance with sound planning and a continuation of existing work. Also be sure to develop a clear understanding of the implementation plan for a new alternative (baseline change) and aggressively communicate that plan to those affected by the change.

\subsection{Subsequent Iterations}

Begin each iteration with a lessons learned exercise. Document any lessons that arise and modify implementation plans, as appropriate, to avoid repeating past mistakes or inefficiencies. The technical challenge of imagining new scenarios and designing new alternatives appeals to most people. This is the "fun" work. However, when the effort changes from design to implementation and real choices have to be made about the real tasks and process that effect real people, the work in no longer perceived as being "fun." The discipline required to fully implement a design alternative requires extraordinary energy. Without the "staying power" to see implementation through to its conclusion, the potential benefits of the new approach cannot be realized.

\subsection{Benefits of SE In Legacy Programs}

Previously, a systems approach has been applied to develop numerous products and facilities-satellites, aircraft, nuclear power plants - in both government and industry environments. Implementing a systems approach in the management of EM programs and projects, however, can be difficult for several reasons: requirements often come from multiple directions and in varying degrees of specificity; customer identification is not always clear; and existing projects are in various and often conflicting stages of development. As outlined in this document, standard SE principles and practices must be adapted to address these issues as they relate to DOE programs and projects. Please note that the sections above highlight those adaptations necessary to meet the needs of EM Integration and are provided as a guide to possible adaptations that can be employed by individual programs. Unless otherwise noted, standard SE processes described in Section 3, Appendix A, and the associated references should be followed throughout the program. Note, however, that adapting these newly developed methods to an existing SE approach, as experienced at the INEL, can help take a difficult situation and produce significant benefits or improvements. 


\section{APPENDIX A: A STANDARD SYSTEMS ENGINEERING PROCESS}

In their 1994 Annual Report to Congress, the Defense Nuclear Facilities Safety Board (DNFSB) noted, “... DOE has not consistently taken a formalized systems approach to solving safety, technical, and managerial problems ... Failure to use a systems approach in planning can lead to greatly increased cost, delays, inferior solutions to problems, and even inability to solve some problems." The Board also added that "a complex-wide DOE standard that formalizes the method would help. The need for better guidance on SE was apparent during a number of the Board's reviews in 1994."

Systems Engineering is a structured approach that considers all aspects of a particular program or project in developing products, systems, and services that meet customer requirements and program objectives. Beginning with the identification of requirements and functions, SE integrates program elements into a structured development process that proceeds from product conception, development, and analysis to the implementation, operation, and decommissioning of a complete system.

When applied to individual programs or projects, such as EM Integration, the SE process provides the following benefits:

1) Decomposing top-level requirements into workable lower-level specifications and guidelines provides a framework for integrated product development.

2) Reporting programmatic changes and assessing and integrating the impact of those changes back into established baselines ensures that there are no surprises in the development of products and services.

3) Integrating various engineering resources ensures products and services will perform as intended and meet customer requirements.

4) Eliminating duplicate efforts reduces program costs and expedites schedules.

5) Establishing a basis for informed decision making results in defensible decisions and increased customer acceptance of products and services.

The SE process shown in Figure A-1 is derived from Lockheed Martin SE practices and consists of (1) Requirements Analysis; (2) Alternatives Development; (3) Alternatives Analyses; (4) System Design and Verification; and (5) System Integration and Controls. SE functions are outlined below.

WEL EXAMPLE-The WEL is faced with treating, disposing, and otherwise managing 405,000 cubic meters of waste. 700 cubic meters of spent miclear fuel, and other materials in a time of declining budgets and increasing regulatory requirements. To address this issue, the INEL assembled a team of over 40 experienced technical and environmental experts. Using a conventional SE approach, as described here, the team integrated waste streams and materials with treatment processes, technologies, and facilities (see Figure A-2) to identif a solution that maximizes waste treatment, maintains acceptable environmental and programmatic risk, reduces the volume of waste requiring shipment to a geologic repository: and minimizes both near-and long-term costs. 


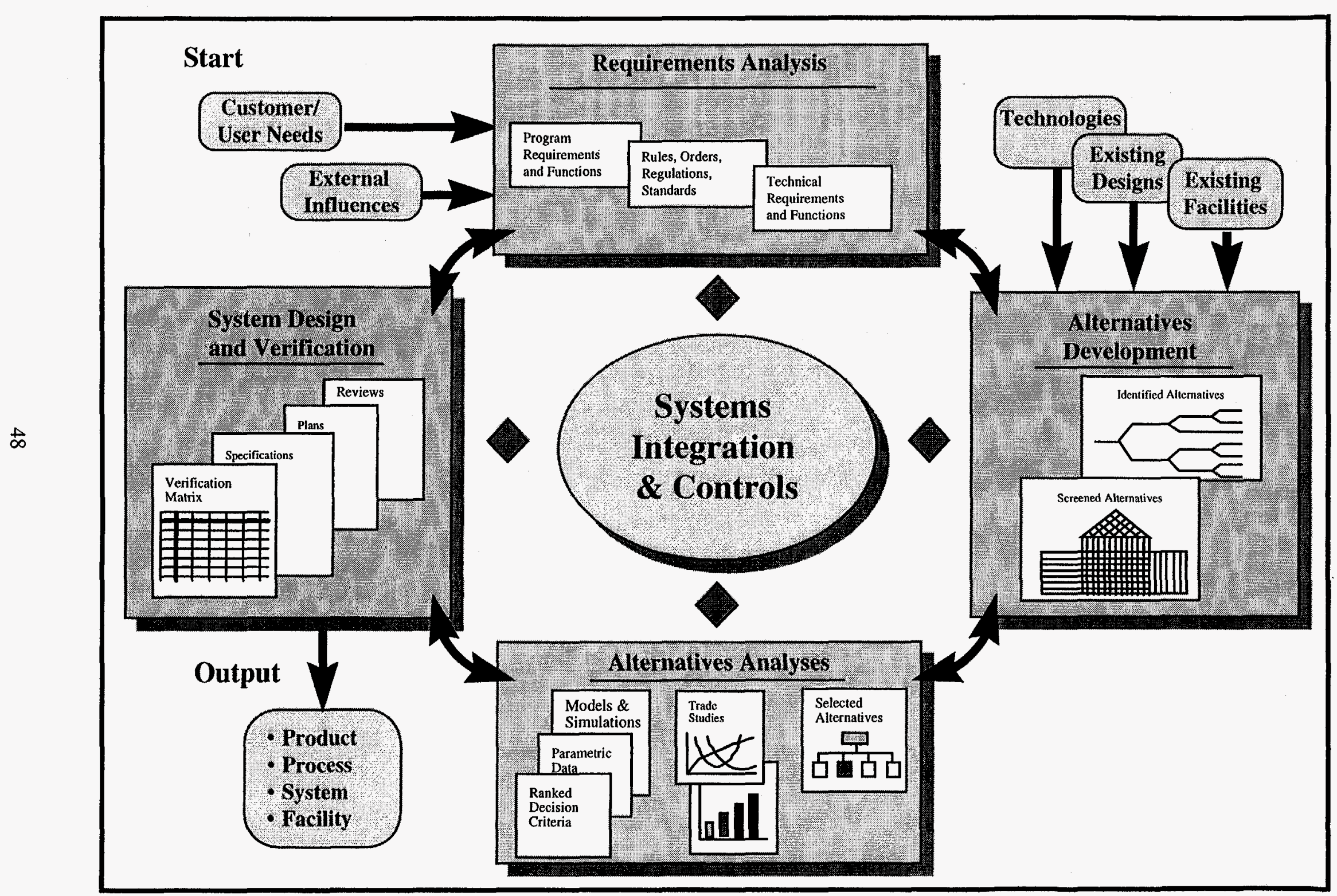




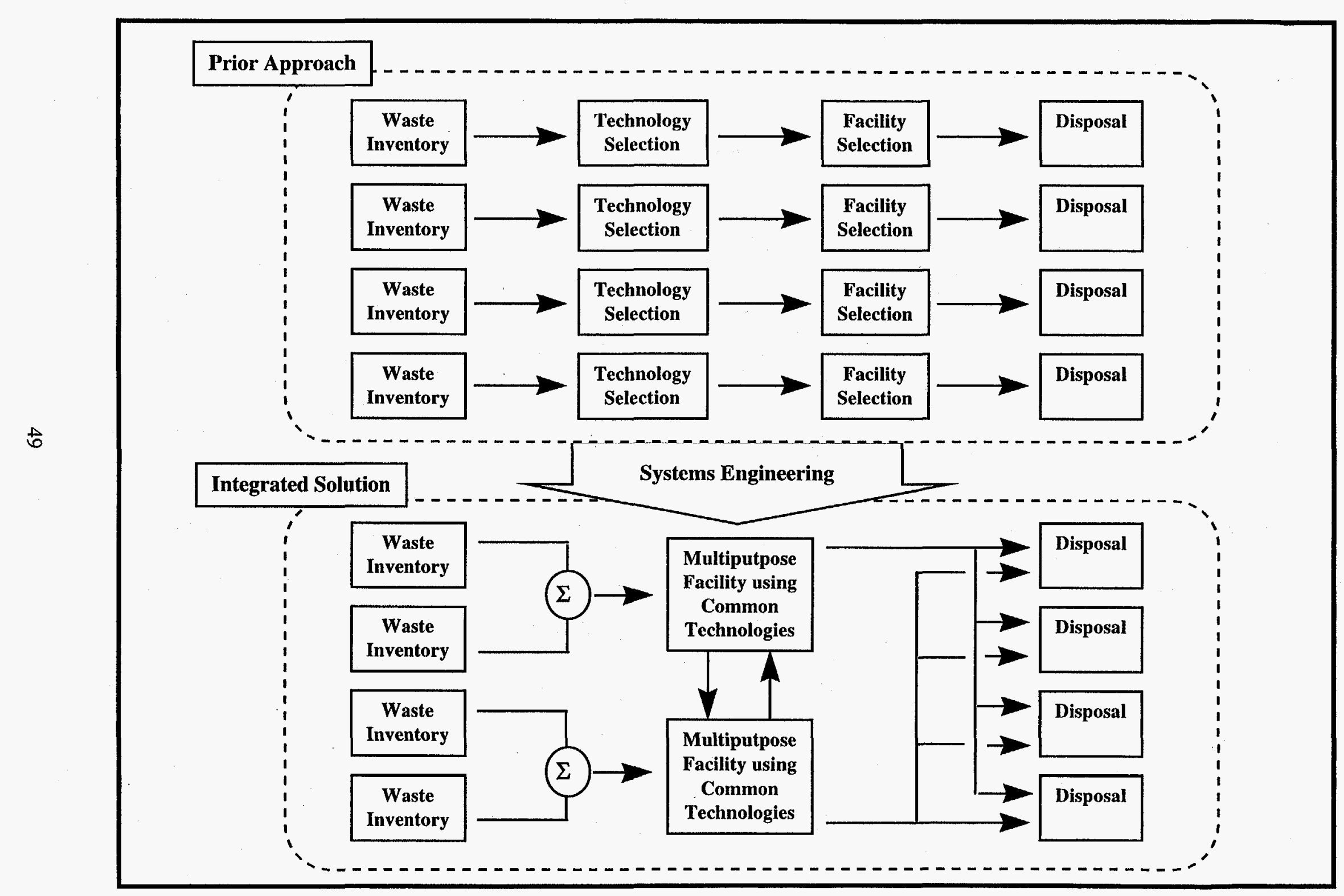

FIGURE A-2. Integration Through Systems Engineering 


\section{A-1. Requirements Analysis}

This phase of the SE process transforms user needs, customer expectations, and stakeholder preferences into a well defined concept of the system under consideration. While still only a paper design, the system can be studied, modified, and refined for minimal cost and effort. Specific activities performed during this phase include:

- $\quad$ Define customer needs

- Identify requirements

- Decompose requirements to appropriate working level

- Identify top-level functions

- Decompose functions to appropriate working level

- Integrate functional interfaces

- Define performance measures of effectiveness

INEL EXAMPLE (cont) - Projected budget estimates for the WEL's EM programs indicated insufficient dollars if business as usual' were to continue. This would prevent the MEL from achieving final disposition of wastes in a timeframe that is acceptable to stakeholders and in compliance with established agreements and Consent Orders. This problem required that INEL plans for waste treatment, storage, and disposition be changed to meet projected funding levels.

Additionally, current political factors severely constrain EM activities. Political decision have generated perturbations in INEI operation in the past. While political decisions will continued to influence future technical decisions, EM and INEI must continue to present sound techrical information to support risk based and fiscally responsible choices. As such, requirements to support resolution of political and buagetary problems were developed at the highest level and include:

- Make major INEI waste "road-ready" for shipment to

- WIPP (transuranic waste)

- Yucca Mountain (spent nuclear fuel/igh-level waste)

- Reduce waste volumes to maximize repository life

- Treat and stabilize high-level liquid waste

- Clean up the site expeditiously

- Move waste out of ldaho

- Meet environmental regulations.

Top-level requirements were subsequently decomposed to increasingly lower-level of detail specific to each waste stream and material type being considered.

The Integration Team then matched all INEL waste management, environmental restoration, technology development, facility transition, infrastructure activities, and related waste streams with the various treatment technologies and facilities eurrently available. This help integration participants better understand the magnitude of the problem being addressed and established and initial listing of the various. functions and activities necessary to comply with existing legal and regulatory requirements: A functional matrix showing the various waste streams and treatment technologies considered appears in Figure A-3. 


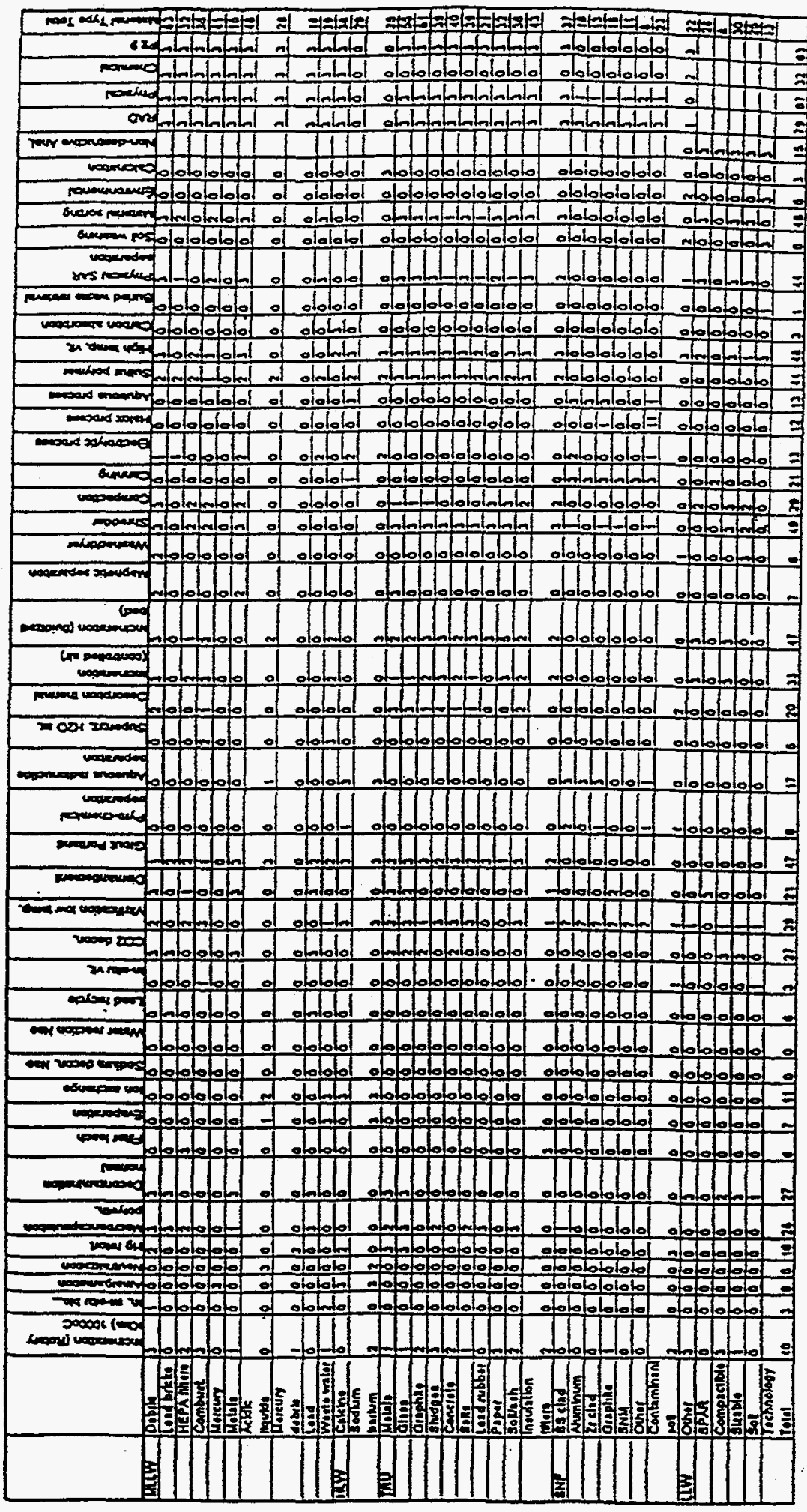

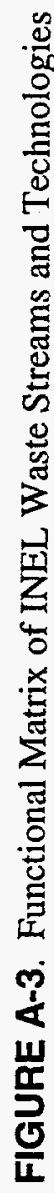




\section{A-2. Alternatives Development}

Once the system has been defined, different methods of providing the desired system are identified. In this phase, alternative technologies, facilities, approaches, time lines, etc. are used to develop system alternatives for further study. Activities typical in this phase include:

- Identify and develop alternatives

- Verify compatibility of program interfaces

- Ensure traceability to program requirements and functions

- Identify, quantify, and mitigate risk

- $\quad$ Reconcile cost, schedule, and scope issues

NEL EXAMPLE (cont.) Using SE methodologies, the integration team produced four alternative solutions for further analysis. Each alternative was examined in light of nine scenarios. From the resultant 36 cases, four were chosen as bounding the conditions for an in-depth analysis. The four bounded alternatives were as follows:

- The Full Treatment Alternative, later determined to be the preferred alternative, provides maximum integrated treatment and disposal with moderate near-term cost and lowest total cost.

- The Baseline Alternative, base on existing plans, generates compliant treatment and disposal, it had the highest near-term cost and high total cost.

- The Minimal Treatment Altemative is similar to the Full Treatment Alternative, but with less treatment completed. It has a slightly lower near term cost than the Full Treatment Altemative, but a higher total cost when legacy costs are considered. (Legacy costs are those costs beyond the 2030 date required to treat, ship, and dispose of the wastes or materials.)

- The Storage Alternative provides storage-only within the planning period. It has the least amount of treatment and the lowest near-term cost but has the highest total cost when legacy costs are considered. It is also likely to be unacceptable to regulators and stakeholders.

Figure A-4 shows the four alternatives matched against nine possible scenarios, creating the 36 total cases considered in the evaluation. Those bounded by circles represent the four detailed cases selected for further analysis. 


\begin{tabular}{|c|c|c|c|c|c|c|c|c|c|}
\hline Allernallves $\quad \begin{array}{l}\text { State Varlable } \\
\text { Comblnallons }\end{array}$ & $\mathbf{S S}_{1}$ & $\mathrm{SS}_{2}$ & $\mathrm{SS}_{3}$ & $\mathrm{SS}_{4}$ & $\mathrm{SS}_{5}$ & $\mathrm{SS}_{6}$ & $\mathrm{SS}_{7}$ & $\mathrm{SS}_{\mathrm{B}}$ & $\mathrm{SS}_{9}$ \\
\hline A Basaline & & 5 & 9 & 13 & 17 & 21 & 25 & 29 & 33 \\
\hline$A_{2}$ Full treatment & & $\because 6:$ & $\because 0^{10}$ & $\because 14 ;$ & $\because 18$ & 22 & 26 & $\because 30$ & $34{ }^{\circ}$ \\
\hline As Minlmal treatment & & 7 & 11 & 15 & 19 & 23 & 27 & 31 & 35 \\
\hline$A_{4}$ Storago & 4 & $\theta$ & 12 & 16 & 20 & 24 & 28 & 32 & (36) \\
\hline
\end{tabular}

Cruclal Stale Variables
- WIPP avallabillity
- No-migratlon delerminallon
- Yucca Mountaln avallability
- Acceplabilily ol HEU al
Yucca Mountaln

FIGURE A-4. INEL EM Integration Alternatives and Scenarios 


\section{A-3. Alternatives Analysis}

With the feasible system alternatives identified, a series of trade studies, simulations, and other analytical efforts are conducted to generate quantitative data for the alternative systems. This data then becomes the basis for detailed comparisons between alternatives as well as the selection of an optimal system solution. Activities common in this phase of the process include:

- $\quad$ Collect parametric data

- $\quad$ Establish technical and cost baseline

- $\quad$ Perform sensitivity and trade analyses

- $\quad$ Optimize alternatives

- $\quad$ Perform decision analyses

- Optimize solution

- Provide documentation that allows customers and management to make informed decisions

WEL EXAMPLE (cont) - Quantitative and qualitative measures, including cost, final waste volume, overall effectiveness, ES\&H risk, program risk, and mission compliance, were defined by the integration team for each alternative. A computer model (see Figure A-5) was then designed as a tool to evaluate the alternatives against identified criteria. The model manages data associated with each altemative and supports tradeoff analyses by examining performance and cost sensitivities to changes in criteria and scemarios.

Cost data were collected from the EM Activity Data Sheets and other planning documents for input. Inputs did not use escalation factors, although the model was capable of generating escalated values upon completion of the analysis.

Waste quantity was tracked by type through various transition states into treatment, storage, or disposal operations. The model measured the volume of material in each state or in each transition state, and allowed for comparison of total volume moved through the process.

ES\&H risk analysis was accomplished through an approach that measured six major factors: (1) contaminant quantities and specific toxicity, (2) mobility and confinement barriers, (3) challenges to confinement, (4) environmental pathways, (5) receptors, and (6) time-at-risk.

The evaluation model was designed to track the quantity of material flow over time and provide a consistent comparison between aitematives. It also calculated total and cormponent costs and risks of alternatives and generated cost- and risk-time profiles.

Tradeoffs between cost, material flows, and risk changes allowed for a consistent comparison between altematives. Time profiles of expenditure and of volume of waste moved allowed for additional evaluations. Finally, mechanisms for evaluating uncertainty were incorporated into the model to identify key parameters needing further analysis. Quantitative and qualitative data resulting from the alternatives analysis are shown in Figures A-6 through A-8. 

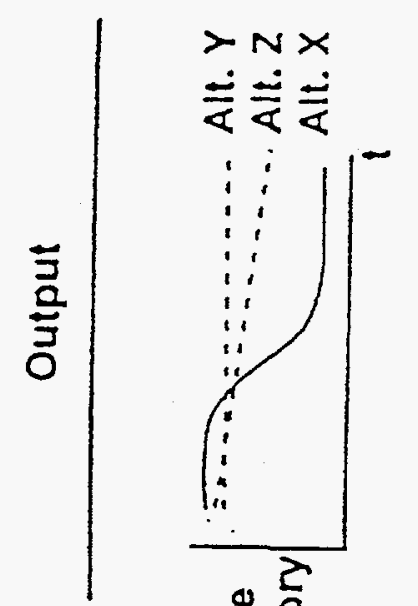

$x>N$
$\dot{\bar{\alpha}} \frac{\dot{0}}{\alpha}$

$x>N$
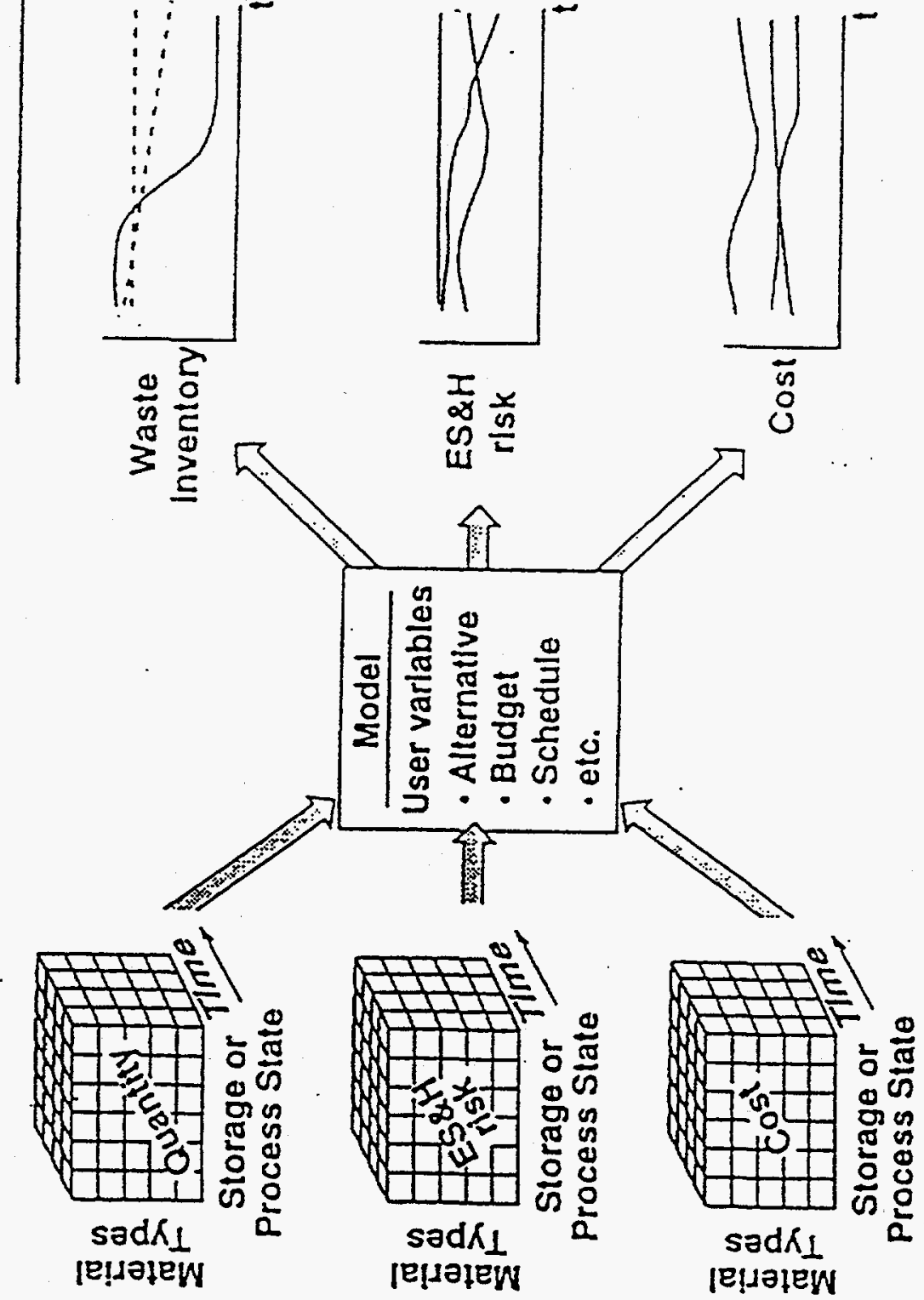

这玄

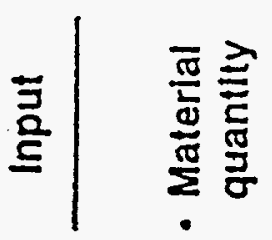

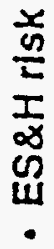

ग̊

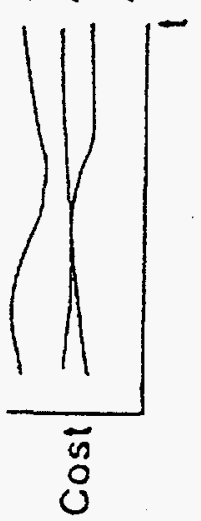

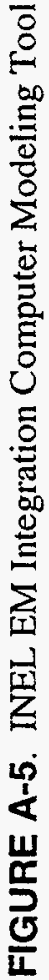




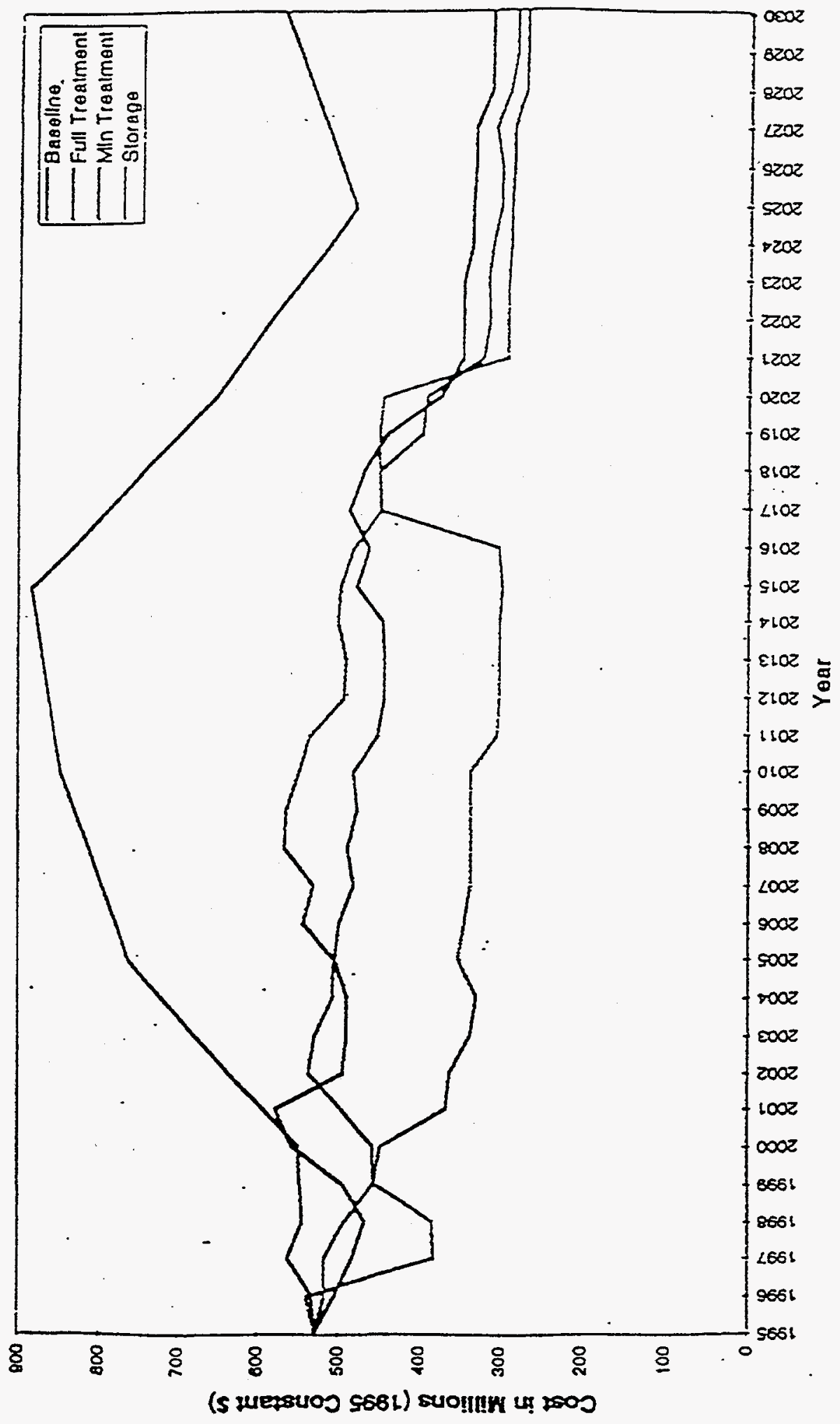




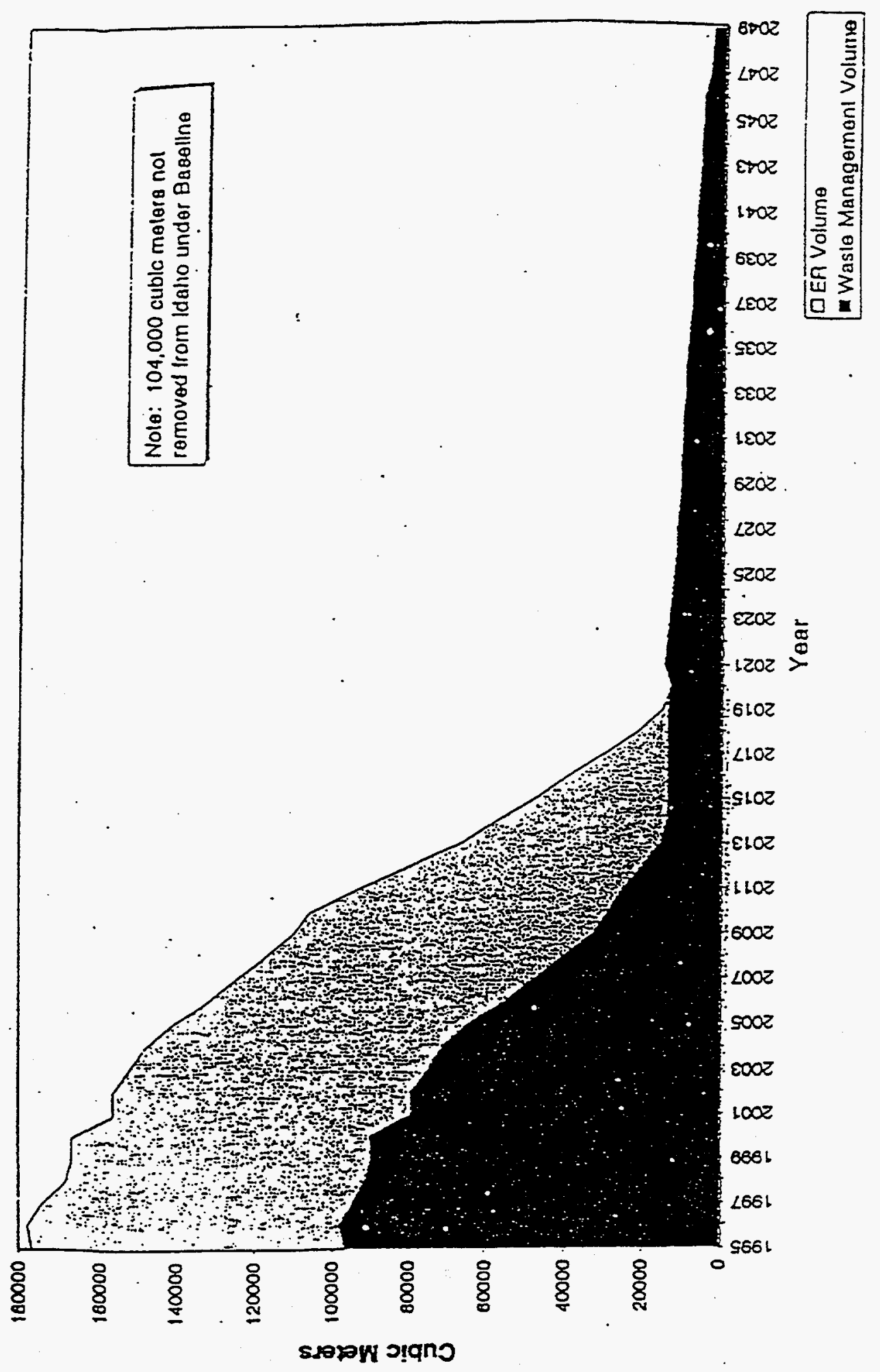

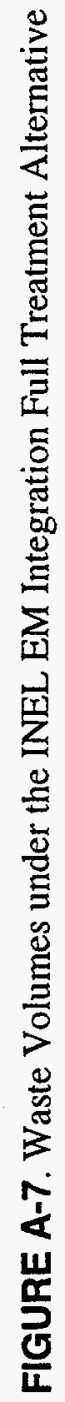




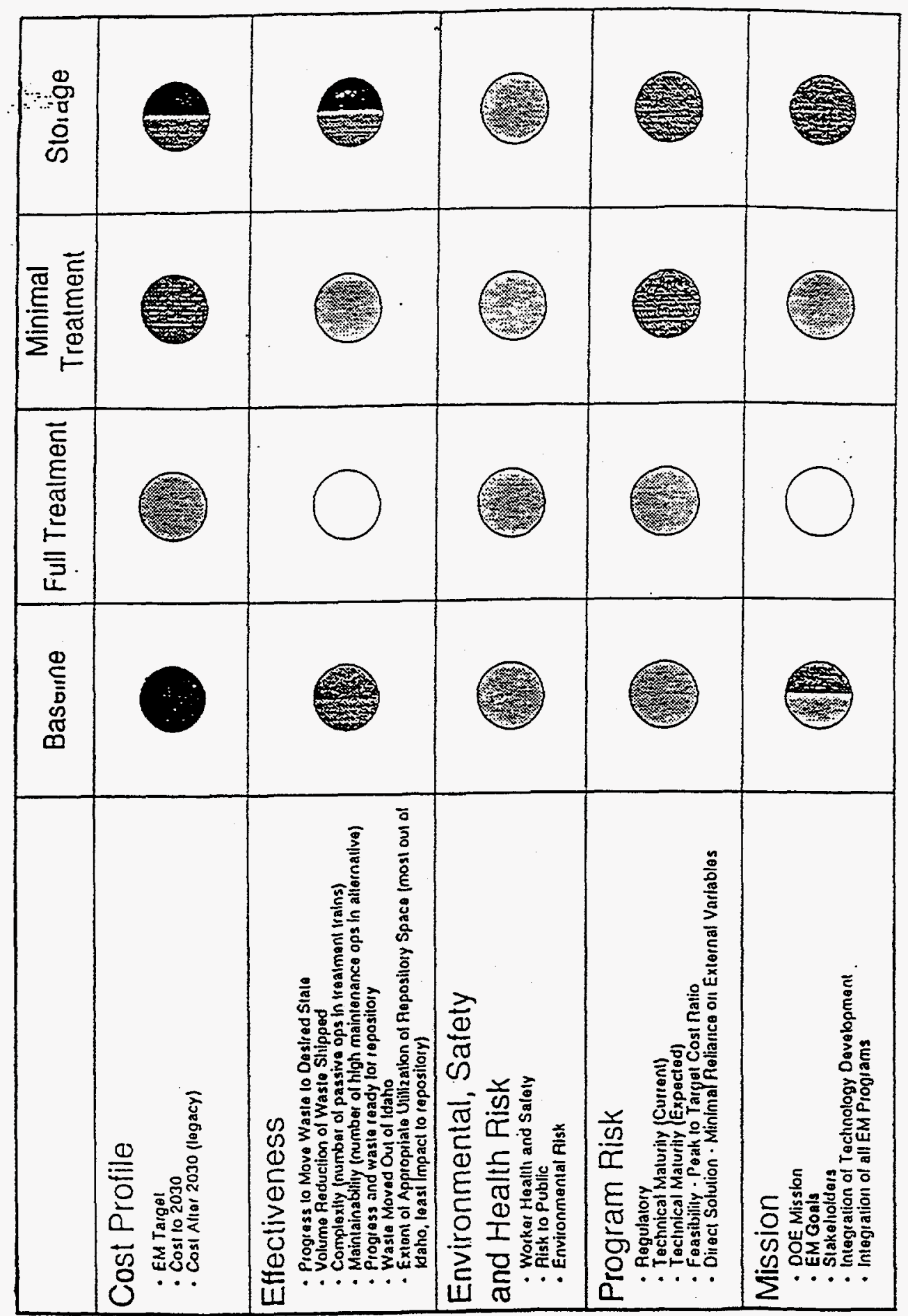

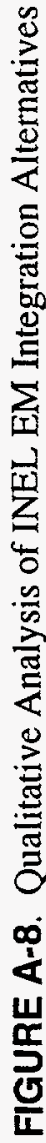




\section{A-4. System Design and Verification}

Once a preferred system solution is defined, the system engineering effort shifts to ensuring that the solution works as designed. This phase consists of design and verification activities that include:

- Develop verification and test plans

- Define verification and test criteria

- $\quad$ Reconcile verification and testing with baseline requirements

- Ensure verification and testing is completed

- $\quad$ Perform test and design reviews

- Support implementation of product

INEL EXAMPLE (cont) -Between May 1995 and February 1996, INEL EM Integration participants revisited initial evaluation results to verify that the preferred altemative met legal and regulatory compliance and fell within DOE budget targets.

As a result of new agreements and Consent Orders between DOE and the State of Idaho and to facilitate preparation of FY98 ADS, modifications were made to the anticipated work scope and to projected budgets. Using ADS preparation guidance documents from DOE-HQ, individual EM program representatives reviewed established requirements and divided the scope of work into compliant and noncompliant control accounts and work packages. Following extensive training, programs were directed to prepare defensible cost estimates for each identified scope of work. SMEs coordinated the work to ensure consistency with the direction of the program's director. DOE.ID Program Manager, and the Senior lntegration Team. EM project managers were then asked to present and defend their work packages before Murder Boards, composed of senior NEL managers and personnel from both LMITCO and DOE-ID independent of the programs being reviewed.

The mission of the Murder Boards Was to provide an independent review of INEL EM decision unit (DU) cost packages to assure defensible cost estimates and requirements flow-down for those activities necessary for legal and regulatory compliance. Four Murder Boards, representing each EM-related directorate at the INEL, reviewed a total of 93 DU cost packages on January 17 and from January 24 through February 7, 1996. These packages defined work scope, compliance drivers, and funding needs for FY96-2002. Each package was reviewed for clarity of activity descriptions, appropriateness of estimated resource needs, definition of regulatory drivers, and maturity of cost estimate.

The result is a scrubbed down, defensible budget tied to top-level requirements for use in budgetary workouts with DOE-HQ personnel, ADSs preparation and submittal activities, and preparation of EM control accounts and out-year plans: 


\section{A-5. Systems Integration and Controls}

This fifth phase is conducted in parallel with each of the previous four phases. It is used to ensure consistency of system designs and data throughout the SE process. The critical activities conducted in conjunction with this phase include:

- Integrate technical system interfaces

- Integrate technical and administrative interfaces

- Maintain SE management plan and schedule

- Support configuration management

- Coordinate technical reviews

- $\quad$ Provide system data for effective decision making

- Support issues management

\section{A-6. Detailed SE References}

The following resources contain specific details regarding the various SE activities necessary to accomplishing EM Integration; Table A-1 lists the respective source page numbers for each aspect of the SE process.

1) Project Execution and Engineering Management Planning Guide for use with DOE Order 430.1, Life Cycle Asset Management (LCAM). Draft. Washington D.C.: U.S. Department of Energy Office of Field Management. September 12, 1995.

2) IEEE P1220: Standard for Application and Management of the Systems Engineering Process. Final Draft. New York: Institute of Electrical and Electronic Engineers, Inc., September 1994.

3) SSD Systems Engineering Manual: Code 66. Sunnyvale, CA: Lockheed Missiles \& Space Company, Inc.. August 30, 1994.

4) Blanchard, Benjamin S., and Wolter J. Fabrycky. Systems Engineering and Analysis. $2 d$ ed. Ed. W. J. Fabrycky and J. H. Mize. Englewood Cliffs, NJ: Prentice Hall. 1990.

5) NASA Systems Engineering Process for Programs and Projects. Version 1.0. Houston, TX: NASA Lyndon B. Johnson Space Center. October 1994.

6) Integration of EM Activities at the INEL. Idaho Falls, ID: Lockheed Martin Idaho Technologies Company, March 31, 1995.

7) Environmental Management Requirements/Defensible Costs Project. Draft Final Report. Idaho Falls, ID: Lockheed Martin Idaho Technologies Company, February 1996. 
Table A-1. Systems Engineering Source References

\begin{tabular}{|c|c|c|c|c|c|}
\hline & LCAM & IEEE & Code 66 & $\mathbf{B} \& \mathbf{F}$ & NASA \\
\hline \multicolumn{6}{|l|}{ GDNERAL INDORMATON } \\
\hline SE Background & $12,13,16,18$ & $1,11,13, \mathrm{~A}-1$ & $1-1 \rightarrow 1-20 ; 3-1$ & 21 & $3-3,3-10$ \\
\hline \multicolumn{6}{|c|}{ SDPROCWSG } \\
\hline Mission Statement & 6,50 & & $1-1,3-2 \rightarrow 3-3$ & $35,37,46$ & $\begin{array}{l}3-5 ; 4-5 ; 5-2 \\
5-4,5-9 ; \text { A-18; } \\
\text { B-2 }\end{array}$ \\
\hline Requirements Analysis & $11,13,14,16,56$ & $33-38$ & $1-1 ; 3-2 \rightarrow 3-10$ & 34 & $\begin{array}{l}5-3,5-4,5-9 \\
5-15,5-21\end{array}$ \\
\hline Requirements Allocation & 11,17 & 38 & $1-1,1-2 ; 3-16$ & 64 & $5-4,5-10,5-16$ \\
\hline Functional Analysis & $13,14,17$ & 38,39 & $1-1 ; 3-23 \rightarrow 3-45$ & $22,55-59,632$ & $5-10,5-21$ \\
\hline Functional Allocation & $11,17,55$ & 38,43 & $1-1 ; 3-37,3-63$ & 64 & $\begin{array}{l}3-6 ; 5-10,5-14 \\
\rightarrow 5-16\end{array}$ \\
\hline Synthesis & 13,17 & $41-44$ & $1-1 ; 3-62 \rightarrow 3-93$ & $22,46,64,73$ & $5-4,5-10,5-16$ \\
\hline Trade-Offs/Trade Studies & $6,58,59$ & $47-50$ & $\begin{array}{l}1-1,1-2 ; 3-46 \\
\rightarrow 3-62\end{array}$ & $22,46,67$ & $\begin{array}{l}5-4,5-10,5-16 \\
\text { A-1, A-31 }\end{array}$ \\
\hline Alternative Selection & $48,58,60$ & 50 & $3-48,3-51$ & $122,128,140$ & $5-16$ \\
\hline Verification/Test \& Evaluation & $13,14,61,65,93$ & $\begin{array}{l}29,36-37,40- \\
41,44-46\end{array}$ & $\begin{array}{l}1-2 ; 3-94 \rightarrow \\
3-108\end{array}$ & 22,100 & $\begin{array}{l}5-4,5-7,5-16, \\
5-22,5-25 \rightarrow 5-28, \\
5-31,5-32,5-36, \\
5-39 ; \text { A-32, A-33, } \\
\text { A-34; B-4 }\end{array}$ \\
\hline Implementation & 93 & $23-32,53$ & & $26-27$ & $3-7 ; 5-43$ \\
\hline \multicolumn{6}{|c|}{ 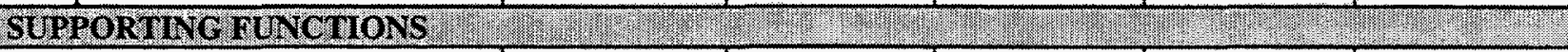 } \\
\hline Interface & 61,64 & $21,24,38,51$ & $\begin{array}{l}1-2 ; 3-111 \\
3-141\end{array}$ & 351,567 & $\begin{array}{l}5-22,5-25 ; A-15, \\
A-28\end{array}$ \\
\hline Controls & $17,19,39$ & $13,50-54$ & $\begin{array}{l}3-16,3-79 \\
3-108,3-142\end{array}$ & $28,323,561$ & $\begin{array}{l}\text { 5-5, 5-10, 5-17, } \\
5-22,5-27,5-32 \\
5-37,5-40,5-45 \\
\text { A-15; B-3 }\end{array}$ \\
\hline Project Execution Plan & 24 & $14,20, \mathrm{~B}-1$ & $3-113,3-139$ & 51,549 & A-23, A-29 \\
\hline Reviews & $29,80-85$ & $\begin{array}{l}22,25,27-28 \\
30\end{array}$ & $3-145$ & 51,75 & $\begin{array}{l}-2 ; 5-5,5-11 \\
5-17,5-22,5-27 \\
5-32,5-37,5-40 \\
5-45 ; 6-1\end{array}$ \\
\hline Risk Management & $62,71-75,87-93$ & $\begin{array}{l}21,24,47,50, \\
53\end{array}$ & $3-115 \rightarrow 3-133$ & 133 & $\mathrm{~A}-24, \mathrm{~A}-25$ \\
\hline Systems Analysis & $17,19,59$ & $47-50$ & & 45,55 & A-11 \\
\hline \multicolumn{6}{|c|}{ 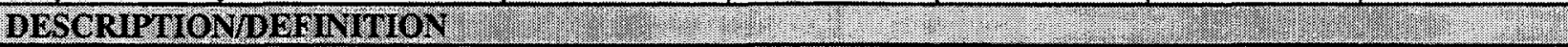 } \\
\hline Architecture & 6,58 & 9,44 & $3-63$ & & $3-5,3-6 ; 4-4 ;$ B-1 \\
\hline Alternatives & $6,12,14$ & 49 & $3-48$ & $46,67,122-124$ & $5-10$ \\
\hline Decision Criteria & $6,12,14,15,48$ & 49 & $3-46,3-48$ & 46,67 & $\begin{array}{l}4-2 ; 5-4,5-9,5- \\
15 ; A-4\end{array}$ \\
\hline Functions & $6,12,14,55$ & 8,38 & $3-24$ & 2,55 & $3-6,3-10$ \\
\hline Integrated Product Teams & 4,47 & B-6 & $1-8,1-16$ & 82,556 & $3-8$ \\
\hline Levels/Hierarchy & 6,55 & $16-17,38$ & $\begin{array}{l}1-1 \rightarrow 1-4 ; 3-16 \\
\rightarrow 3-26\end{array}$ & 9,57 & $4-5 ; \mathrm{B}-3$ \\
\hline Modeling & 59,101 & 14,51 & $\begin{array}{l}3-27,3-64 \rightarrow \\
3-70,3-86 \\
\end{array}$ & $\begin{array}{l}46,57,70,124, \\
141\end{array}$ & A-2 \\
\hline Requirements & $6,12,16,17,56$ & $10,36-38$ & $3-2$ & $23,34,35,78$ & $\begin{array}{l}3-10 \rightarrow 3-11 ; 4-5 \\
\text { B-3 }\end{array}$ \\
\hline Technical Baseline & $12,14-15$ & $\begin{array}{l}22,32,36,51, \\
54\end{array}$ & $3-70$ & & $4-4 ; B-1, B-2$ \\
\hline
\end{tabular}




\section{APPENDIX B: REFERENCES}

EM Integration Office, "Environmental Management Requirements/Defensible Costs Project," INEL96/0101, Lockheed Idaho Technologies Company, February 1996.

Frandsen, G. B., et al., "Integration of EM Activities at the INEL" (Volumes I and II), INEL-95/0148, Lockheed Martin Idaho Technologies, 1995.

Murphy, J. A., "Integration of the Idaho National Engineering Laboratory Environmental Management Activities Using Systems Engineering," INCOSE 1996 Symposia Proceedings (to be published in July 1996).

Plowman, Catherine, "Requirements-Based Performance Measures in Incentives Contracting," Lockheed Martin Idaho Technologies Company SE Working Paper, May 1996.

-----, "Determining Customer Requirements for Engineering \& Science Projects," Lockheed Martin Idaho Technologies Company SE Working Paper, April 1996.

-----, "Performance Measurement Development," Lockheed Martin Idaho Technologies Company SE Training Package, April 1996.

Sector Integration Team, "Integration of Environmental Management Activities Across the Lockheed Martin Energy and Environment Sector," INEL-96/0207, Lockheed Martin Idaho Technologies Company, June 1996.

Smith, T. H., et al. "A Simplified Method for Quantitative Assessment of the Relative Health and Safety Risk of Environmental Management Activities," INEL-95/0645, Lockheed Idaho Technologies Company, March 1996 


\section{APPENDIX C: ILLUSTRATIONS FOR DEVELOPING PERFORMANCE MEASURES}

The following five figures show various forms and processes that can be used to develop the performance measures used to evaluate alternatives and to assess customer satisfaction regarding a particular program or task. 


\section{Project Initiation Checklist}

\begin{tabular}{|c|c|c|c|c|c|}
\hline \multirow{2}{*}{ HAVE THE CUSTOMER AND I DISCUSSED... } & \multicolumn{5}{|c|}{ STATUS } \\
\hline & 1 & 2 & 3 & 4 & 5 \\
\hline Who the Customer's Key Project Personnel are? & o & 0 & $\mathbf{o}$ & o & o \\
\hline What the Project's Driving Forces ("Big Picture") are? & o & o & 0 & o & 0 \\
\hline Any Relationship(s) to Other Projects \& Overall Plans? & o & 0 & o & o & 0 \\
\hline What the Project Summary Description is? & o & 0 & o & o & 0 \\
\hline What the Project Operating/Analysis Objectives are? & o & o & o & o & o \\
\hline Where the Project is Located? & 0 & o & o & o & o \\
\hline Use of Government Furnished Services \& Facilities? & o & 0 & 0 & o & o \\
\hline What the Customer's Contractual Arrangements are? & o & 0 & o & o & o \\
\hline What the Customer's Contract Strategy is? & o & 0 & o & o & $\circ$ \\
\hline Who the Project Interfaces are? & 0 & $\circ$ & 0 & 0 & o \\
\hline What the Project Execution Priorities are? & o & o & o & o & o \\
\hline Who makes Major Funding Decisions? & $\circ$ & o & 0 & o & o \\
\hline What their Conditions of Satisfaction are? & o & o & 0 & o & o \\
\hline What their Quality Measures \& Expectations are? & o & 0 & 0 & 0 & o \\
\hline Any other Pertinent Questions? & o & 0 & o & $\mathbf{o}$ & \\
\hline \multirow[t]{2}{*}{ HAVE I DISCUSSED WITH THE CUSTOMER... } & \multicolumn{5}{|c|}{ STATUS } \\
\hline & 1 & 2 & 3 & 4 & 5 \\
\hline Who our Key Personnel are? & $\circ$ & o & o & o & 0 \\
\hline What our Job Order Strategy is? & o & 0 & $\mathbf{0}$ & $\mathbf{o}$ & 0 \\
\hline What our Budget Estimate \& Premises are? & o & o & o & o & ० \\
\hline What our proposed Project Block/Flow Diagram is? & o & 0 & o & 0 & o \\
\hline What our proposed Engineering Design Process is? & $\circ$ & 0 & o & o & o \\
\hline What our Procurement Work Flow Process is? & o & 0 & o & o & o \\
\hline What our Subcontracting Strategies are? & o & o & o & o & o \\
\hline What our Known Critical Lead Times are? & 0 & o & o & o & o \\
\hline What our Work Activation Sequence is? & o & 0 & o & $\circ$ & o \\
\hline What our Major Project Milestones are? & o & $\mathbf{o}$ & o & o & o \\
\hline What our or the customer's List of Critical Issues are? & o & o & o & o & o \\
\hline What the Prevention Action Plans are? & 0 & o & 0 & o & o \\
\hline What our or the customer's Risk Reduction Plans are? & o & o & $\mathbf{0}$ & o & o \\
\hline Any other pertinent questions? & o & 0 & o & 0 & \\
\hline
\end{tabular}

STATUS fields, 1. to r::

(1) N/A;

(2) This should be explored;

(3) The conversation has been started;

(4) The conversation is completed;

(5) The resulting information should be included in project plans.

OTHER QUESTIONS fields; (1) None identified; (2) More questions needed; (3) New questions developed; (4) New questions added to Project Initiation Checklist. 


\section{Family of Measures Development Process}

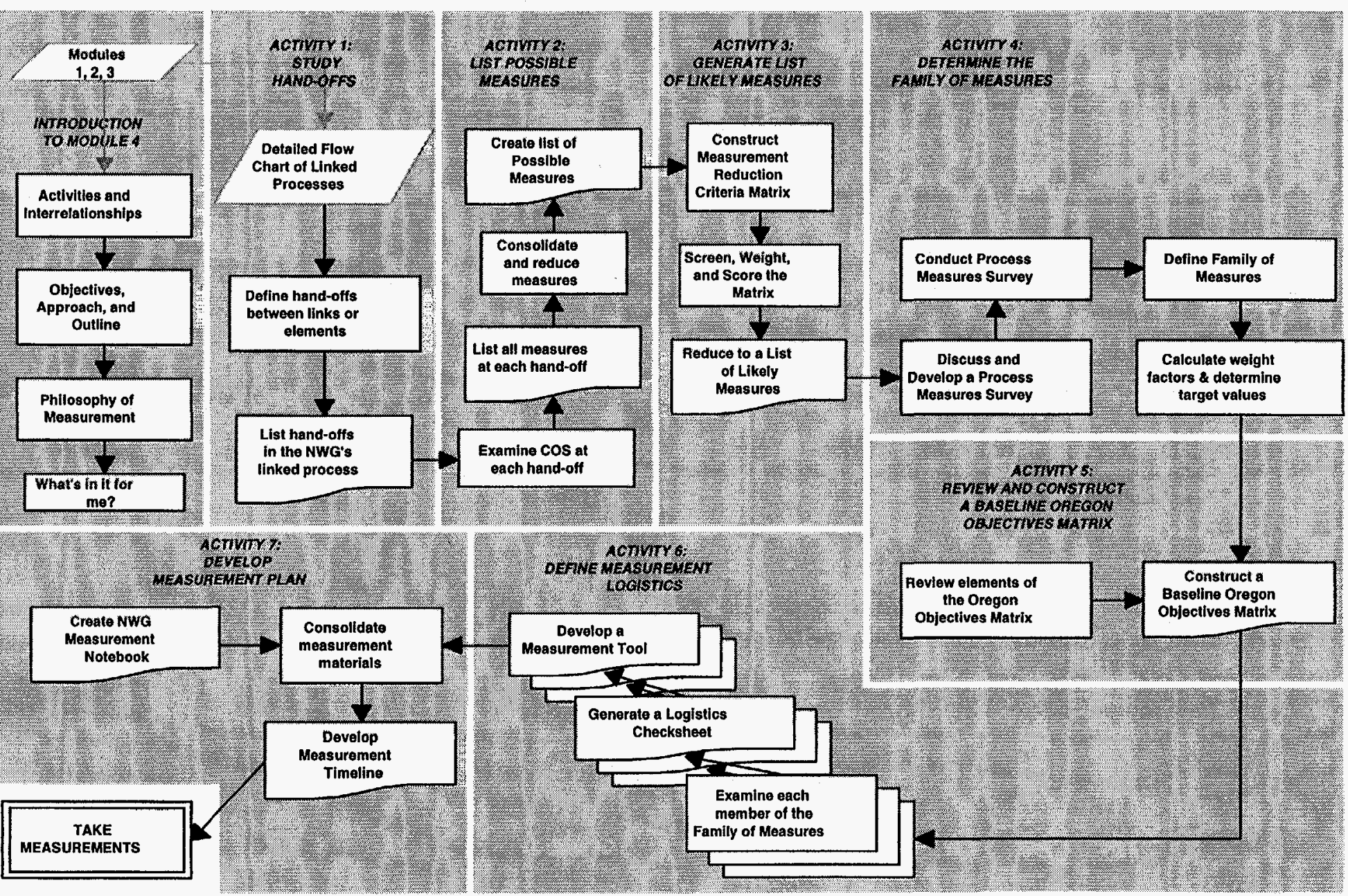

FIGURE C-2. Family of Measures Development Process 


\section{Objectives Matrix}

\begin{tabular}{|l|l|}
\hline Jan & 300 \\
\hline Feb & $\mathbf{4 0 5}$ \\
\hline Mar & \\
\hline Apr & \\
\hline May & \\
\hline Jun & \\
\hline Jul & \\
\hline Aug & \\
\hline Sep & \\
\hline Oct & \\
\hline Nov & \\
\hline Dec & \\
\hline
\end{tabular}

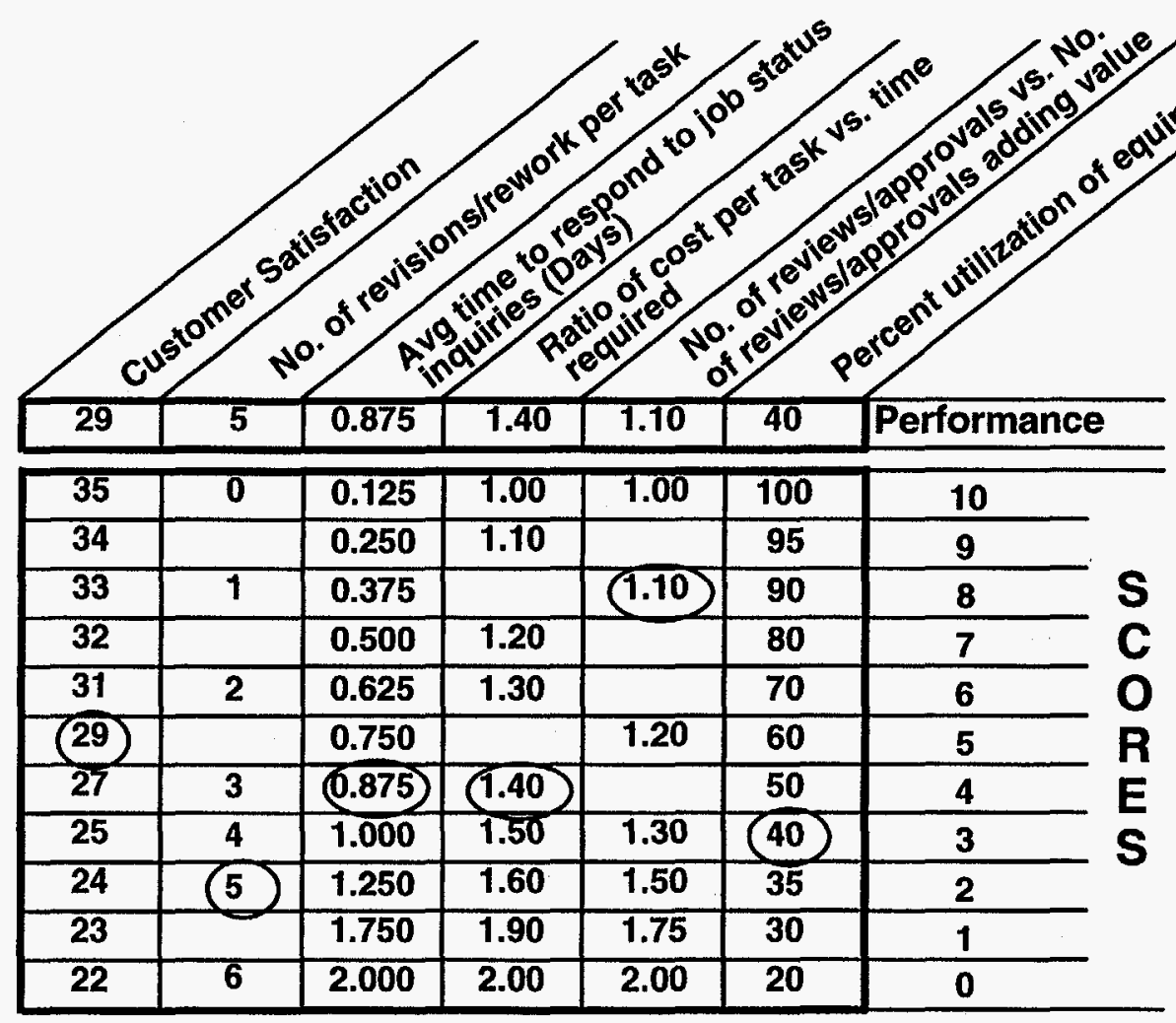

Current

Performance

\begin{tabular}{|c|c|c|c|c|c|c|c|}
\hline 5 & 2 & 4 & 4 & 8 & 3 & Score & Indicate \\
\hline 30 & 10 & 20 & 15 & 20 & 5 & Weight & Total \\
\hline
\end{tabular}




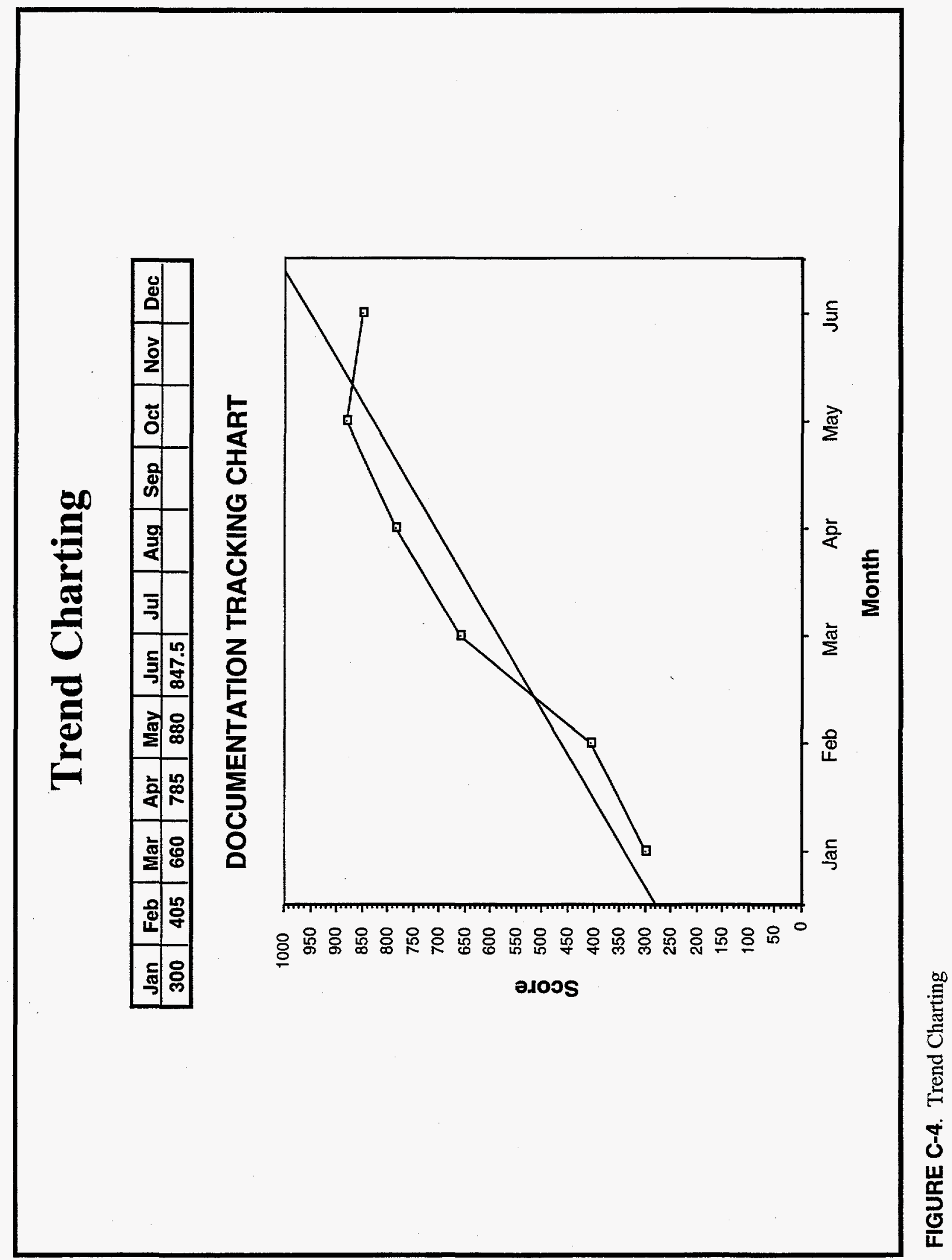




\section{Customer Satisfaction Survey Form}

TO:

ORGANIZATION:

DATE:

FROM: ADV ARCH NWG ORG: LESC Flight Data Systems Dept PHONE: 333-7698

We would appreciate your personal evaluation of our performance on the task we recently completed for you. Please mark the blocks in the following matrix that most closely represent our performance for each category. Give me a call if you have questions. We will pick the evaluation up from you upon notification that it is completed.

TASK:

\begin{tabular}{|l|c|c|c|c|c|}
\hline \multicolumn{1}{|c|}{ Conditions of Satisfaction } & $\begin{array}{c}\text { Very } \\
\text { Good } \\
\mathbf{5}\end{array}$ & $\begin{array}{c}\text { Good } \\
\mathbf{4}\end{array}$ & $\begin{array}{c}\text { OK } \\
\mathbf{3}\end{array}$ & $\begin{array}{c}\text { Not } \\
\text { OK } \\
\mathbf{2}\end{array}$ & $\begin{array}{c}\text { Poor } \\
\mathbf{1}\end{array}$ \\
\hline $\begin{array}{l}\text { Responsiveness to Technical Support } \\
\text { Needs }\end{array}$ & & & & & \\
\hline Planning Effectiveness & & & & & \\
\hline $\begin{array}{l}\text { Facilitate Arch Acceptance within } \\
\text { Technical Community }\end{array}$ & & & & & \\
\hline $\begin{array}{l}\text { Content \& Quality of Technical } \\
\text { Presentations }\end{array}$ & & & & & \\
\hline $\begin{array}{l}\text { Content \& Quality of Reports \& } \\
\text { Papers }\end{array}$ & & & & & \\
\hline
\end{tabular}

SUGGESTED IMPROVEMENTS:

OTHER COMMENTS:

FIGURE C-5. Customer Satisfaction Survey Form 


\section{APPENDIX D: GLOSSARY}

Activity Data Sheets (ADS)

Alternative

Architecture

Baseline

Concept

Conceptual Design

Configuration

Current Operations Baseline

Customer
Documentation of congressionally approved scope, schedule, and budget for environmental programs within the DOE System.

In the context of this document, a detailed system solution based on one of several sets of assumptions and creative ideas.

Alternatives are built from concepts and scenarios resulting from a brain-storming creativity process. They represent alternative views and assumptions and carry associated risks and probabilities.

In the SE design process, the conceptualization of the endproduct at any level of design. The architecture at each level performs all functions and meets all requirements for that level. Usually, several different architectures can perform functions and meet requirements for a level of allocation, and these different architectures are called alternatives. The systems approach selects the preferred architecture from the alternatives at each level of allocation before proceeding to the next level.

At each tier or level of allocation, this will be an implementation that represents a solution for the requirements and functions defined. In most cases there will be more than one implementation; these are called alternatives.

A documented and agreed upon version of a plan, assessment, description, code, or other document which is intended to be the reference point for discussion, proposed changes, or decisions.

In the context of alternatives development, this is a grouping of scenarios and previously defined functionalities that provide an opportunistic or synergistic combination resulting in savings or efficiencies.

That phase of a project during which the essential functionality of the solution is determined and agreed upon.

The 'as built' architecture for a given project. There is a transition from architecture to configuration during the design process.

A record of the technologies, facilities, functional flows, and personnel resources associated with current program management activities.

For a program or project, in the simplest case, the entity providing the funding. In more complex cases, there may be a funding entity, a product consumer, and other parties whose 


\section{Decision Criteria}

Decision Unit

Department of Energy (DOE)

\section{Discriminating Criteria}

Environmental Management (EM)

Functions

Integration

Iterative

Level

Metric

Requirements requirements become vested interests of the funding entity. Not to be confused with 'Stakeholder'

A definitive statement of the values that will be applied in developing the final decision in a trade off study.

A collection of cost packages assembled according to similarities in characteristics or processes. Used to determine funding levels for ADS submittal at the INEL.

The cabinet-level United States Government Agency responsible for nuclear weapons production and energy research and the cleanup of hazardous and radioactive waste at its sites. Created from the Energy Research and Development Administration and other Federal Government functions in 1977.

The values to be considered in the selection or ranking of the final alternative set.

The Department of Energy Office responsible for the management and clean-up of environmental resources within the DOE complex.

A description of 'what should be done' to meet requirements allocated from the Mission Statement. The first or higher level function(s) is expected to be expanded into lower tiers or levels.

Environmental Management Data Base The configuration-controlled store of information resulting from the EM integration effort. Contains program documents, the integrated baseline, the SRD, and all other controlled products of the effort.

The consolidation of a set of programs, projects, equipment, facilities, or processes with compatible or similar components into a single program, project, or process.

A process that is repeated for continuing benefit, each repetition yielding a more refined result until a closure is reached or an ending condition is met.

A name used to imply a hierarchical relationship of tiers for a given subject. The lower the level, the more details in the description for the given allocation.

A quantitative measurement which can be used to determine accurately whether a requirement has been met. Both the value and the unit of measure are present.

Descriptive statements in quantitative terms describing how well a Mission Statement must be accomplished. Requirements may 
Scenario

Stakeholder

Statement of Work (SOW) be of two types, performance and constraints. Performance requirements describe how well the product must perform a function. Constraints describe how well the product must satisfy geometrical, timing, regulatory, legal, environmental characteristics, or specialty engineering requirements.

In the context of alternatives design, this is a creative idea for an improved method to handle an EM issue. It may result from brainstorming, a paradigm shift, or another creative process.

An entity, not necessarily a customer, who is affected by a program or project and can potentially impede the success of the program or project.

The means by which the cognizant organization provides direction to the performer of engineering objectives expected to be met during a phase of a project. The objectives will be directed towards achieving the project mission through the development of the appropriate organization, definition and development of an end-product and definition of the environment in which it is to function. The SOW will direct the performer towards the accomplishment of work necessary to meet the success criteria.

SOWs contain, but not be limited to, the following information:

1) An identification of the SOW and its relationship to all other SOWs (to support traceability)

2) A definition of the SOW objectives

3) A description of the Scope of Work covered within the SOW

4) The high level Work Breakdown Structure and Dictionary, or a reference to it, if it is included in a higher level document

5) Identification of the work to be performed

6) Identification and description of the reviews to take place

7) Description of deliverables

8) Identification of milestones

9) Definition of responsibilities.

System Requirements Document (SRD) A configuration-controlled document containing the complete set of requirements, original and derived, for a project.

System Requirements Review (SRR) A formal review of an SRD by an appropriate decision authority.

Systems Engineering (SE)
An interdisciplinary approach to evolve and verify an integrated and optimally balanced set of product and process designs that satisfy user needs and provide information for management decision making 
Traceability

Trade Trees

Trade-Off Studies

Validation

Verification

Work Breakdown Structure
The ability to trace a requirement or function to an original source document or decision, including all derivation or decomposition steps and decisions which resulted in the requirement or function

A tool providing a view of the selected alternatives result from various conditions or scenarios. The tree structure is formed by creating a branch for each of the potential results of an unknown future event, with multiple events creating multiple branch nodes. The leaves of the tree being the appropriate alternatives for the combination of event 'branches' leading to the leaf.

The method used to select an alternative. The study is the process of evaluating alternatives and selecting the preferred architecture.

The process of testing a model or problem solution to demonstrate its consistency with reality.

The process of proving that an alternative architecture performs the functions and meets the requirements.

A product-oriented division tree showing the hardware, software, facilities, personnel, and other items that define and organize all aspects of the work to be performed in accomplishing project objectives. 